MARIA DEL PILAR ESTEVEZ DIZ

\title{
Impacto do encaminhamento para ambulatório de câncer hereditário na qualidade de vida de pacientes portadoras de câncer de mama
}

Tese apresentada à Faculdade de Medicina da Universidade de São Paulo para obtenção do título de Doutor em Ciências

Área de concentração: Oncologia

Orientador: Profa. Dra. Miriam Hatsue Honda Federico

São Paulo

2007 


\section{Agradecimentos}

O trabalho em um ambulatório de câncer hereditário é necessariamente um trabalho em equipe. Para seu desenvolvimento, todos os membros desse grupo multiprofissional precisam estar comprometidos com o bem estar físico e emocional dos pacientes, cientes dos preceitos éticos e legais, cientes dos benefícios e riscos potenciais para os pacientes atendidos e, sobretudo, cientes de que os diagnósticos aqui firmados têm implicações não apenas individuais, mas também para os familiares desses pacientes. Assim, é claro que um trabalho como este somente pôde ser realizado a partir da colaboração de um grande grupo, que trabalha para o desenvolvimento do Ambulatório de Câncer Hereditário desde setembro de 2004. As pacientes desempenham um papel fundamental no estudo, pois em se tratando de um estudo que tem como objetivo a qualidade de vida e depende de respostas a questões muito pessoais e, uma vez que não é possível agradecer a cada uma individualmente pela sua colaboração, deixo aqui meu agradecimento sincero a todas. Nosso grupo de

trabalho é grande e gostaria de agradecer algumas pessoas pela sua colaboração especial:

Prfa. Dra. Miriam Hatsue Honda Federico por seu apoio, sua orientação constante, pela confiança depositada e pelo emprenho na implantação do Serviço de Oncologia e Ambulatório de Câncer Hereditário.

Prfa. Dra. Maria Mitzi Brentani, pelo apoio dado a este trabalho.

Dr. Igor Moysés Longo Snitcovsky pela sua grande colaboração e incentivo no desenvolvimento deste projeto. 
Dr. Gustavo Fernandes Godoy Almeida pelo seu empenho nas discussões e auxílio na construção das rotinas do Ambulatório de Câncer Hereditário.

Profa. Dra. Maria Aparecida Azevedo Koike Folgueira pela amizade e incentivo.

Dr. Gilberto de Castro Junior pelo seu apoio e auxílio na tradução e validação dos questionários de qualidade de vida.

Dra. Simone Maistro pelo seu intenso trabalho no sequenciamento dos genes BRCA1 e BRCA2.

Dra. Fátima Solange Pasini e Dra. Flavia Regina Rotea Mangone pelo seu apoio no laboratório e emprenho no grupo de discussão de Câncer Hereditário.

Enfermeira Maria Auxiliadora Cury Xará pelo trabalho desenvolvido na coleta de sangue das pacientes consideradas de risco elevado.

Enfermeira Daniela Vivas dos Santos pelo auxílio na coleta de sangue das pacientes consideradas de risco elevado.

Psicóloga Gabriela de Souza Zemel pelo trabalho de apoio psicológico desenvolvido com as pacientes de risco.

Thiago Sanches Brambila pelo seu trabalho no auxílio instalação do programa CancerGene.

Marcelo Soares Lopes pelo seu auxílio no recrutamento das pacientes.

Marlene Pereira Salgado pelo auxílio nas tramitações do trabalho junto às comissões deste hospital.

Elisabete Regina Sangirotti pela sua colaboração na secretaria.

Aos residentes de cancerologia que participaram do atendimento dessas pacientes no ambulatório. 
A todos os membros do Grupo de Discussão de Câncer Hereditário, pela inestimável contribuição nas discussões. 


\section{Sumário}

Lista de abreviaturas, símbolos e siglas

Lista de tabelas

Lista de gráficos e diagramas

Resumo

Summary

1 INTRODUÇÃO

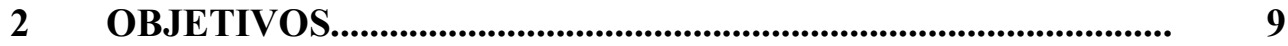

$3 \quad$ MÉTODOS......................................................................... 10

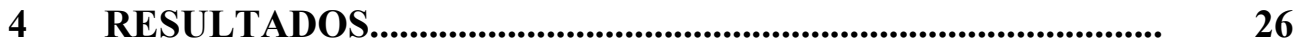

5 DISCUSSÃO

6 CONCLUSÕES................................................................ 53

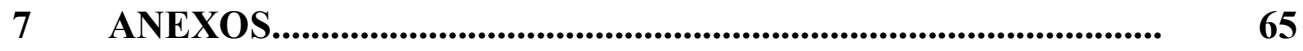

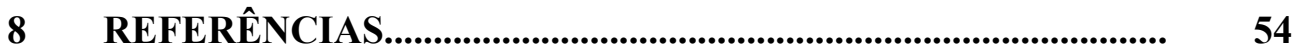


Lista de abreviaturas, símbolos e siglas

EORTC - "European Organization for Research and Treatment of Cancer"

QLQ-C30 - Quality of life questionnaire - C30

QLQ-BR23 - Quality of life questionnaire - BR23

HCFMUSP - Hospital das Clínicas da Faculdade de Medicina da Universidade de São Paulo

BRCAPRO - é um modelo estatístico com software associado, para determinação da probabilidade de um determinado indivíduo ser portador de mutação germinativa deletéria dos genes BRCA1 e BRCA2

$\geq$ - maior ou igual a 
Lista de tabelas

Tabela 1 - Mutações do BRCA1 e BRCA2 identificadas em pacientes brasileiras portadoras de câncer de mama................................................................................pag 6

Tabela 2 - Descrição dos possíveis resultados do teste genético para determinação da presença de gene de predisposição a câncer. .pag 13

Tabela 3 - Convenções utilizadas para interpretação de heredogramas ambíguos pag14

Tabela 4 - Prevalência de mutações em BRCA1/2 correlacionadas com a história pessoal e familiar de câncer em 4.716 indivíduos não Ashkenazi...................pag 92

Tabela 5. Prevalência de mutações em BRCA1/2 em indivíduos não Ashkenazi correlacionadas com a idade do diagnóstico de câncer e a história familiar.....pag 93

Tabela 6 - Prevalência de mutações em BRCA1/2 correlacionadas com a história pessoal e familiar de câncer em 2.233 indivíduos Ashkenazi...............................pag 94

Tabela 7 - Prevalência de mutações em BRCA1/2 em indivíduos Ashkenazi correlacionadas com a idade do diagnóstico de câncer e a história familiar......pag 95

Tabela 8 - Comparação entre a prevalência de mutações em BRCA1/2 em indivíduos não Ashkenazi com carcinoma ductal in situ e carcinoma invasivo de 
mama diagnosticado antes dos 50 anos de idade. .pag 96

Tabela 9 - Comparação entre a prevalência de mutações em BRCA1/2 em indivíduos Ashkenazi com carcinoma ductal in situ e carcinoma invasivo de mama diagnosticado antes dos $50 \quad \operatorname{anos}$ de idade. .pag 97

Tabela 10 - Sistema de escores proposto por Evans para identificação de mutações deletérias

de BRCA1/2. pag 19.

Tabela 11 - Avaliação da qualidade de vida das pacientes, antes da primeira consulta (E1) e após a determinação do risco de ser portadora de mutações deletérias dos BRCA1/2 (E2). Total de 119 pacientes avaliadas, n=número de respostas em cada domínio...................................................................................................................................pag 35

Tabela 12 - Avaliação da qualidade de vida das pacientes, antes da primeira consulta (E1) e após a determinação do risco de ser portadora de mutações $\begin{array}{lllllll}\text { deletérias dos } & \text { BRCA1/2 } & \text { (E2). } & \text { Total de } & 180 & \text { pacientes }\end{array}$ avaliadas.................................................pag 37 
Lista de gráficos e diagramas

Gráfico 1 - Distribuição das pacientes segundo idade, em anos, ao diagnóstico, pag 27.

Gráfico 2 - Classificação das 180 pacientes avaliáveis segundo o risco de mutações do BRCA1 e BRCA2 pelos modelos de Frank, Evans (Manchester) e BRCAPRO, pág 34.

Gráfico 3 - resultados do contato telefônico com as pacientes faltantes, pág 43

Diagrama 1. Resultados das entrevistas para avaliação das pacientes faltantes, pág 42 
Anexos

Anexo 1 - Termo de consentimento pós informação aplicado às pacientes do estudo, pág 69

Anexo 2 - Termo de aprovação na Comissão de Ética para Análise de Projetos de Pesquisa - CAPPesq da Diretoria Clínica do HCFMUSP, pág 70

Anexo 3 - ficha de pré consulta, pág. 71.

Anexo 4 - questionário EORTC QLQ-C30 - versão 3.0, pág. 73

Anexo 5 - questionário EORTC QLQ - BR23, pág. 77

Anexo 6 - Ficha Clínica, pág. 79.

Anexo 7 - Relação das pacientes avaliáveis e o respectivo risco de ser portadora de mutação deletéria segundo os modelos de Frank, Evans e BRCAPRO. O risco está expresso em \% nos modelos de Frank e Evans e em valores absolutos no modelo BRCAPRO (grifados em amarelo os valores iguais ou superiores a $10 \%)$, pág. 98.

Anexo 8 - Critérios para determinação dos candidatos ao teste genético para mutações deletérias do BRCA1/2. “Canadian Coordinating Office for Health Technology Assessment” ( adaptado de McGahan, 2006), pag. 98.

Anexo 9 - Orientações internacionais para o encaminhamento para o teste genético em indivíduos sem historia pessoal de câncer porém com história familiar positiva, pág. 86 .

Anexo 10 - Critérios propostos pelo "National Comprehensive Cancer Network", V.I. 2006, para câncer de mama e/ou ovário hereditários. v.1.2006 ${ }^{\mathrm{ab}}$, pág. 88 


\section{Resumo}

Diz, MDPE. Impacto do encaminhamento para ambulatório de câncer hereditário na qualidade de vida de pacientes portadoras de câncer de mama [tese]. São Paulo: Faculdade de Medicina da Universidade de São Paulo; 2007.

Neste trabalho, medimos o impacto da avaliação do risco de mutações dos genes BRCA1/2 na qualidade de vida de pacientes com câncer de mama, avaliada pelos questionários EORTC QLQ-C30 e QLQ-BR23. Convidamos 282 pacientes a participar, respondendo aos questionários antes e depois da avaliação do risco pelos métodos de Frank, Evans e BRCAPRO. Consideramos risco elevado pelo menos 10\%. 272 foram incluídas e 198 completaram o estudo. Nas 180 avaliáveis, a idade mediana das pacientes foi de 53 anos com desvio padrão de 11,5 anos e, em 89 , o tempo desde o diagnóstico de menos de 36 meses. 40 pacientes estavam em seguimento e 137 em hormonioterapia. Não detectamos alterações significativas da qualidade de vida com a determinação do risco para mutações. Houve diferença significativa entre imagem corporal negativa e cirurgia conservadora da mama ( $<<0,001)$. Classificamos 45 como risco elevado pelo método de Frank, 35 pelo BRCAPRO e 21 por Evans, sendo que em 12 dessas pacientes houve conconrdância dos três métodos juntos. Concluímos que, apesar do grande interesse demonstrado pelas pacientes em participar no estudo, a determinação do risco não interferiu na qualidade de vida dessas pacientes. Aparentemente, as informações sobre hereditariedade são desejadas, mas não acarretam estresse adicional e deveriam ser prestadas, pois o número de pacientes com risco elevado é semelhante ao indicado em outras populações. Além disso, a baixa concordância entre os métodos utilizados 
indica a necessidade de definir parâmetros para determinação de risco em nosso meio.

Descritores: Neoplasias mamárias, qualidade de vida, fatores de risco, hereditariedade, gene BRCA1, gene BRCA2. 


\section{Summary}

Impact of hereditary breast cancer risk evaluation on the quality of life of life of patients diagnosed with breast cancer [thesis]. São Paulo: "Faculdade de Medicina, Universidade de São Paulo"; 2007.

Here we evaluated the "impact of breast cancer hereditary cancer risk evaluation" on the quality of life in a population of breast cancer patients, as measured by the EORTC questionnaires QLQ-C30 and QLQ-BR23. Of the 282 invited patients, 272 agree to participate and answered QLQ before and after the risk determination by Frank, Evans and BRCAPRO methods. High risk was defined as at least $10 \%$. Overall 198 pts completed the study. In the 180 evaluable patients, median age was $53( \pm 11,5)$ years old and time since diagnosis was less than 36 months in 89 . We did not detected significant differences in quality of life parameters after risk determination, except for negative body image and mastectomy/conservative surgery $(\mathrm{p}<0.001)$ There were 45 patients classified as high risk by Frank, 35 by the BRCAPRO and 21 by Evans, agreement being reached in 12 . We conclude that pts wish to know about their hereditary breast cancer risk, and this do not cause necessarily more stress. Apart from that, there is a need for local methods of risk calculation.

Descriptors: breast neoplasms, quality of life, risk factors, gene BRCA1, gene BRCA2 


\section{Introdução}

No Brasil, como em outros países, existe uma alta prevalência de câncer de mama na população, como indicados pela taxa de 41.610 casos novos e 9.335 mortes apontadas pelo Ministério da Saúde, Brasil, no ano de 2003. Essa alta prevalência do câncer faz com que aproximadamente um terço das mulheres com câncer de mama tenha pelo menos um parente de primeiro grau também portados de câncer de mama (Linch; 1986). Apesar das mulheres com um parente de primeiro grau com câncer terem seu risco de câncer aumentado quando comparado com mulheres sem parentes com câncer, sabe-se que somente entre $4 \%$ a $9 \%$ dessa população apresenta predisposição hereditária para o mesmo (Anderson, 1993).

Há freqüentemente uma tendência para majoração do risco de câncer hereditário, com maior grau de preocupação e ansiedade para essas pacientes já comprometidas pelo câncer. Para a avaliação do impacto desses fatores na saúde global da paciente com câncer foram desenvolvidos diversos instrumentos nas últimas décadas para a medida objetiva da qualidade de vida, com o formato de questionários, de fácil aplicação ou auto-aplicáveis. Dentre eles podemos citar: WHOQOL-bref, questionário de qualidade de vida resumido da Organização Mundial da Saúde (OMS-1993); GHQ-20, General Health Questionnaire (Goldberg, 1988); Spitzer QL (Spitzer, 1981); UW-QOL, Universidade de Washington (Hassan \& Weymuller, 1993); FACT-G, Functional Assessment of Câncer Therapy (Cella, 1993); EORTC QLQ-C30 e EORTC BR23 (European Organization for Research and 
Treatment of Cancer Quality of Life-EORTC, 1993). A maior parte deles tem o intuito de aferir aspectos subjetivos dos pacientes, proporcionando uma possibilidade única de considerar a percepção que o paciente tem dos benefícios clínicos gerados pelo tratamento em pacientes com câncer. O WHOQOL-bref (OMS-1993), apresenta 26 questões, sendo duas questões gerais de qualidade de vida e as demais 24 representam cada uma das facetas que compõem o instrumento original que continham 100 questões compostas por quatro domínios: físico, psicológico, relações sociais e com o meio ambiente; este índice não é usado pelas pesquisas em oncologia rotineiramente pela sua falta de especificidade. O GHQ-20 (Goldberg, 1988), também deriva de um questionário maior que é o GHQ-60 que tem como função rastrear distúrbios psiquiátricos em ambientes não psiquiátricos e pode ser usado para avaliação da qualidade de vida pela abordagem de aspectos positivos e negativos. Spitzer QL (Spitzer, 1981) foi um dos primeiros instrumentos de qualidade de vida publicados na literatura. Este índice, que necessita de componentes clínicos, é composto por cinco questões: atividades do paciente, rotina diária, saúde geral, suporte e perspectiva de vida; ele apresenta limitações e necessita de outros instrumentos para dar um panorama geral da condição dos pacientes. Outro questionário é o UW-QOL (Hassan, 1993), composto por duas questões gerais de saúde e dez específicas de condição física e sintomas, apresenta, entretanto, limitação importante nos aspectos psicológicos e emocionais, que não são avaliados. O FACTG (Cella, 1993) é um dos instrumentos mais utilizados nos Estados Unidos da América, composto de 29 questões, ele é dividido em quatro domínios: bem estar físico, social/familiar, emocional e funcional, sem, contudo, uma avaliação dos sintomas. O QLQ-C30 é composto de escalas de múltiplos itens e de medidas de um 
único item. Estas incluem cinco escalas funcionais, três escalas de sintomas, avaliação global de estado de saúde, avaliação global da qualidade de vida e seis itens isolados, pode ser complementado por instrumento desenvolvido especificamente para portadoras de câncer de mama, o QLQ-BR23. Uma das vantagens deste instrumento é o de avaliar também a relação do paciente com o meio social e familiares.

Especificamente em 244 pacientes com câncer de mama, Kemmler et al, 1999, compararam o FACT-G com o QLQ-C30 (EORTC 1993), chegando à conclusão que, apesar de não serem comparáveis, o QLQ-C30 tem uma abordagem mais ampla da condição física do paciente. O questionário QLQ-C30 apresenta nove escalas de múltiplos itens: cinco escalas funcionais (físico, cotidiano, cognitivo, emocional e social); três escalas de sintomas (fadiga, dor, náusea e vomito), uma sobre a saúde geral uma escala de qualidade de vida. Os resultados da validação do questionário mostraram que o instrumento de mensuração é aplicável em pesquisas clínicas em pacientes com câncer em varias culturas diferentes [EORTC Study Group on Quality of Life, 1993], sendo que nós mesmos trabalhamos recentemente na validação desse questionário para o português do Brasil.

A identificação de dois genes, o BRCA1 e o BRCA2, ambos ligados ao aumento de risco familiar para câncer de mama e de ovário reafirmam a importância de se coletar dados relativos aos antecedentes hereditários das pacientes com câncer de mama. Desses genes, o BRCA1 tem um tamanho de aproximadamente 100.000 pares de base e codifica uma proteína de 1863 aminoácidos e parece funcionar como supressor de tumor. Está localizado no braço longo do cromossomo 17 (17q21) e estima-se que os portadores de mutações deletérias desse gene sejam responsáveis 
por cerca de $20 \%$ a $85 \%$ dos cânceres de mama nas famílias de alto risco, taxa essa que parece variar dependendo do país (Couch, 1988). O segundo gene, BRCA2, está localizado no braço longo do cromossomo (13q 12-13) e também confere susceptibilidade aumentada para o câncer de mama e para o câncer de ovário, além de maior susceptibilidade para o câncer de mama masculino.

Uma das dificuldades no estudo do câncer de mama hereditário é o amplo espectro de mutações relacionadas a um risco aumentado de neoplasias. Foi descrito mais de 1200 mutações de cada um dos gen descritos acima, o que torna bastante difícil a proposição de uma metodologia rápida e de baixo custo para sua detecção. As mutações estão espalhadas por todo o gene, sendo que o exon 1, tanto no gene BRCA1 como no BRCA2, não é traduzido e o exon 11 é muito extenso. Mutações que com inserção ou deleção de um ou mais nucleotídeos (não múltiplos de três) com conseqüente modificação da seqüência de leitura foram identificadas em $70 \%$ das vezes e mutações com mudança de códon ocorrem com uma freqüência de $10 \%$.

Outra dificuldade é o fato de que, embora a maioria das mutações tivesse sido descrita só uma vez, foram descritas várias mutações fundadoras. Uma dessas mutações fundadoras é a 185delAG no gene BRCA1, que é encontrada em uma de cada 100 mulheres da população judia Ashkenazi, a qual acredita-se tenha sido gerada há cerca de 600 anos. Outras mutações, como a 5382insC no gene BRCA1 e a 6174delT no gene BRCA2 foram descritas como afetando aproximadamente $0,15 \%$ e 1,5\%, respectivamente (Koifman, 2001, Kauff, 2002, Neuhausen, 1996, Struewing, 1997, Gorski, 2004).

Várias outras mutações fundadoras foram descritas. Entre elas a 999del15 no gene BRCA2, que parece ser responsável por 40\% dos cânceres de mama masculina 
e $25 \%$ dos cânceres de mama femininos com caráter hereditário na Islândia. Em famílias polonesas, três mutações são comuns no gene BRCA1 (5382insC, C61G e a 153delA), conforme demonstrado em estudo com 100 famílias polonesas com história familiar de câncer de mama e ovário (Gorski, 2005).

Apesar das inúmeras mutações descritas, a susceptibilidade herdada para o câncer de mama parece ocorrer em menos de $10 \%$ dos pacientes com câncer de mama (Colditz, 1993; Couch, 1988; Wooster, 1995). Desses 10\%, acredita-se que dois terços ou três quartos sejam causados por mutações nos gen BRCA1 ou BRCA2. Além disso, acredita-se que cerca de 15-20\% dos casos ocorram como resultado de predisposição multifatorial em agrupamentos familiares. Nesses últimos, o câncer pode surgir como o resultado da interação de múltiplos genes e fatores ambientais, ou de um gene que confere susceptibilidade, mas de baixa penetrância.

A prevalência de mutações do BRCA1/2 no Brasil não é conhecida. A literatura disponível ainda é escassa. Em um trabalho conduzido no Rio de Janeiro, em que foram pesquisadas mutações do BRCA1 e BRCA2 de 402 pacientes não selecionadas portadoras de câncer de mama e provenientes de um hospital público e duas clínicas privadas foram identificadas nove mutações nessas pacientes, representando 2,3\% do total. Seis mutações foram identificadas no BRCA1, sendo a mais freqüente a 5382insC, e 3 três no BRCA2, onde a mutação 6633del5 foi encontrada em dois casos (tabela 1) (Gomes, 2006). Os autores sugerem que a deportação de judeus portugueses em 1509, pela Inquisição, com sua migração para diversos países, inclusive o Brasil, poderia explicar o fato dessa mutação fundadora característica de populações Ashkenazi e eslavos ter sido encontrada com essa freqüência. 
Tabela 1 - Mutações do BRCA1 e BRCA2 identificadas em pacientes brasileiras portadoras de câncer de mama

\begin{tabular}{|c|c|c|c|c|c|}
\hline Paciente & Gene & Exon & Mutação & $\begin{array}{l}\text { Idade ao } \\
\text { diagnóstico }\end{array}$ & História familiar \\
\hline 26257 & BRCA1 & 11 & 3347delAG & M32 & Ov64 \\
\hline 24579 & BRCA1 & 20 & 5382insC & M28 & M47 \\
\hline 24122 & BRCA1 & 20 & 5382insC & M38 & M50 \\
\hline 24535 & BRCA1 & 20 & 5382insC & M46 & M63 \\
\hline 26288 & BRCA1 & 20 & 5382insC & M37, LNH35 & $\begin{array}{l}\text { M42, M35, M30, } \\
\text { M32,M36, M38 }\end{array}$ \\
\hline 28844 & BRCA1 & 20 & 5382insC & M41 & Ut56, M60 \\
\hline 26243 & BRCA2 & 11 & 6174delT & M48 & $\begin{array}{l}\text { M37, MMasc70, } \\
\text { Ov37 }\end{array}$ \\
\hline 26260 & BRCA2 & 11 & 6633del15 & M32 & Ignorado \\
\hline 24591 & BRCA2 & 11 & 6633del15 & M53 & M49 \\
\hline
\end{tabular}

No Brasil, estudos epidemiológicos apontam para possíveis diferenças com outros países. Em estudo realizado em São Paulo e Porto Alegre, por meio do exame cuidadoso de atestados de óbito depositados em órgão da comunidade judia, não foi demonstrado aumento de mortalidade por câncer de mama em judeus Aschenazi, o que sugere que outros fatores ambientais estejam no surgimento da doença 
(Koifman, 2001). Além disso, pesquisa feita pela Escola Nacional de Saúde Pública, Fundação Oswaldo Cruz, indica a existência de agregação familiar 5 a $8 \%$ dos casos de câncer de mama. Este estudo, que analisou 250 famílias estudadas durante quatro gerações, estimou que existiria entre 8 a 10 anos de declínio na idade de aparecimento do câncer de uma geração para outra, dado esse que difere da literatura, que indica que a idade de aparecimento do câncer nas famílias com mutações de BRCA1/2 segue padrões familiares. Os autores concluem que a influência do meio ambiente seja particularmente forte nesses casos de agregação familiar (Koifman, 1998).

A identificação das pacientes portadoras das mutações no Brasil é muito importante, uma vez que o risco de câncer de mama em portadoras de mutações deletérias do BRCA1 ou do BRCA2 é de $60-85 \%$ durante a vida e de ovário é de 15 40\% durante a vida (Armstrong, 2000), risco muito superior aos outros fatores de risco como idade, história familiar, idade da menarca, idade da menopausa, idade do primeiro parto, doença benigna da mama ou terapia de reposição hormonal (Armstrong, 2000). Com esses números, é fácil inferir que grande parte da população com câncer de mama deve sofrer de alta ansiedade, com a possibilidade em mente de ser portador de um gene de susceptibilidade ao câncer hereditário (Hallowell, 2004, Claus, 2004). Mulheres com pelo menos um parente comprometido por câncer de mama com freqüência procuram espontaneamente serviços de aconselhamento genético devido a sua percepção de risco elevado de câncer, estudo conduzido por Evans (1994) mostrou que apenas $11 \%$ tinham uma noção correta do risco de câncer hereditário antes do aconselhamento genético e $41 \%$ após o aconselhamento. De fato, estudos anteriores em mulheres com história familial de câncer de mama e de ovário 
sugerem que, tanto mulheres saudáveis em risco de câncer como mulheres que já tiveram câncer, se sentem ansiosas com o fato de que a sua chance de ter câncer possa ser elevada e geneticamente determinada.

Pelos motivos acima, consideramos que, a avaliação dessas pacientes em um ambulatório de aconselhamento genético, com os esclarecimentos necessários sobre o caráter familial da doença e a determinação real da possibilidade de ser essa paciente uma portadora de mutações deletérias do BRCA1 ou do BRCA2 pode dirimir dúvidas, aumentar a percepção de apoio e, como conseqüência, ajudar na qualidade de vida dos pacientes de uma forma geral, talvez contribuindo para diminuir a ansiedade. Por isso, nosso objetivo neste projeto foi o de avaliar a qualidade de vida de pacientes portadora de câncer de mama, atendidas no ambulatório de Oncologia do Hospital das Clínicas da Faculdade de Medicina da Universidade de São Paulo (HCFMUSP), para as quais tenha sido oferecido atendimento no ambulatório de câncer de hereditário. Além disso, pretendemos avaliar o potencial de demanda para um ambulatório de câncer hereditário oriundo de um ambulatório de Oncologia em nosso meio, além do percentual de pacientes candidatas à pesquisa de mutações nos genes BRCA1/2. 


\section{Objetivos}

\section{Objetivos}

Os objetivos primários deste trabalho foram:

1. Avaliar a qualidade de vida dos pacientes com câncer de mama para os quais foi oferecida avaliação no ambulatório de câncer hereditário.

2. Identificar os possíveis candidatos ao teste genético em um ambulatório de Oncologia clínica. 


\section{Métodos}

\section{Pacientes e métodos}

No período compreendido entre 01 de setembro de 2005 e 31 de junho de 2006 foi oferecida, sistematicamente, uma consulta no grupo de câncer hereditário a todas as pacientes com diagnóstico de câncer de mama matriculadas no ambulatório da Oncologia Clínica e que estivessem em seguimento clínico ou em tratamento com hormonioterapia, independente da presença de doença ativa. As pacientes eram informadas dos objetivos da pesquisa, suas dúvidas esclarecidas e, caso concordassem eram incluídas no estudo após a assinatura do termo de consentimento livre e esclarecido (anexo 1). O estudo foi aprovado pela comissão de ética do HCFMUSP (anexo 2).

Os critérios para inclusão neste estudo foram:

1. assinatura do consentimento livre e esclarecido.

2. sexo feminino.

3. idade igual ou superior a 18 anos.

4. confirmação histológica de câncer primário de mama.

Os critérios para exclusão deste estudo foram:

1. recusa em assinar o consentimento livre e esclarecido.

2. sexo masculino.

3. idade inferior a 18 anos.

4. ausência de confirmação histológica de câncer primário de mama. 
Foi solicitado a todas as participantes do estudo o preenchimento no domicílio de uma "ficha de triagem" com dados familiares (anexo 3). Além da ficha de triagem as pacientes receberam os questionários de qualidade de vida da EORTC QLQ-C30 versão 3.0 (anexo 4) (Aaronson, 1993) e o questionário QLQ-BR23 (anexo 5) (Fayers, 2001). Foi solicitado a essas pacientes que trouxessem a ficha de triagem e os questionários QLQ-C30 e QLQ-BR23 preenchidos no dia da primeira consulta agendada no ambulatório de câncer hereditário, a qual ocorreu num período de duas a quatro semanas a partir da inclusão no estudo.

Os questionários utilizados, QLQ-C30 e QLQ-BR23, foram traduzidos e validados para o português do Brasil anteriormente pela Profa. Dra. Miriam H. H. Federico, da Disciplina de Oncologia da Faculdade de Medicina da Universidade de São Paulo. As pacientes foram esclarecidas da importância do preenchimento por elas mesmas e não permitirem a interferência de familiares ou outras pessoas nas respostas. Naquelas pacientes não alfabetizadas ou com dificuldades visuais, os familiares ou acompanhantes responsáveis pelo auxílio no preenchimento dos questionários foram orientados a apenas ler as perguntas para as pacientes não interferindo nas respostas escolhidas pelas mesmas.

Durante todas as consultas no ambulatório de câncer hereditário, foram observados os princípios gerais que regem o aconselhamento genético e, sobretudo, os princípios éticos, de beneficiência, não maleficência, autonomia e justiça. Todo atendimento foi realizado de maneira individualizada, com clareza, tendo sido preservada a confidencialidade da informação ali obtida. Os princípios éticos chaves, do aconselhamento genético foram seguidos (Pembey, 1996): 
a) a natureza voluntária do teste genético e a liberdade e responsabilidade do indivíduo ou casal em decidir;

b) a importância de se certificar que todos os indivíduos para quem for oferecido o rastreamento compreendem a proposição do teste e o significado de um resultado positivo, indeterminado ou negativo;

c) o compromisso de confidencialidade no manejo dos resultados acoplado com a ênfase na responsabilidade dos indivíduos com um resultado positivo (anormal) em informar companheiros(as) e membros da família; e

d) o fato de que o consentimento para o rastreamento ou para um teste confirmatório subseqüente não implica em consentimento para nenhum tratamento específico ou para a interrupção de gestação.

Na primeira consulta, após a devolução dos questionários QLQ-C30 e QLQBR23 devidamente preenchidos, as pacientes foram informadas quanto à natureza do atendimento, ao significado do risco de ser portadora de uma ou mais mutações que predisponham ao câncer e quanto aos potenciais benefícios e malefícios do teste, se indicado. Foram explicitadas as potencialidades e limitações da metodologia de avaliação de risco, inclusive da possibilidade de obtenção de resultados inconclusivos (Tabela 2) da necessidade de obtenção de informações e eventualmente material biológico de outros membros da família para confirmação de resultados. Também foi explicado, de maneira compreensível para as pacientes, o 
significado da transmissão hereditária. Após os esclarecimentos iniciais foi obtida a história familiar detalhada, com base na ficha de triagem trazida pela paciente e foi construído o heredograma com três gerações, sempre que possível.

Tabela 2 - Descrição dos possíveis resultados do teste genético para determinação da presença de gene de predisposição a câncer

Resultado Descrição

\begin{tabular}{ll}
\hline Verdadeiro positivo & A pessoa é portadora de uma alteração em \\
& um gene de predisposição a câncer \\
& conhecido
\end{tabular}

Verdadeiro negativo A pessoa não é um portador de um gene de predisposição a câncer que foi positivamente identificado em outro membro da família

Indeterminado

A pessoa não é portadora de um gene de predisposição ao câncer conhecido e a condição de portador de outro membro da família é negativa ou desconhecida

Inconclusivo A pessoa é portadora de uma alteração em um gene que não tem significado conhecido 
Dentro da história familiar foram confirmados dados relativos à idade ao diagnóstico dos tumores, tratamento e evolução (se vivo ou morto), exposição ambiental a fatores de risco conhecidos e construção do heredograma com pelo menos três gerações. Ambigüidades do heredograma foram solucionadas segundo a tabela 3 (Kang, 2006). A informação sobre etnia também foi coletada, visto a prevalência de algumas alterações genéticas em determinadas populações e as pacientes foram classificadas segundo possuírem ascedência judaica ou não.

Tabela 3 - Convenções utilizadas para interpretação de heredogramas ambíguos

\section{Modelo}

\begin{tabular}{llll} 
Problema & \multicolumn{1}{l}{ Resolução } & aplicável \\
\hline Meio-irmãos & Considerar irmãos plenos & E, B, F \\
Idade ao diagnóstico de & Atribuir a menor díade possível & $\mathrm{E}$ \\
câncer desconhecida & compatível com a idade atual & \\
Câncer de mama & Contabilizar como dois casos & E, F \\
bilateral & diferentes & \\
Câncer & ovário & Contabilizar como um caso & E, B, F \\
bilateral & & & \\
Idade de parente vivo & Estimada como 25 anos mais jovem & B \\
desconhecida & que os pais ou dois anos de diferença &
\end{tabular}

Idade de morte não Estimada como 70 anos ou a idade de $\mathrm{B}$ 
especificada morte de irmãos

Câncer $>70$ anos de Morte estimada como dois anos após o B

idade, idade da morte diagnóstico de câncer se o câncer foi a

desconhecida causa da morte

Morte na infância Idade da morte registrada como um B

ano

Idade ao diagnóstico de Estimada como dois anos antes da B

câncer desconhecida morte para parentes falecidos e dois

anos mais jovem que os parentes, para

os vivos

E = Evans, B = BRCAPRO, F = Frank. Adaptado de Kang, 2006.

Nas pacientes sem história familiar de câncer relacionado aos genes BRCA1/2, foi calculado o risco de ser portador da mutação nessa mesma consulta. Nas pacientes com história familiar de risco foi solicitado que a mesma obtivesse documento confirmatório da neoplasia e marcada nova consulta para a apresentação desse documento. Foram considerados documentos confirmatórios: resultados de exames anátomo-patológicos, atestados de óbito, relatórios médicos e prontuários médicos. Consideramos positivos apenas os casos passiveis de documentação confirmatória. As pacientes de risco elevado e com indicação da pesquisa de mutações foram encaminhadas para avaliação com a psicóloga antes da coleta de sangue para exame. A coleta do sangue só foi realizada após novo esclarecimento das limitações do método (sensibilidade, especificidade, valor preditivo), seus riscos 
e benefícios potenciais e após plena concordância da paciente com o teste genético. Todos os exames foram realizados sem ônus para s pacientes.

Uma vez que nem todos os casos suspeitos de serem portadores de predisposição genética para o câncer são candidatos ao teste genético, discutimos com as pacientes qual sua percepção do risco de desenvolvimento de câncer e motivação para investigação da predisposição hereditária, procurando assim traçar um perfil do paciente e antecipar suas reações a possíveis decisões de manejo frente a um risco real de câncer.

Uma vez concluída a investigação familiar, o risco de ser portador de mutação deletéria dos genes BRCA1/2 foi calculado e informado para a paciente. As pacientes foram categorizadas em risco de serem portadoras de mutações deletérias < $10 \%$ ou $\geq 10 \%$. Optamos por definir o risco elevado como $\geq 10 \%$ segundo as diretrizes da American Society of Clinical Oncology (1996, 2003). Em análise fármaco econômica conduzida em nosso serviço, avaliamos a relação custo-benefício se considerássemos como risco elevado $\geq 10 \%$ em relação a uma conduta mais conservadora, que consideraria risco elevado apenas o $\geq 20 \%$. A relação de custobenefício foi mais favorável quando utilizado o valor $\geq 10 \%$ por ser menos restritiva e ter como potenciais beneficiários um maior número de familiares (Brentani, 2006). O teste genético foi oferecido para as pacientes consideradas de risco alto para mutações $(\geq 10)$.

Após a determinação do risco e esclarecimentos prestados, foi solicitado às pacientes que respondessem pela segunda vez os questionários de qualidade de vida QLQ-C30 e QLQ-BR23, em um prazo não superior a um mês. Essa segunda avaliação foi necessária para que pudéssemos avaliar se houve impacto positivo, 
negativo ou nulo, na qualidade de vida dessas pacientes após a determinação do risco de ser portadora de genes de susceptibilidade para câncer de mama hereditário e terem sido convidadas a colher sangue para determinação de possíveis mutações. Para as pacientes com indicação do teste, foi solicitado o seu preenchimento antes da consulta com a psicóloga.

Nos casos com indicação para o teste genético foi iniciada a discussão quanto a opções de tratamento/prevenção disponíveis no momento.

Caso a paciente não comparecesse à primeira consulta após a inclusão no estudo, foi tentado contato telefônico para a determinação da causa do não comparecimento e, se desejado, para a remarcação da consulta. Esse contato foi realizado por entrevista telefônica as pacientes foram agrupadas segundo

A. Contato efetuado ou não;

B. Quando contato efetuado, se a mesma continuava interessada no atendimento ou não, se interessada, a consulta era remarcada nesse momento e a entrevista encerrada;

C. Quando não interessada no atendimento, as perguntas foram formuladas para identificação do motivo da desistência na consulta, em:

1. não tem tempo para comparecimento ao ambulatório;

2. não tem mais interesse no atendimento especializado em câncer hereditário;

3. não deseja se preocupar com o assunto tem problemas em demasia no momento;

4. paciente não reside no local e o morador desconhece seu telefone ou endereço; 
5. paciente evoluiu para óbito antes da consulta;

6. paciente ausente no domicílio;

7. paciente presente no domicílio, mas não quer atender ao telefonema;

8. paciente presente no domicílio, mas recusa-se a atender a equipe ao telefone;

9. paciente presente no domicílio, porém, muito doente e não pode atender.

Em resumo, o desenho do estudo está diagramado abaixo:

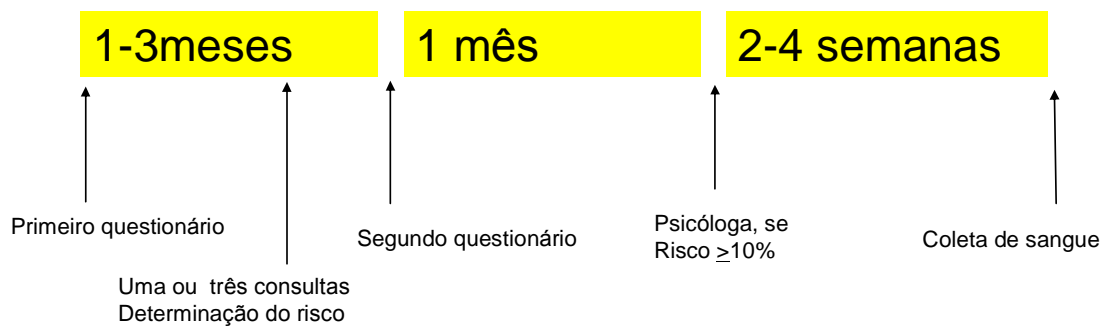

Diversos modelos foram descritos para avaliar o risco de um paciente ser portador de mutações deletérias do BRCA1/2 e todos eles apresentam algumas limitações. Optamos por determinar o risco de ser portadora de mutações deletérias dos genes BRCA1/2 foi por três modelos: Frank (Frank, 2002) (tabelas 4 a 9), Evans (Evans, 2004) (tabela 10) e BRCAPRO (Parmigiani, 1998, Berry, 2002). Também poderiam ser considerados, em casos com história familiar importante, mas que 
eventualmente não alcançassem os $10 \%$ de risco pelos métodos descritos (Anexos $\mathrm{X})$.

O modelo proposto por Frank (2002) correlaciona mutações deletérias do BRCA1 e do BRCA2 com dados de história pessoal e familiar em indivíduos de ascendência Ashkenazi e não Ashkenazi. Esses dados foram obtidos a partir da análise de 10.000 sequenciamentos consecutivos dos genes citados, correlacionados com dados clínicos obtidos antes do sequenciamento. O risco é determinado a partir da consulta de uma tabela. (tabelas 4-9).

O modelo de Evans (2004) foi proposto a partir da análise de dados de história pessoal e familiar e de mutações deletérias obtidas a partir do sequenciamento dos genes BRCA1 e BRCA2 em 422 famílias não judias da Inglaterra. Foi validado em dois outros grupos de famílias, 192 e 298 famílias, e incorpora na análise do risco além do carcinoma de ovário os carcinomas de próstata e de pâncreas (tabela 10).

Tabela 10 - Sistema de escores proposto por Evans para identificação de mutações deletérias de BRCA1/2.

Câncer, idade ao

BRCA1

BRCA2

diagnostico

CA mama feminino, $<30$

6

5

CA mama feminino, 30-39

4

4

CA mama feminino, 40-49 
CA mama feminino, 50-59

CA mama feminino, $>59$
1

5 (se BRCA2 já testado)

5 (se BRCA2 já testado)

5 (se BRCA1 já testado)

CA ovário, $<60$

8

5

5 (se BRCA1 já testado)

CA pâncreas

CA próstata, $<60$

CA próstata, $>59$

0

0

0
2

1

8

5

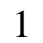

2

1

CA, câncer. Em casos de câncer de mama bilateral, cada lado é contado separadamente. $O$ carcinoma ductal in situ é incluído na contagem.Os escores devem ser somados contando cada câncer em uma linhagem direta. Adaptado de Evans, 2004.

O programa BRCAPRO é um modelo estatístico com software associado, para determinação da probabilidade de um determinado indivíduo ser portador de mutação germinativa deletéria dos genes BRCA1 e BRCA2, baseado na história familiar de câncer de mama e ovário, baseado na história pessoal de câncer de mama ou ovário do(a) paciente, incluindo câncer de mama masculino e câncer de mama bilateral sincrônico ou metacrônico. Utiliza uma abordagem Mendeliana que presume uma herança autossômica dominante. A penetrância e prevalência, ambas dependentes da idade do probando são assumidas a partir de revisão sistemática da literatura. Foi desenvolvido por Omar Aguillar, Donald A. Berry e Giovanni Parmigiani no Institute of Statistics and Decision Sciences, Duke University, EUA. Para a aplicação desse modelo utilizamos o programa CancerGene, versão 4.2, que 
foi gentilmente cedido para a FMUSP pelo Prof. David Euhus, da University of Texas Southwestern Medical Center, solicitação esta realizada por nós para uso no estudo e no ambulatório de câncer hereditário do Serviço de Oncologia. A licença para o uso do programa nos foi concedida em julho de 2006.

Para os valores faltantes nos questionários de qualidade de vida QLQ-C30 e QLQ-BR23, foi considerada a média da categoria, quando aplicável, ou deixados em branco quando determinações de sintomas isolados. Os escores foram calculados segundo os manuais da EORTC (Fayer, 2001). Em resumo, os escores para cada item variam de zero a 100. Um elevado escore para as escalas funcionais representa um desempenho funcional elevado e saudável. Um escore elevado para saúde global representa uma boa qualidade de vida. Entretanto, escores elevados para escalas de sintomas ou para itens isolados de sintomas representam um nível elevado de sintomas ou de problemas. Para os valores obtidos referentes aos dados de qualidade de vida, o método mais utilizado para definir variações clinicamente significativas foi o baseado na distribuição, proposto por Cohen (1988) e em resumo propõe que variações de 0,2 do desvio padrão representam pequenas variações, variações de 0,5 representam variações moderadas e aquelas iguais ou superiores a 0,8 representam grandes variações. Portanto, variações superiores ou iguais a 0,5 do desvio padrão foram consideradas clinicamente significativas (Brozek, 2006, Revicki, 2006, US, 2006).

Os dados clínicos e patológicos descritos na ficha clínica (anexo X) foram obtidos durante as consultas e complementados com dados do prontuário das pacientes. 
Com relação aos dados referente à qualidade de vida obtidos a partir das respostas das pacientes aos questionários QLQ-C30 e QLQ-BR23, estes foram agrupados em diferentes domínios, conforme preconizado pela EORTC, como esquematizado abaixo:

\section{QLQ-C30}

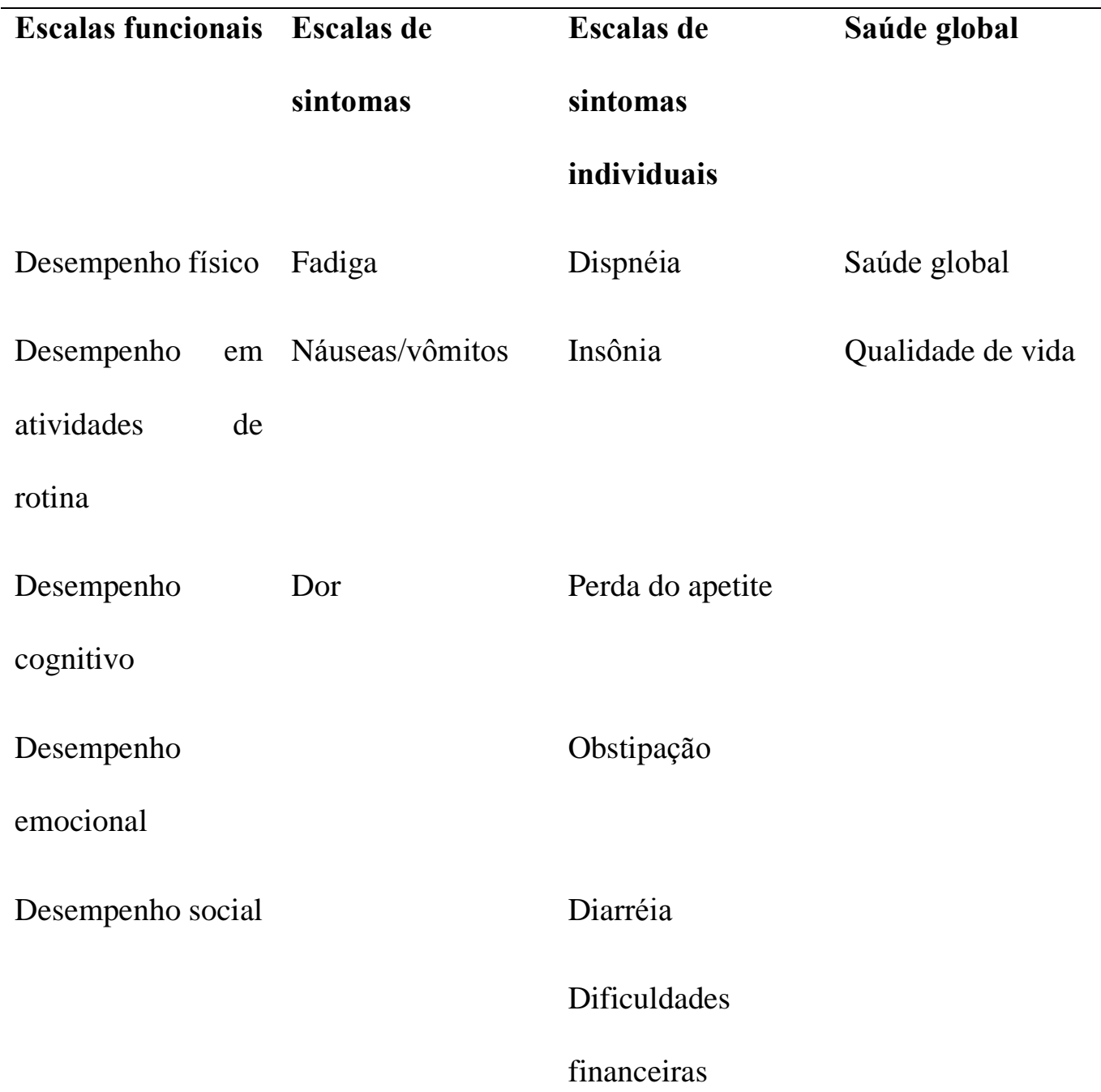

financeiras

\section{QLQ-BR23}


Escalas funcionais

Imagem corporal

Função sexual

Prazer sexual

Perspectivas futuras

\section{Escalas de sintomas}

Toxicidade do tratamento sistêmico

Sintomas mamários

Sintomas no braço

Preocupação com queda de cabelos

Para cálculo dos escores foram seguidas as orientações do manual da EORTC

(Fayers, 2001) e as questões foram agrupadas da seguinte maneira no QLQ-C30:

- saúde Global: questões 29 e 30.

- desempenho físico: questões 1, 2, 3, 4 e 5.

- desempenho de rotina: questões 6 e 7.

- desempenho emocional: questões 21, 22, 23 e 24.

- capacidade cognitiva: questões 20 e 25.

- desempenho social: questões 26 e 27.

- fadiga: questões 10, 12 e 18 .

-náuseas e vômitos: questões 14 e 15.

- dor: questões 9 e 19.

- dispnéia: questão 8 .

- insônia: questão 11.

- perda do apetite: questão 13. 
- obstipação: questão 16.

- diarréia: questão 17.

- dificuldades financeiras: questão 28.

Para o QLQ-BR23 o agrupamento foi feito da seguinte forma:

- imagem corporal: questões 9, 10, 11 e 12 .

- função sexual: questões 14 e 15.

- prazer sexual: 16.

- perspectivas futuras: questão 13.

- toxicidade do tratamento sistêmico: questões 1, 2, 3, 4, 6, 7 e 8 .

- sintomas mamários: questões 20, 21, 22 e 23.

- sintomas no braço: questões 17, 18 e 19.

- preocupação com queda de cabelos: questão 5.

\section{Análise estatística}

Os dados foram analisados segundo testes de regressão logística e foi considerado $\mathrm{p}$ significativo se $\leq 0,05$. Foram obtidas as médias e medianas em todos os domínios e comparamos os resultados da qualidade de vida antes do aconselhamento e após o aconselhamento pelos métodos de Wilcoxon e Spearman, bi-caudados. Realizamos também análises exploratórias de fatores que poderiam 
predizer ou não a qualidade de vida, neste caso apenas as primeiras medidas foram correlacionadas com esses fatores. 


\section{Resultados}

No período compreendido entre 01 de setembro de 2005 e 31 de julho de 2006, 282 pacientes atendidas seqüencialmente no ambulatório da Oncologia Clínica do Instituto de Radiologia do HCFMUSP foram convidadas a participar do estudo. Destas, 272 concordaram em participar e, após terem sido prestados os esclarecimentos, assinaram o termo de consentimento pós-informado (anexo 1). 198 completaram todos os procedimentos do estudo. Destas, 18 pacientes foram excluídas da análise por falha de inclusão, a saber: uma por ser portadora de Neoplasia Endócrina Múltipla, 11 por não serem portadoras de câncer de mama apesar de história familiar importante, três pacientes por serem portadoras de câncer de cólon, duas pacientes por serem portadoras de câncer de ovário sem câncer de mama e um paciente por ser portador de câncer de mama e pertencer ao sexo masculino. Todas as 180 pacientes avaliáveis responderam aos questionários QLQC30 e QLQ-BR23 antes da primeira consulta e 134 entregaram os questionários citados após ter sido completada a avaliação no ambulatório de câncer hereditário e após a determinação do risco. Nenhuma das pacientes com risco superior a $10 \%$ deixou de completar o processo. Os dados faltantes nos questionários de qualidade de vida ocorreram em menos de $1 \%$ das questões.

A idade atual média das pacientes foi de 57,8 anos, mediana de 57 anos, intervalo de 28 a 84 anos, desvio padrão de 11,3 anos. A idade ao diagnóstico média foi de 53,7 anos, mediana de 53 anos, com intervalo de 24 a 82 anos, desvio padrão de 11,3 meses (Gráfico 1). 
Gráfico 1 - Distribuição das pacientes segundo idade, em anos, ao diagnóstico.

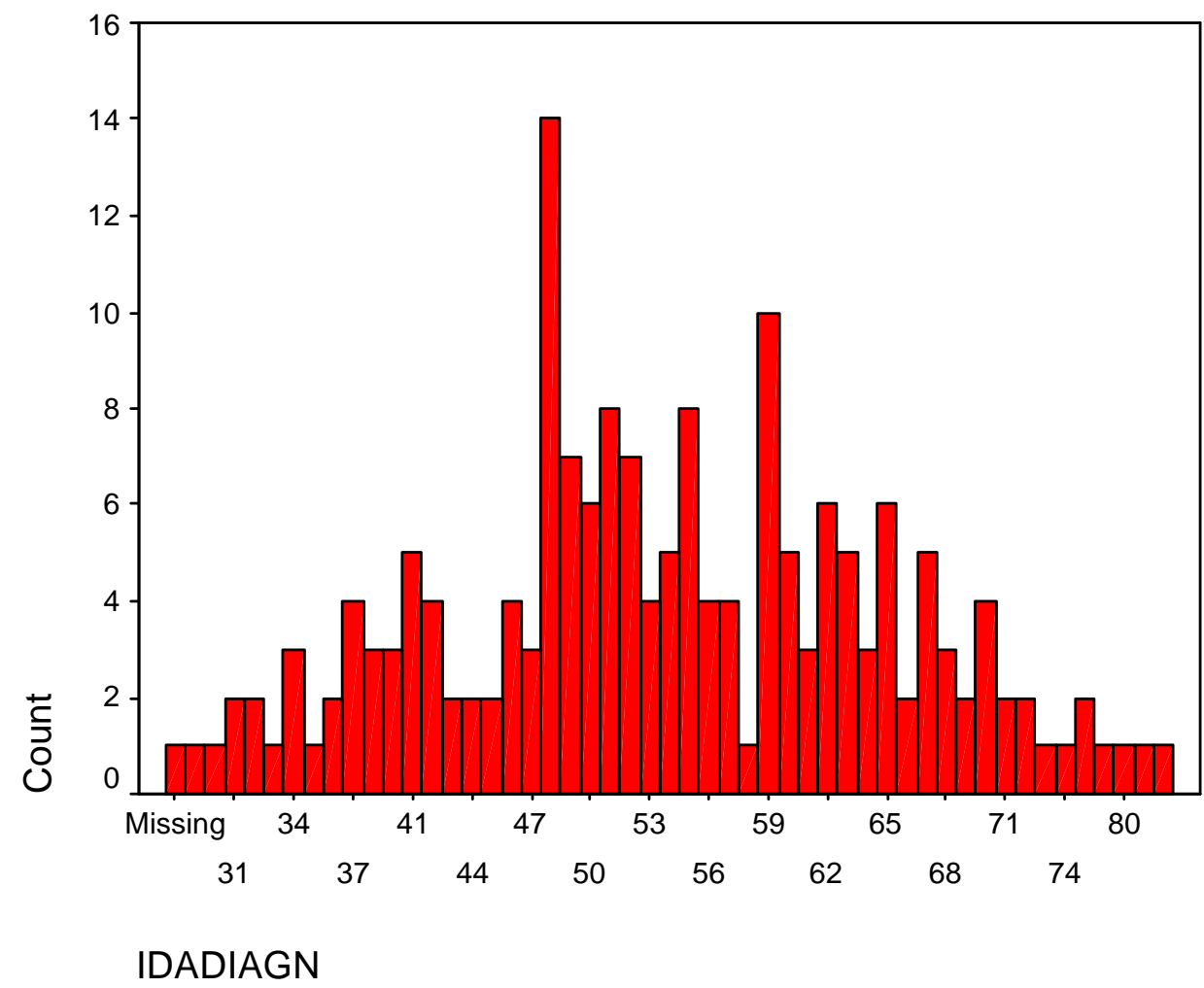

O tempo decorrido desde o diagnóstico médio foi de 50,2 meses, mediano de 37 meses, intervalo de seis a 552 meses e desvio padrão de 55,5 meses. Com relação ao tempo decorrido desde o diagnóstico, em 89 (49,4\%) pacientes o diagnóstico havia sido realizado há menos de 36 meses, em 51 (28,3\%) há 36-59 meses e em 39 $(21,7 \%)$ há 60 meses ou mais (tabela 11$)$. 
Tabela 11 - Características clínicas das 180 pacientes avaliáveis

\begin{tabular}{|c|c|c|}
\hline \multirow[t]{4}{*}{ Idade atual (anos) } & Media & $\mathbf{5 7 , 8}$ \\
\hline & Mediana (desvio padrão) & $5( \pm 11,3) 7$ \\
\hline & Intervalo & $28-84$ \\
\hline & Ignorado & \\
\hline \multirow[t]{4}{*}{ Idade ao diagnóstico (anos) } & Média & 53,7 \\
\hline & Mediana (desvio padrão) & $53( \pm 11,5)$ \\
\hline & Intervalo & 24-82 \\
\hline & Ignorado & $1(0,6 \%)$ \\
\hline \multirow[t]{4}{*}{ Tempo desde o diagnóstico (meses) } & $<36$ meses & $89(49,4 \%)$ \\
\hline & $\geq 36<60$ meses & $51(28,3 \%)$ \\
\hline & $\geq 60$ meses & $39(21,7 \%)$ \\
\hline & Ignorado & $1(0,6 \%)$ \\
\hline \multirow[t]{3}{*}{ Status da menopausa ao diagnóstico } & Pré menopausa & $57(31,7 \%)$ \\
\hline & Pós menopausa & $121(67,2 \%)$ \\
\hline & Ignorado & $2(1,1 \%)$ \\
\hline \multirow[t]{3}{*}{ Lateralidade } & Unilateral & $161(89,4 \%)$ \\
\hline & Bilateral & $17(9,4 \%)$ \\
\hline & Ignorado & $2(1,2 \%)$ \\
\hline
\end{tabular}


Estádio ao diagnóstico

Histologia do tumor primário

Status do receptor hormonal

Recidiva

$\begin{array}{lr}\text { In situ } & 18(10,0 \%) \\ \text { I } & 44(24,4 \%) \\ \text { II } & 58(32,2 \%) \\ \text { III } & 47(26,1 \%) \\ \text { IV } & 8(4,4 \%) \\ \text { Ignorado } & 5(2,0 \%)\end{array}$

Ca ductal invasivo

$143(79,4 \%)$

Ca ductal in situ

Ca lobular invasivo

$15(8,3 \%)$

$7(3,9 \%)$

Ca lobular in situ

$1(0,6 \%)$

Ca tubular invasivo

$4(2,2 \%)$

Outros

$8(3,4 \%)$

Ignorado

$4(2,2 \%)$

RE e/ou RP positivo(s)

$153(85 \%)$

RE e RP negativos

$14(7,6 \%)$

ignorado

$13(7,4 \%)$
Ausente

Local

Metástases

Ignorado
$154(85,6 \%)$

$6(3,3 \%)$

$18(10,0 \%)$

$2(1,1 \%)$ 


\begin{tabular}{|c|c|c|}
\hline \multirow[t]{6}{*}{ Tratamento inicial - quimioterapia } & Nenhum & $45(25,0 \%)$ \\
\hline & Antraciclinas $^{\&}$ & $96(53,3 \%)$ \\
\hline & $\mathbf{C M F}^{\#}$ & $19(10,6 \%)$ \\
\hline & Taxanos* & $14(7,8 \%)$ \\
\hline & Outros & $1(0,6 \%)$ \\
\hline & Ignorado & $5(2,7 \%)$ \\
\hline \multirow{5}{*}{$\begin{array}{l}\text { Tratamento } \\
\text { hormonioterapia }\end{array}$} & Nenhum & $14(7,8 \%)$ \\
\hline & & \\
\hline & Tamoxifeno & $149(82,8 \%)$ \\
\hline & Inibidor da aromatase & $11(6,2 \%)$ \\
\hline & Ignorado & $6(3,2 \%)$ \\
\hline \multirow[t]{3}{*}{ Tratamento inicial - radioterapia } & Sim & $131(72,8 \%)$ \\
\hline & Não & $43(23,9 \%)$ \\
\hline & Ignorado & $6(3,3 \%)$ \\
\hline \multirow[t]{3}{*}{ Tratamento atual } & Nenhum & $40(22,2 \%)$ \\
\hline & Hormonioterapia & $137(76,1 \%)$ \\
\hline & Ignorado & $3(1,7 \%)$ \\
\hline \multirow[t]{2}{*}{ Tratamento cirúrgico inicial } & Cirurgia conservadora & $61(33,9 \%)$ \\
\hline & Mastectomia unilateral & $95(52,8 \%)$ \\
\hline
\end{tabular}


Mastectomia bilateral

Nenhum

Ignorado

Linfadenectomia

Sem linfadenectomia

Ignorado
$16(8,9 \%)$

$4(2,2 \%)$

$4(2,3 \%)$

$137(76,1 \%)$

$38(21,1 \%)$

$5(2,8 \%)$

\footnotetext{
${ }^{\&}$ Antraciclinas $=$ protocolos contendo antraciclinas, sem taxanos; ${ }^{\#}$ protocolos contendo ciclofosfamida, metotrexate e 5-fluorouracil; *taxanos = protocolos contendo taxanos, com ou sem antraciclinas.
}

Nenhuma das pacientes avaliadas declarou ser de ascendência judaica.

A maioria das pacientes encontrava-se na pós-menopausa ao diagnóstico (67,2\%, 121 pacientes), enquanto que 31,7\% (30 pacientes) encontravam-se na prémenopausa (tabela 11). Quanto à histologia do tumor, $143(79,4 \%)$ eram portadoras de carcinoma ductal invasivo, $15(8,3 \%)$ de carcinoma ductal in situ e as demais histologias encontradas, em $18(10,1 \%)$ casos, foram carcinoma lobular invasivo, carcinoma lobular in situ, carcinoma tubular invasivo, carcinoma papilífero in situ e carcinoma indiferenciado (tabela 11). O receptor de estrógeno ou de progesterona foi positivo em $153(85 \%)$ das pacientes (tabela 11), e desconhecido em $13(7,3 \%)$.

A reclassificação das pacientes para o estádio ao diagnóstico foi feita segundo o TNM $6^{\text {a }}$ edição (Brasil, 2006) e mostrou que 18 (10\%) apresentavam carcinomas in situ, 102 (56,6 \%) doença localizada (estádios I e II), 47 (26,1 \%) doença localmente avançada (estádio III) e $8(4,4 \%)$ com doença metastática (estádio IV). O 
diagnóstico foi feito com tumores com diâmetro superior a 5 cm em $28(15,56 \%)$ das pacientes e $20(11,11 \%)$ tiveram a apresentação como T4 (tabela 11). Como a maioria dessas pacientes teve o seu diagnóstico a mais de 36 meses e havia sido classificada inicialmente pela $5^{\text {a }}$ edição do TNM estão incluídos no grupo classificado como T4 tanto aquelas com apresentação clínica de carcinoma inflamatório quanto aquelas apenas com embolização linfática na derme identificada pela histologia. A maioria das pacientes $(161,89,4 \%)$ apresentou carcinoma de mama unilateral e $17(9,4 \%)$ apresentaram carcinoma de mama bilateral, sincrônico ou metacrônico.

A maioria das pacientes não havia apresentado ainda recidiva da doença e 18 (10\%) apresentaram recidiva com metástases à distância e seis $(3,3 \%)$ recidiva local (tabela 11).

A maioria das pacientes $(53,3 \%, 96$ pacientes $)$ recebeu como parte do tratamento inicial quimioterapia sistêmica baseada em antraciclinas, AC (doxorrubicina e ciclofosfamida), FAC (5-fluorouracil, doxorrubicina e ciclofosfamida) ou FEC (5-fluorouracil, epirrubicina e ciclofosfamida). Quimioterapia sistêmica com CMF (ciclofosfamida, metotrexate e 5-fluorouracil) ou variantes deste foi empregada em 19 pacientes $(10,6 \%)$ e quimioterapia com taxanos (paclitaxel ou docetaxel), em sua maioria em combinação com antraciclinas, foi administrada para 14 pacientes $(7,8 \%)$ (tabela 11$)$. A radioterapia para tratamento do tumor primário foi utilizada em 131 (72,8 \%) pacientes (tabela 11), e a hormonioterapia em 160 pacientes (89\%), sendo que a maioria das pacientes (149, $82,8 \%$ ) recebeu como primeira linha de hormonioterapia o tamoxifeno (tabela 11 ). 
A mastectomia unilateral foi o tratamento cirúrgico efetuado em $95(52,8 \%)$ das pacientes, mastectomia bilateral foi realizada em $16(8,9 \%)$ e cirurgia conservadora, quadrantectomia ou setorectomia, em $61(33,9 \%)$ das pacientes (tabela 11). O esvaziamento axilar foi realizado em $137(76,1 \%)$ das pacientes (tabela 11) sendo que na quase totalidade das 38 pacientes que não foram submetidas a esvazimento axilar isto ocorreu porque a pesquisa do linfonodo sentinela foi negativa.

Avaliamos se as pacientes estavam sendo submetidas a algum tipo de tratamento durante o estudo e observamos que a maioria delas avaliadas (137, $76,1 \%$ ) estava em hormonioterapia com tamoxifeno, inibidores da aromatase (anastrozol ou letrozol) ou fulvestranto e 40 pacientes $(22,2 \%)$ não estavam recebendo nenhum tipo de tratamento (tabela 11)

As pacientes foram agrupadas segundo categoria de risco de serem portadoras de mutações deletérias dos genes BRCA1/2, pelos modelos de Frank, Evans e BRCAPRO. Risco elevado foi considerado aquele maior ou igual a $10 \%$ e risco baixo aquele menor que 10\%. 45 pacientes foram classificadas como de risco elevado pelo modelo de Frank, 35 pelo BRCAPRO e 21 pacientes pelo modelo de Evans (Gráfico 2, anexo 7) . Constamos uma considerável divergência na classificação de risco entre esses métodos, sendo que 57 pacientes foram consideradas de risco elevado em pelo menos um dos modelos e apenas 12 pacientes foram consideradas de risco elevado pelos três modelos. Observamos que há uma correlação entre menor idade ao diagnóstico e risco $\geq 10 \%$ de ser portador de mutações deletérias (teste bicaudado, $\mathrm{p}<0,001$ ). 
Gráfico 2 - Classificação das 180 pacientes avaliáveis segundo o risco de mutações do BRCA1 e BRCA2 pelos modelos de Frank, Evans (Manchester) e BRCAPRO.

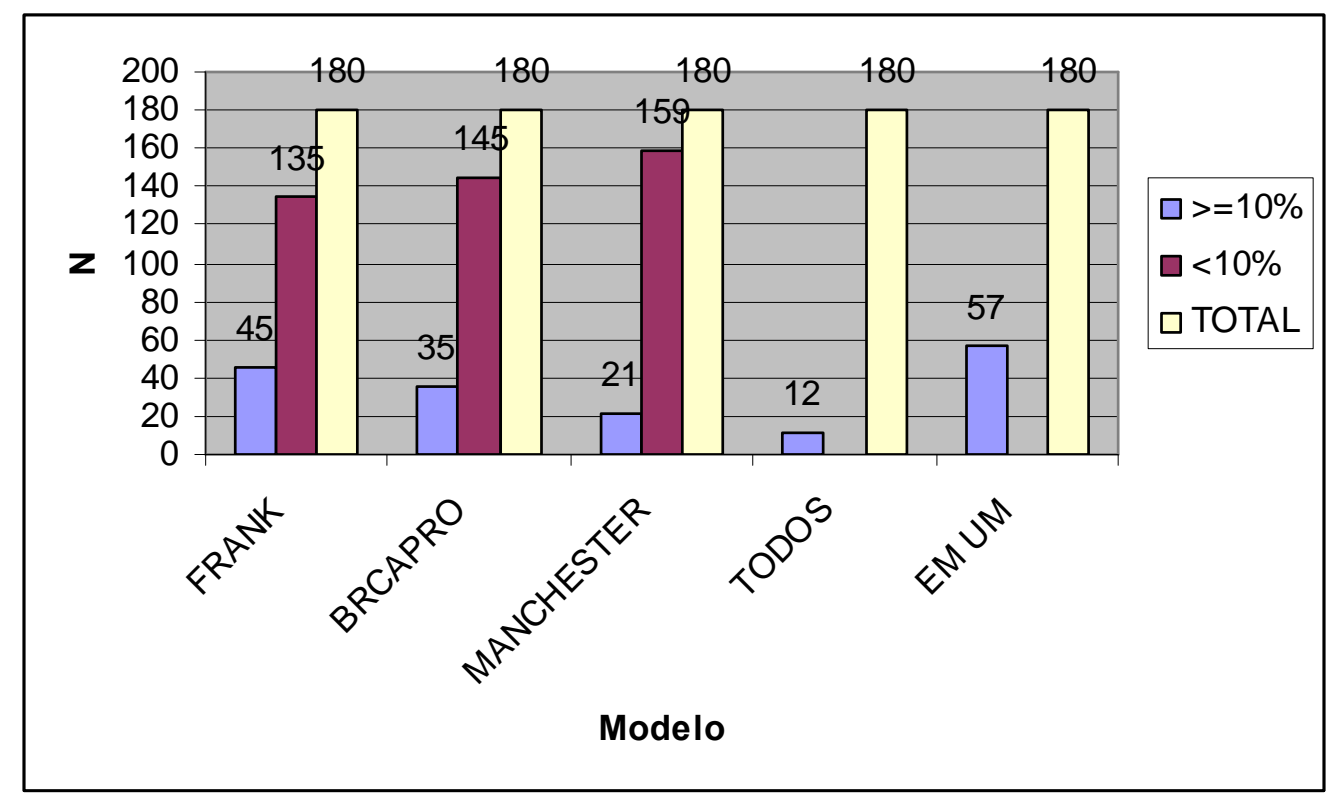

As 180 pacientes avaliáveis foram classificadas segundo o risco de serem portadoras de mutações do BRCA1/2 pelos modelos de Frank, Manchester e BRCAPRO em risco alto (> 10\%) ou baixo (<10\%) para mutações. Nas colunas denominadas como "todos" é mostrado o número de casos com concordância dos três métodos e na coluna "em um" o número de casos em que o risco é elevado em pelo menos um modelo.

Com relação aos dados de qualidade de vida obtidos a partir dos questionários QLQ-C30 e QLQ-BR23, os valores médios, com os respectivos desvios-padrão para cada aspecto analisado nos domínios avaliados, nas escalas funcionais, de sintomas e de saúde global estão descritos nas tabelas 11 e 12 . 
Tabela 11 - Avaliação da qualidade de vida das pacientes, antes da primeira consulta (E1) e após a determinação do risco de ser portadora de mutações deletérias dos BRCA1/2 (E2). Total de 119 pacientes avaliadas, n=número de respostas em cada domínio.

\begin{tabular}{|c|c|c|c|c|c|c|c|c|c|}
\hline & $\begin{array}{l}\mathrm{N} \\
\mathrm{E} 1\end{array}$ & $\begin{array}{l}\mathrm{N} \\
\mathrm{E} 2\end{array}$ & $\begin{array}{l}\text { Media } \\
\text { E1 }\end{array}$ & $\begin{array}{l}\text { Media } \\
\text { E2 }\end{array}$ & $\begin{array}{l}\text { Desvio } \\
\text { padrão } \\
\text { E1 }\end{array}$ & $\begin{array}{l}\text { Desvio } \\
\text { padrão } \\
\text { E2 }\end{array}$ & $\begin{array}{l}\text { Intervalo } \\
\text { E1 }\end{array}$ & $\begin{array}{l}\text { Intervalo } \\
\text { E2 }\end{array}$ & $\mathrm{p}$ \\
\hline \multicolumn{10}{|l|}{ QLQ-C30 } \\
\hline Saúde global & 180 & 134 & 69,1 & 65,4 & 22,5 & 23,6 & $0-100$ & $0-100$ & 0,0608 \\
\hline \multicolumn{10}{|c|}{ Escalas funcionais } \\
\hline Físico & 180 & 134 & 75,9 & 75,9 & 20,1 & 20,4 & $20-100$ & $6,7-100$ & 0,478 \\
\hline Rotina & 179 & 133 & 79,2 & 75,3 & 28,1 & 31,1 & $0-100$ & $0-100$ & 0,33 \\
\hline Emocional & 180 & 134 & 59,4 & 59,8 & 31,2 & 33,2 & $0-100$ & $0-100$ & 0,466 \\
\hline Cognitivo & 180 & 133 & 66,3 & 64,5 & 31,5 & 35,2 & $0-100$ & $0-100$ & 0,633 \\
\hline Social & 179 & 134 & 82,9 & 80,3 & 28,4 & 30,9 & $0-100$ & $0-100$ & 0,279 \\
\hline \multicolumn{10}{|c|}{ Escalas de sintomas } \\
\hline Fadiga & 180 & 134 & 24,4 & 27,6 & 24,7 & 28,3 & $0-100$ & $0-100$ & 0,358 \\
\hline $\begin{array}{l}\text { Náuseas e } \\
\text { vômitos }\end{array}$ & 180 & 134 & 8,5 & 9,8 & 16,3 & 21,3 & $0-83,33$ & $0-100$ & 0,227 \\
\hline Dor & 180 & 134 & 21,1 & 24,4 & 33,0 & 37,3 & $0-100$ & $0-100$ & 0,457 \\
\hline Dispnéia & 180 & 134 & 15 & 17,4 & 26,7 & 27,3 & $0-100$ & $0-100$ & 0,287 \\
\hline Insônia & 180 & 133 & 32,9 & 32,3 & 36,9 & 36 & $0-100$ & $0-100$ & 0,943 \\
\hline $\begin{array}{l}\text { Perda do } \\
\text { apetite }\end{array}$ & 180 & 134 & 10,2 & 12,2 & 24,4 & 24,4 & $0-100$ & $0-100$ & 0,344 \\
\hline Obstipação & 180 & 126 & 12,4 & 11,9 & 27,5 & 26,5 & $0-100$ & $0-100$ & 0,179 \\
\hline Diarréia & 180 & 134 & 6,3 & 7,5 & 20,2 & 22,2 & $0-100$ & $0-100$ & 0,293 \\
\hline
\end{tabular}




\begin{tabular}{|c|c|c|c|c|c|c|c|c|c|}
\hline Dificuldades & 180 & 134 & 32,4 & 35,8 & 38 & 40,5 & $0-100$ & $0-100$ & 0,242 \\
\hline nancoir & & & & & & & & & \\
\hline
\end{tabular}

\section{QLQ-BR23}

\begin{tabular}{|l|l|l|l|l|l|l|l|}
\hline N & N & Media & Media & Desvio & Desvio & Intervalo & Intervalo \\
\hline E1 & E2 & E1 & E2 & padrão & padrão & E1 & E2 \\
\hline & & & E1 & E2 & & \\
& & & & & & &
\end{tabular}

Escalas funcionais

\begin{tabular}{|c|c|c|c|c|c|c|c|c|c|}
\hline $\begin{array}{c}\text { Imagem } \\
\text { corporal }\end{array}$ & 180 & 132 & 65,7 & 66,4 & 35,2 & 36,1 & $0-100$ & $0-100$ & 0,205 \\
\hline $\begin{array}{l}\text { Função } \\
\text { sexual }\end{array}$ & 180 & 119 & 76,5 & 73,4 & 28,7 & 30,2 & $0-100$ & $0-100$ & 0,221 \\
\hline $\begin{array}{l}\text { Prazer } \\
\text { sexual }\end{array}$ & 101 & 83 & 61,1 & 62,6 & 38 & 38 & $0-100$ & $0-100$ & 0,589 \\
\hline $\begin{array}{l}\text { Perspectivas } \\
\text { futuras }\end{array}$ & 180 & 133 & 43 & 43,4 & 41,5 & 40,4 & $0-100$ & $0-100$ & 0,191 \\
\hline Escalas de sint & $\operatorname{mas}$ & & & & & & & & \\
\hline $\begin{array}{l}\text { Toxicidade } \\
\text { sitêmica }\end{array}$ & 179 & 132 & 25,3 & 24,9 & 20,8 & 21,4 & $0-90,48$ & $0-95,24$ & 0,57 \\
\hline $\begin{array}{l}\text { Sintomas } \\
\text { mamários }\end{array}$ & 178 & 129 & 23 & 23,5 & 25,5 & 28,3 & $0-100$ & $0-100$ & 0,21 \\
\hline $\begin{array}{l}\text { Sintomas no } \\
\text { braço }\end{array}$ & 177 & 130 & 32,6 & 35,5 & 31 & 33,1 & $0-100$ & $0-100$ & 0,722 \\
\hline $\begin{array}{l}\text { Preocupação } \\
\text { com queda de } \\
\text { cabelos }\end{array}$ & 81 & 61 & 35,4 & 35,5 & 40,9 & 39,4 & $0-100$ & $0-100$ & 0,439 \\
\hline
\end{tabular}


Tabela 12 - Avaliação da qualidade de vida das pacientes, antes da primeira consulta (E1) e após a determinação do risco de ser portadora de mutações deletérias dos BRCA1/2 (E2). Total de 180 pacientes avaliadas, $\mathbf{n}=$ número de respostas em cada domínio.

\begin{tabular}{|c|c|c|c|c|c|c|c|c|c|}
\hline & $\begin{array}{l}\text { E1 } \\
n\end{array}$ & $\begin{array}{l}\text { E2 } \\
n\end{array}$ & $\begin{array}{l}\text { E1 } \\
\text { 25th }\end{array}$ & $\begin{array}{l}\text { E1 50th } \\
\text { (mediana) }\end{array}$ & $\begin{array}{l}\text { E1 } \\
75 \text { th }\end{array}$ & $\begin{array}{l}\text { E2 } \\
\text { 25th }\end{array}$ & $\begin{array}{l}\text { E2 50th } \\
\text { median } \\
\quad \text { a }\end{array}$ & $\begin{array}{l}\text { E2 } \\
\text { 75th }\end{array}$ & $P$ \\
\hline \multicolumn{10}{|l|}{ QLQ-C30 } \\
\hline Saúde global & 180 & 134 & 50 & 75 & 83,3 & 50 & 75 & 83,3 & 0,0608 \\
\hline \multicolumn{10}{|c|}{ Escalas funcionais } \\
\hline Físico & 180 & 134 & 60 & 80 & 93,3 & 60 & 80 & 93,3 & 0,478 \\
\hline Rotina & 179 & 133 & 66,7 & 100 & 100 & 50 & 83,3 & 100 & 0,33 \\
\hline Emocional & 180 & 134 & 33,3 & 66,7 & 91,7 & 31,2 & 66,7 & 91,7 & 0,466 \\
\hline Cognitivo & 180 & 133 & 50 & 83,3 & 83,3 & 33,3 & 83,3 & 100 & 0,633 \\
\hline Social & 179 & 134 & 66,7 & 100 & 100 & 66,7 & 100 & 100 & 0,279 \\
\hline \multicolumn{10}{|c|}{ Escala de sintomas } \\
\hline Fadiga & 180 & 134 & 0 & 16,7 & 33,3 & 0 & 22,2 & 44,4 & 0,358 \\
\hline $\begin{array}{l}\text { Náuseas e } \\
\text { vômitos }\end{array}$ & 180 & 134 & 0 & 0 & 16,7 & 0 & 0 & 16,7 & 0,227 \\
\hline Dor & 180 & 134 & 0 & 0 & 33,3 & 0 & 0 & 33,3 & 0,457 \\
\hline Dispnéia & 180 & 134 & 0 & 0 & 33,3 & 0 & 0 & 33,3 & 0,287 \\
\hline Insônia & 180 & 133 & 0 & 33,3 & 66,7 & 0 & 33,3 & 66,7 & 0,943 \\
\hline $\begin{array}{l}\text { Perda do } \\
\text { apetite }\end{array}$ & 180 & 134 & 0 & 0 & 0 & 0 & 0 & 8,3 & 0,344 \\
\hline Obstipação & 180 & 126 & 0 & 0 & 0 & 0 & 0 & 0 & 0,179 \\
\hline
\end{tabular}




\begin{tabular}{|c|c|c|c|c|c|c|c|c|c|}
\hline Diarréia & 180 & 134 & 0 & 0 & 0 & 0 & 0 & 0 & 0,293 \\
\hline Dificuldades & 180 & 134 & 0 & 33,3 & 66,7 & 41,7 & 75 & 100 & 0,205 \\
\hline financeiras & & & & & & & & & \\
\hline
\end{tabular}

\begin{tabular}{|c|c|c|c|c|c|c|c|c|c|}
\hline & $\begin{array}{c}\text { E1 } \\
n\end{array}$ & $\begin{array}{c}\text { E2 } \\
n\end{array}$ & $\begin{array}{l}\text { E1 } \\
\text { 25th }\end{array}$ & $\begin{array}{c}\text { E1 50th } \\
\text { (mediana) }\end{array}$ & $\begin{array}{l}\text { E1 } \\
\text { 75th }\end{array}$ & $\begin{array}{c}\text { E2 } \\
\text { 25th }\end{array}$ & $\begin{array}{l}\text { E2 50th } \\
\text { mediana }\end{array}$ & $\begin{array}{l}\text { E2 } \\
75 \text { th }\end{array}$ & $P$ \\
\hline \multicolumn{10}{|l|}{ QLQ-BR23 } \\
\hline \multicolumn{10}{|c|}{ Escalas funcionais } \\
\hline $\begin{array}{c}\text { Imagem } \\
\text { corporal }\end{array}$ & 180 & 132 & 41,7 & 75 & 100 & 33,3 & 83,3 & 100 & 0,205 \\
\hline $\begin{array}{l}\text { Função } \\
\text { sexual }\end{array}$ & 180 & 119 & 66,7 & 83,3 & 100 & 50 & 83,3 & 100 & 0,221 \\
\hline $\begin{array}{l}\text { Prazer } \\
\text { sexual }\end{array}$ & 101 & 83 & 33,3 & 66,7 & 100 & 33,3 & 66,7 & 100 & 0,589 \\
\hline $\begin{array}{l}\text { Perspectivas } \\
\text { futuras }\end{array}$ & 180 & 133 & 0 & 33,3 & 100 & 0 & 33,3 & 66,7 & 0,191 \\
\hline \multicolumn{10}{|c|}{ Escalas de sintomas } \\
\hline $\begin{array}{l}\text { Toxicidade } \\
\text { sitêmica }\end{array}$ & 179 & 132 & 9,5 & 19,1 & 38,1 & 9,5 & 19,1 & 38,1 & 0,57 \\
\hline $\begin{array}{l}\text { Sintomas } \\
\text { mamários }\end{array}$ & 178 & 129 & 0 & 16,6 & 33,3 & 0 & 16,7 & 33,3 & 0,21 \\
\hline $\begin{array}{l}\text { Sintomas no } \\
\text { braço }\end{array}$ & 177 & 130 & 11,1 & 22,2 & 55,6 & 8,3 & 22,2 & 58,3 & 0,722 \\
\hline $\begin{array}{l}\text { Preocupação } \\
\text { com queda de } \\
\text { cabelos }\end{array}$ & 81 & 61 & 0 & 33,3 & 66,7 & 0 & 33,3 & 66,7 & 0,439 \\
\hline
\end{tabular}


Não observamos em nos domínios avaliados, tanto do questionário QLQ-C30 quando do QLQ-BR23, diferenças estatisticamente significativas entre os valores obtidos no primeiro e segundo questionários, portanto antes e depois da determinação do risco de ser portadora de mutações (tabelas 11 e 12).

Em uma análise exploratória, observamos uma correlação estatisticamente significativa entre o tipo de cirurgia e a imagem corporal no primeiro questionário. Pacientes com cirurgia conservadora apresentaram escores superiores de imagem corporal (Spearman, $\mathrm{p}<0,001)$.

Não observamos qualquer correlação entre ter recebido a informação de risco elevado $(\geq 10 \%)$ de ser portadora de mutações do BRCA1/2 e resultados negativos nos seguintes aspectos da qualidade de vida: estado emocional $(\mathrm{p}=0,086)$, capacidade cognitiva $(\mathrm{p}=0,640)$, desempenho social $(\mathrm{p}=0,303)$, insônia $(\mathrm{p}=$ 0,708), perspectivas futuras $(\mathrm{p}=0,607)$ e saúde global $(\mathrm{p}=0,711)$.

Quando correlacionamos a saúde global das pacientes com dados clínicos, também não houve diferença significativa quando esta foi correlacionada com: a idade ao diagnóstico $(\mathrm{p}=0,304)$, idade atual $(\mathrm{p}=0,349)$, tempo desde o diagnóstico $(\mathrm{p}=0,692)$, status de menopausa $(\mathrm{p}=0,951)$, estadiamento ao diagnóstico $(\mathrm{p}=$ $0,880)$, presença ou não de recidiva $(\mathrm{p}=0,405)$, tipo de cirurgia realizada (conservadora ou mastectomia) $(\mathrm{p}=0,608)$, dissecção axilar ou não $(\mathrm{p}=0,798)$ ou estar tratamento no momento ou não $(\mathrm{p}=0,369)$.

Ao avaliarmos o impacto do tipo de cirurgia, conservadora ou mastectomia, na qualidade de vida, não houve correlação entre o tipo de cirurgia e sintomas no braço $(p=0,095)$, saúde global $(p=0,068)$, função sexual $(p=0,374)$ ou prazer sexual $(p=0,551)$. A dissecção ou não dos linfonodos axilares também não teve 
nenhuma correlação com a imagem corporal $(\mathrm{p}=0,208)$, os sintomas mamários $(\mathrm{p}=$ $0,678)$ ou com sintomas no braço $(\mathrm{p}=0,105)$.

Avaliamos também a correlação do sintoma fadiga com alguns parâmetros e não foi observada diferença significativa com relação ao tratamento inicial com quimioterapia $(\mathrm{p}=0,995)$, idade atual $(\mathrm{p}=0,528)$, risco elevado de mutações $(\mathrm{p}=$ $0,607)$, tratamento atual ou não $(p=0,246)$ ou recidiva $(p=0,953)$.

Do ponto de vista da função emocional das pacientes não houve diferenças no segundo questionário, aplicado após o esclarecimento do risco $(\mathrm{p}=0,466)$. O conhecimento do risco elevado ou baixo de ser portador da mutação também não causou nenhuma diferença significativa entre os valores obtidos no primeiro e segundo questionários nos seguintes parâmetros: saúde global $(\mathrm{p}=0,0608)$, estado físico $(p=0,478)$, função social $(p=0,279)$, desempenho de rotina $(p=0,33)$ e dificuldades financeiras $(\mathrm{p}=0,242)$.

Também procedemos à avaliação das pacientes que faltaram à primeira consulta após a constatação de que 84 pacientes preencheram o termo de consentimento e não compareceram à consulta no ambulatório de câncer hereditário. A fim de esclarecer o motivo da desistência no atendimento foi tentado contato com as pacientes faltantes. Foi realizada a identificação das pacientes e constatado que em 55 dos casos constava um telefone, pessoal ou de recados, para contato no registro do hospital e/ou no termo de consentimento. Desenvolvemos uma entrevista telefônica padronizada para avaliação do motivo do não comparecimento (Anexo X) e, caso a paciente viesse a demonstrar interesse na avaliação do risco, uma nova consulta era agendada nesse momento. 
As tentativas de contato foram realizadas por três vezes antes de considerarmos "contato não efetuado". Em 21 dos casos o contato não foi possível. O contato telefônico foi completado em 34 casos. Dessas pacientes, 18 demonstraram interesse na remarcação da consulta e a mesma foi remarcada e a entrevista encerrada. Em 16 casos não houve interesse na remarcação, uma paciente referiu não ter mais interesse na participação no estudo, duas pacientes referiram que não desejavam se preocupar com mais essa questão neste momento, em cinco casos foi informado que a paciente não residia nesse endereço e não foi informado outro telefone para contato, em um caso a paciente foi a óbito pelo câncer de mama antes da data prevista para consulta, em cinco casos a paciente foi declarada ausente no domicílio por três vezes e em dois casos foi informado que as pacientes estavam muito doentes e não desejavam atender ao telefone. As pacientes que remarcaram a consulta não foram incluídas na presente análise.

Nenhuma das pacientes retirou o termo de consentimento para participação no estudo, apesar de nem todas terem manifestado o interesse no atendimento no ambulatório de Câncer Hereditário.

O diagrama abaixo e o gráfico 3 resumem os resultados encontrados dentre as faltantes. 
Diagrama 1. Resultados das entrevistas para avaliação das pacientes faltantes

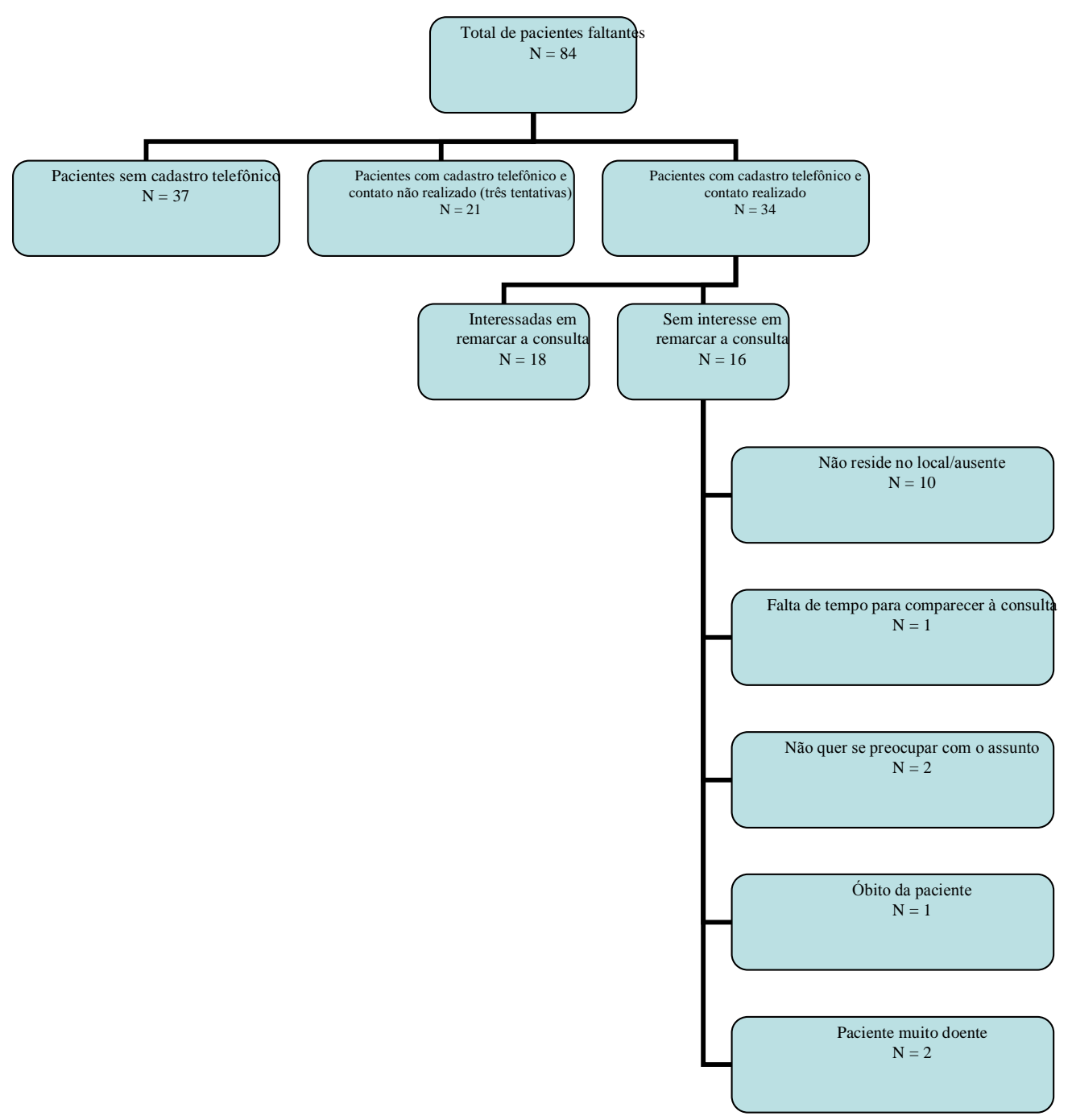




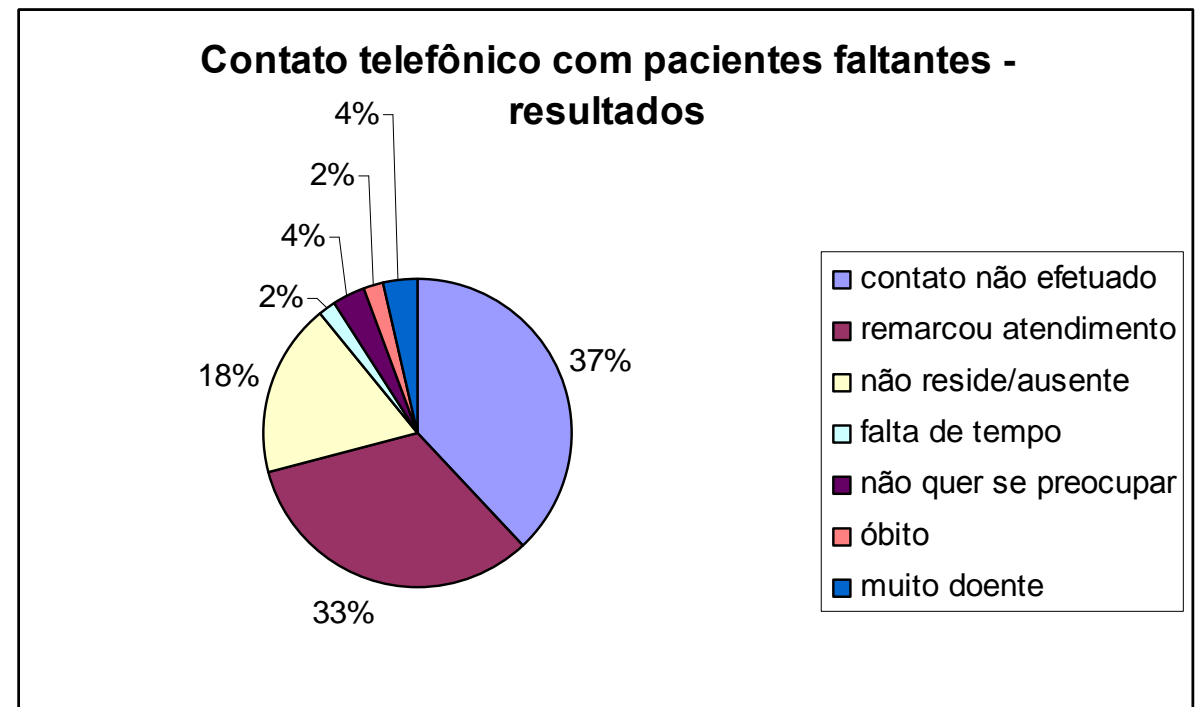

84 pacientes não compareceram à primeira consulta e em 34 foi possível contato telefônico para identificação do motivo da ausência. 18 dessas pacientes demonstraram interesse em remarcar a consulta.

Apesar de não ser objetivo do estudo, amostras de sangue para o sequenciamento dos genes BRCA1 e BRCA2 foram colhidas em 30 das pacientes classificadas como de alto risco. Destas, em 15 o sequencimento do BRCA1 já foi completado e identificamos uma mutação deletéria além de alguns polimorfirmos (dados não apresentados). 


\section{Discussão}

Neste estudo, analisamos 180 casos de pacientes com diagnóstico de câncer de mama que, conforme mostrado no gráfico 1, têm uma distribuição de idade gaussiana que indica que talvez esta população seja representativa da população de pacientes com câncer.

A maioria das pacientes aceitou em participar do estudo (272 de 282) o que pode demonstrar um grande interesse em esclarecer dúvidas referentes à hereditariedade do câncer que as mesmas apresentaram. Isso pode ainda refletir uma majoração do risco pessoal de câncer hereditário, que está de acordo com dados da literatura que apontam para essa sobre-estimação desse risco (Evans, 1994) e para a necessidade de esclarecimento do risco real. Esta disposição para participar do aconselhamento genético difere de dados encontrados em outras populações, como mulheres americanas de cor negra, no qual cerca de um terço das convidadas a participar do aconselhamento recusaram o convite. Os fatores preditivos para participar do aconselhamento foram história familiar (dois ou mais parentes com câncer de mama) e terem sido encaminhadas para o aconselhamento por oncologista (Halbert, 2005). No nosso estudo, de acordo com esses dados, verificamos que aproximadamente $30 \%$ das pacientes que assinaram o termo de consentimento não compareceram à primeira consulta, entretanto, em metade do grupo em que foi possível o contato telefônico houve interesse em remarcar a consulta e participar efetivamente do estudo (esses dados não foram incluídos nesta análise), resultando num interesse maior do que o relatado no estudo anteriormente citado. 
Apesar da idade media das nossas pacientes ao diagnóstico ser de 53 anos (intervalo de 24 a 82 anos), chama a atenção que mesmo pacientes mais idosas e inclusive sem descendentes demonstraram interesse em participar do estudo. Isto pode apontar para um interesse pessoal no esclarecimento, que nem sempre leva em conta o interesse no potencial pessoal de transmissão da neoplasia. Isto está de acordo com dados de literatura referentes a pacientes portadoras de câncer ginecológico em que o engajamento em atividades que estão associadas com redução do risco de câncer, como dieta adequada e exercícios, está associado a uma redução do estresse emocional (Constanzo, 2005). Assim, essa preocupação em esclarecer questões referentes à hereditariedade pode ser positiva, na medida em as pacientes positivas possuem um risco elevado de segundo câncer, de mama ou ovário, e possibilita a tomada de medidas preventivas com relação a essas neoplasias.

Do ponto de vista anátomo-patológico, $143(79,4 \%)$ das pacientes eram portadoras de carcinoma ductal invasivo e não há nenhum caso de carcinoma medular invasivo, que é mais incidente em portadoras de mutações do BRCA1 (Petrucelli, 2005). Entretanto, não dispomos ainda de dados finais do sequenciamento das pacientes com risco elevado $(\geq 10 \%)$ e, portanto, do número de pacientes com mutações deletérias para avaliar o significado dessa ausência de casos de carcinoma medular.

De acordo com a literatura, a maioria das pacientes $(153,85 \%)$ apresentava receptores hormonais (RE e/ou RP) positivos, o que concorda com o tratamento inicial com hormonioterapia com tamoxifeno ou inibidores da aromatase. Chamo a atenção para o fato de que algumas pacientes tiveram seu diagnóstico há mais de cinco anos, quando a pesquisa de receptores hormonais no tumor não era disponível 
em todos os serviços, aquelas com receptores ignorados recebiam hormonioterapia empiricamente. A maiorias das pacientes recebeu algum tipo de quimioterapia sistêmica e apenas 45 pacientes (25\%) não receberam nenhum tipo de quimioterapia. Isto reside no fato de que apenas 18 pacientes tiveram o diagnóstico de "in situ" e no fato de que no Serviço de Oncologia do INRAD-FMUSP a conduta mais freqüente foi a de indicar quimioterapia sistêmica adjuvante para pacientes com tumores maiores que um centímetro.

Quanto aos resultados de qualidade de vida, todas as pacientes participantes no estudo tiveram o diagnóstico de câncer de mama, quase metade delas há menos de 36 meses $(89,49,4 \%)$ e a mais de seis meses. Também não foram incluídas pacientes em tratamento com radioterapia ou quimioterapia, e isto possibilitou que alterações decorrentes de sintomas agudos do tratamento não interferissem nos resultados. Dados anteriores mostram elevado grau de estresse, depressão e distúrbio de estresse pós-traumático (Hegel, 2006). Apesar dos questionários aplicados não serem específicos para o diagnóstico de estresse e depressão, esses sintomas estão contidos no domínio de desempenho emocional do QLQ-C30 e não observamos diferença quando comparamos as pacientes com menos que 36 meses do diagnóstico, entre 36 e 59 meses e 60 meses ou mais do diagnóstico e não há diferença estatisticamente significativa entre o primeiro e o segundo questionário (tabelas 11 e 12). Se considerarmos os valores de desempenho emocional obtidos no primeiro questionário em nosso grupo de pacientes (mediana de 59,4 desvio padrão de 31,2) com os valores da população de referência da EORTC, composta por mulheres norueguesas sem câncer, que é de 82,8 , veremos que é uma diferença com importância clínica (maior que 0,5 vezes o desvio padrão), mostrando que existe um 
grau elevado de estresse emocional de base nas pacientes com diagnóstico de câncer de mama, independente do tempo desde o diagnóstico e da estimativa de risco de câncer hereditário.

Quanto à influência na notificação dos resultados na qualidade de vida, alguns autores sugerem que a notificação do resultado positivo não aumenta o grau de estresse dos pacientes notificados nem dos familiares com mutação (Schwartz, 2002).

Em revisão realizada por Cullen et al. (2004), observamos que os dados da literatura são bastante divergentes com relação ao estresse após aconselhamento genético ou teste, porém a maioria deles aponta para uma redução do estresse após resultado positivo, por redução das incertezas, sucesso nos programas de aconselhamento, maior apoio social ou por personalidades colaborativas e em pacientes com resultado positivo para mutações foi observada tendência a redução do estresse, em oposição ao aumento de depressão e estresse em pacientes que recusaram os testes ou o aconselhamento. Em famílias com mutações conhecidas dos BRCA1/2, as pessoas com elevado estresse relacionado ao câncer e que recusam o teste genético correm um maior risco de depressão (Lerman, 1998). Como não temos os resultados dos sequenciamentos, não pudemos avaliar se haverá impacto na notificação dos resultados.

Da mesma forma não notamos diferença na saúde global ou na fadiga $(24,4 \underline{ \pm}$ 28,8) relatada quando comparamos pacientes que foram submetidas a tratamento clínico anterior ou com relação à situação terapêutica atual (hormonioterapia ou seguimento). Quando comparado com os valores de referência da EORTC, nossas pacientes apresentaram dados de fadiga semelhantes à população norueguesa sem 
câncer $(28,8)$ e inferiores, apesar de da diferença ser considerada irrelevante, à população de mulheres com câncer de mama $(31,4)$. Esses resultados também foram semelhantes aos obtidos em uma população de mulheres dinamarquesas com antecedentes de câncer de mama em que a fadiga foi avaliada pelo QLQ-C30 e cujo resultado foi 36,4 (Groenvold, 2006).

Quando comparamos os resultados obtidos com os valores de referência da EORTC em pacientes portadoras de câncer de mama há uma pior qualidade de vida de nossas pacientes com relação ao desempenho cognitivo $(66,3 \pm 31,5$ vs 83,1$)$ e dificuldades financeiras $(32,4 \pm 35,8$ vs 9,0$)$. Cabe ressaltar que este estudo foi conduzido em um ambulatório do Sistema Único de Saúde e a baixa renda per capta do nosso país quando comparada com a população européia e a escassa rede de apoio aos pacientes adultos portadores de câncer pode explicar essa enorme diferença com relação a dificuldades financeiras percebidas pelo nosso grupo de pacientes. Por outro lado, as pacientes do estudo apresentaram uma menor percepção de perda do apetite quando comparadas com a população de referência da EORTC $(12,4 \pm 27,5$ vs 19,9$)$, talvez por se tratar de um grupo que não esteja em programa de radioterapia ou quimioterapia. Os resultados também foram semelhante com relação ao desempenho físico, atividades de rotina, desempenho social, náuseas e vômitos, dispnéia, insônia, obstipação e diarréia.

No nosso estudo observamos uma correlação estatisticamente significativa entre uma imagem corporal negativa e a realização mastectomia quando comparado com o grupo de pacientes que foi submetida à cirurgia conservadora. Dado semelhante foi observado por Claus (2006) quando avaliou a qualidade de vida em pacientes com antecedentes de carcinoma de mama in situ, nas quais a mastectomia 
interferiu de maneira negativa nas relações sexuais, fato que não ocorreu nas pacientes que foram submetidas à tumorectomia ou à radioterapia exclusiva. Em um estudo brasileiro, conduzido por Conde et al. (2005), este autor também ressalta que a cirurgia conservadora da mama está associada a uma melhor qualidade de vida nas pacientes com câncer de mama. Nossos achados ressaltam a importância do tratamento conservador, quando possível, para a manutenção da qualidade de vida das pacientes portadoras de câncer de mama.

Observamos que há uma correlação entre menor idade ao diagnóstico e risco $\geq 10 \%$ de ser portador de mutações deletérias (teste bicaudado, $\mathrm{p}<0,001$ ), que pode ser explicado pelo fato de que as portadoras de mutações deletérias com maior freqüência desenvolvem o câncer antes dos 50 anos de idade e este é um dos critérios mais importantes na determinação do risco de serem portadoras de mutações dos BRCA1/2. É necessário comparar com o resultado do sequenciamento para verificar se a correlação entre idade ao diagnóstico e mutação se mantém.

Observamos em nosso grupo de pacientes uma discordância no risco determinado entre os três programas. A atualização do modelo de Evans (Evans, 2005) propõe que utilizemos o valor total de 15 ao invés do individual de 10 para selecionar as famílias, porém mesmo com essa modificação o grau de divergência em nossas pacientes continuaria elevado. Avaliando a concordância, 57 pacientes foram consideradas de risco elevado em pelo menos um dos modelos e apenas 12 pacientes foram consideradas de risco elevado pelos três modelos (gráfico 2, anexo 7).Diferenças importantes entre os modelos podem ajudar a explicar essas divergências. Primeiro, no modelo de Frank (2002) somente membros da família afetados podem ser incluídos, não é aplicável para mulheres com diagnóstico de 
câncer após os 50 anos de idade e requer extrapolação para mulheres não afetadas (Domchek, 2003). Segundo, o modelo de Evans (2004) também considera apenas os familiares comprometidos, não se aplica para judeus Ashkenazi. Por último, o modelo BRCAPRO(Parmigiani, 1998) requer a informação de todos os familiares de primeiro e segundo grau para cálculo adequado, incorpora apenas parentes de primeiro e segundo grau, utiliza alta penetrância para os cálculos (Domchek, 2003). Outros autores descrevem as mesmas dificuldades, e alguns trabalhos compararam modelos diferentes de cálculo de risco em populações específicas. James et al., na Austrália, comparou cinco modelos, dentre eles BRCAPRO, Frank e Evans, concluindo que talvez a associação de critérios clínicos, como dados de anatomia patológica, possam melhoram a acurácia desses modelos (James, 2006). Em outro estudo, que compara três modelos, dentre eles o BRCAPRO e Myriad II, que não deixa de ser uma atualização do modelo de Frank utilizado em nosso serviço, não encontrou diferença de desempenho entre os dois citados (Barcenas, 2006). James et al. compara modelos que não necessitem de computador, dentre eles de Evans e Frank e observa uma boa concordância com a presença de mutações quando determina como alto risco para Frank pelo menos $16 \%$ e para Evans pelo menos 12 Bodmer, 2006). Gerdes (2006), em uma população dinamarquesa, conclui que tanto os modelos de Evans quanto os modelos de Frank são métodos pouco eficientes para o rastreamento naquela população e $28 \%$ das mutações encontradas não foram rastreadas por nenhum deles, outros autores também apontam para uma baixa utilidade dos modelos atuais para seleção de portadoras de mutações (Kang, 2006). Assim, talvez seja compreensível a divergência encontrada entre o risco estimado pelos três modelos empregados neste trabalho talvez seja necessário o resultado do 
sequenciamento das pacientes do estudo para que possamos determinar qual deles melhor se aplica à nossa população ou se devemos trabalhar para o desenvolvimento de instrumentos locais de avaliação de risco. Em nossa opinião, tendo em conta a origem multiracial de nossa população, acreditamos que mais de um modelo deve ser utilizado para a seleção de pacientes de risco elevado de mutações, Além disso, também é necessário que a história familiar seja cuidadosamente avaliada e essa avaliação complementada pelos consensos internacionais que determinam populações de risco para as mutações (anexos 8-10).

Não foi nosso objetivo determinar o momento ideal para realização do aconselhamento genético. Alguns estudos sugerem que o seu resultado pode inclusive interferir em decisões terapêuticas por parte das pacientes como, por exemplo, opção pela mastectomia ao invés de cirurgia conservadora quando o resultado do teste é disponível rapidamente após o diagnóstico (Schwartz, 2005) ou interferir na decisão terapêutica tanto do cirurgião quanto das pacientes (Schwartz, 2003, 2004). Dados revelam que mulheres com antecedentes de câncer de mama invasivo ou in situ optam com maior freqüência por mastectomia profilática e mulheres com história familiar de câncer de ovário optam com maior freqüência pela ooforectomia profilática (Uyei, 2006). Em pacientes com diagnóstico recente de câncer e que se submeteram a mastectomia contralateral profilática após o teste para mutações do BRCA1/2 não houve piora da qualidade de vida em um ano quando comparadas com pacientes que optaram pela mastectomia unilateral ou por cirurgia conservadora da mama (Tercyak, 2007). Esses dados sugerem que a determinação da presença de mutações pode interferir fortemente na decisão de quais medidas podem 
ser tomadas no futuro com relação a prevenção de segunda neoplasia nas pacientes portadoras de mutações dos BRCA1/2.

Ainda não é possível avaliar o impacto do resultado da informação de risco de ser portadora de mutações deletérias em decisões terapêuticas, porém pelo menos duas pacientes jovens, em que foi proposta mastectomia bilateral profilática pelo cirurgião durante o estudo, optaram por aguardar o resultado do sequenciamento para tomar essa decisão. Talvez a informação de que pelo menos de $50 \%$ das mulheres com padrão familial são portadoras de mutações do BRCA1/2 tenha contribuído para essa decisão. Associado ao fato de não termos acarretado maior estresse emocional às pacientes do estudo, esses dados podem significar que a realização do teste genético, quando indicado, poderia fazer parte da avaliação inicial das pacientes portadoras de câncer de mama. 


\section{Conclusões}

Neste estudo, não conseguimos interferência na determinação do risco de serem portadoras de câncer hereditário na qualidade de vida das pacientes com câncer de mama,, medida pelos questionários de qualidade de vida da EORTC. Observamos que, apesar de muitas mulheres serem candidatas ao teste genético, estas não haviam sido identificadas como de risco alto para mutações durante o seu seguimento na rotina ambulatorial do Serviço de Oncologia, demonstrando a necessidade de ambulatórios especializados para tal, além de maior orientação para os médicos que atendem a essas pacientes. Além disso, a baixa concordância entre os resultados de risco de mutações entre os três métodos utilizados, de Frank, Evans e BRCAPRO, impede que recomendemos qualquer um deles como preferencial em nosso meio. Até que outros métodos de determinação de risco sejam propostos para a nossa população, acreditamos que as nossas pacientes devam ser avaliadas por diversos métodos. 


\section{Referências}

1. Aaronson NK, Ahmedzais S, Bergman B, Bullinger M, Cull A, Duez NJ et al.. The European Organisation for Research and Treatment of Cancer QLQC30: A quality-of-life instrument for use in international clinical trials in oncology. Journal of the National Cancer Institute. 1993;85:365-376.

2. American Society of Clinical Oncology: American Society of Clinical Oncology Policy Statement: Genetic testing for cancer susceptibility. J Clin Oncol.1996;14:1730-1736.

3. American Society of Clinical Oncology: American Society of Clinical Oncology Policy Statement: Genetic testing for cancer susceptibility. J Clin Oncol. 2003;21:2397-406.

4. Anderson DE, Badzioch MD. Famial breast cancer risks. Effects of prostate and other cancers. Cancer;1993:74:114-9.

5. Armstrong K, Eisen A, Weber B. Assesssing the risk of breast cancer. The New England Journal of Medicine. 2000;342:564-71.

6. Barcenas CH, Hosain GMM, Arun B, Zong J, Zhou X, Chen J, Cortada JM, Mills GB, Tomlinson GE, Miller AR, Strong LC. Assessing BRCA carrier probabilities in extended families. J Clin Oncol. 2006;24:354-360. 
7. Berry DA, Iversen ES Jr, Gudbjartsson DF et al. BRCAPRO validation, sensitivity of genetic testing of BRCA1/BRCA2, and prevalence of other breast cancer susceptibility genes. J Clin Oncol. 2002;20:2701-712.

8. Bodmer D, Ligtenberg MJL, Hout AH, Gloudemans S, Ansink K, Oosterwijk JC, Hoogerbrugge N. Optimal selection for BRCA1 and BRCA2 mutation testing using a combination of 'easy to aplly' probability models. British Journal of Cancer. 2002;95:757-62.

9. Brasil. Ministério da Saúde. Secretaria da Atenção à Saúde. Instituto Nacional do Câncer. TNM: classificação de tumores malignos. 6 ed. Rio de Janeiro: INCA. 2004;254p.

10. Brentani A, Diz MDPE, Maistro S, Snitcovsky I, Federico M. Defining guidelines on BRCA mutation testing at a medical oncology unity - at an university hospital in South-Eastern Brazil. Value in Health. 2006;3:A111.

11. Brozek JL, Guyatt GH, Schunemann HJ. How a well-grounded minimal important difference can enhance transparency of labeling claims and improve interpretation of a patient reported outcome measure. Health and Quality of Life Outcomes. 2006;4:69.

12. Cella DF, Tulsky DS, Gray G et al: The Functional Assessment of Cancer Therapy Scale: Development and validation of the general measure. J Clin Oncol. 1993;11:570-79.

13. Claus E, Evers-Kiebooms G, Boogaerts A, Decruyenaere M, Denayer L, Legius E. Diagnostic genetic testing for hereditary breast and ovarian cancer 
in cancer patients: women's looking back on the pre-test period and a psychological evaluation. Genet Test. 2004;8:13-21.

14. Claus EB, Petruzella S, Carter D, Kasl S. Quality of life for women diagnosed with breast carcinoma in situ. J Clin Oncol. 2006;24:4875-4881.

15. CohenJ. Statistical power analysis for the behavioral sciences, $2^{\text {nd }}$ edn. Hillsdale, NJ: Lawrence Erlbaum Associates; 1998.

16. Colditz Ga, Willet WC, Hunter Dj et al. Family history and risk of breast cancer. JAMA. 1993;270:338-43.

17. Conde DM, Pinto-Neto AM, Cabello C, Santos-Sá D, Costa-Paiva L, Martinez EZ. Quality of life in brazilian breast cancer survivors age 45-65 years: associated factors. The Breast Journal. 2005;11:425-32.

18. Conroy T, Mercier M, Bonnetere J, et al. Comparison of quality of life cancerspecific instruments: FACT-G, EORTC QLQ-C30 and FLIC. Proc Am Soc Clin Oncol. 2001; 20:401a.

19. Costanzo ES, Lutgendorf SK, Bradley SL, Rose SL, Anderson B. Cancer attributions, distress and health practices among gynecologic cancer survivors. Psychosomatic Medicine. 2005;67:972-80.

20. Couch FJ, Hartmann LC. BRCA1 testing - advances and retreats. JAMA. 1998;279:955-7.

21. Couch FJ, Weber BL. Breast câncer. In Volgestein G, Kinzler (eds), The genetic basis of human câncer. New York ; Mc Grau-Hill. 1988:537-63. 
22. Cullen J, Schwartz MD, Lawrence WF, Selby JV, Mandelblatt JS. Short-term impact of cancer prevention and screening activities on quality of life. J Clin Oncol. 2004;22:943-52.

23. Domchek SM, Eisen AE, Jill KC, Blackwood A, Weber BL. Application of breast cancer risk prediction models in clinical practice. J Clin Oncol. $2003 ; 21: 593-601$.

24. EORTC Study Group on Quality of Life - 1993; The European Organization for Research and Treatment of Cancer QLQ-C30: A Quality-of-Life Instrument for Use in International Clinical Trials in Oncology. J. Nat. Cancer Inst.1993;85(5).

25. Evans DG, Lalloo F, Wallace A, Rahman N. Update on the Manchester scoring system for BRCA1 and BRCA2 testing. J Med Gen. 2005;42:e39.

26. Evans DGR, Blair V, Greenhalg R, Hopwood P, Howell A. The impact of genetic counseling on risk perception in women with a family history of breast cancer. Br J Cancer. 1994;70:934-8.

27. Evans DRG, Eccles DM, Rahman N, Young N, Bulman M, Amir E, Shenton A, Howel A, Lalloo F. A new scoring system for the chances of identifying a BRCA1/2 mutation outperforms existing models including BRCAPRO. $J$ Med Genet. 2004;41:474-80.

28. Fayers PM, Aaronson NK, Bjordal K, Groenvold M, Curran D, Bottomlly A on behalf of the EORTC Quality of Life Group. The EORTC QLQ-C30 
Scoring Manual ( $3^{\text {rd }}$ Ed.). Published by: European Organisation for Research and Treatment of Cancer, Brussels. 2001.

29. Frank TS, Deffenbaugh AM, Reid JE, Hulik M, Ward BE, Lingenfelter B, Gumpper KL, Scholl T, Tavtigian SV, Pruss DR, Critchfield GC. Clinical characteristics of individuals with germline mutations in BRCA1 and BRCA2: analysis of 10,000 individuals. J Clin Oncol. 2004;20:1480-90.

30. Gerdes AM, Cruger DG, Thomassen M, Kruse TA. Evaluation of two different models to predict BRCA1 and BRCA2 mutations in a cohort of Danish hereditary breast and/or ovarian cancer families. Clin Genet. 2006;69:171-8.

31. Goldberg D, Williams P. A user's guide to the General Health Questionnaire. Windsor, Berkshire, UK, NFER-NELSON, 1988.

32. Gomes MCB, Costa MM, Borojevic R, Monteiro ANA, Vieira R, Koifman S, Koifman RJ, Li S, Royer R, Zhang S, Narod SA. Prevalence of BRCA1 and BRCA2 mutations in breast cancer patients from Brazil. Breast Cancer Res Treat. Published ahead of print, 2006

33. Gorski B, Menkiszak J, Gronwald J, Lubinski J, Narod SA. A pr otein truncating BRCA1 allele with a low penetrance of breast cancer. $J$ Med Genet. 2004;41:e130.

34. Gorski B, Cybulski C, Huzarski T, Byrski T,Gronwald J, Jakibowska A, Stawicka M, Gozdecka-Grodecka S, Szwiec M, Urbanski K, Mitus J, Marczyk E, Dziuba J, Wandzel P, Surdyka D, Haus O, Janiszewska J, 
Debniak T, Toloczko-Grabaek A, Medrek K, Masojc B, Mierzejewski M, Kowalska E, Narod SA, Lubinski J. Breast Cancer predisposing alleles in Poland. Breast Cancer Res Treat. 2005;92:19-24.

35. Groenvold M, Petersen MA, Idler E, Bjorner JB, Fayers PM, Mouridsen HT. Psychological distress and fatigue predicted recurrence and survival in primary breast cancer patients. Breast Cancer Res Treat. 2006

36. Haites NE. The ethical management of genetic testing. European Journal of Cancer. 2003;39:1339-40.

37. Halbert CH, Brewster K, Collier A, Smith C, Kessler L, Weathers B, Stopfer JE, Domchek S, Wileyto EP. Recruiting African American women to participate in hereditary breast cancer research. J Clin Oncol. 2005;23:796773.

38. Hallowell N, Foster C, Eeles R, Ardern-Jones A, Watson M. Accommodating risk: responses to BRCA1/2 genetic testing of women who have had cancer. Soc Sci Med. 2004;59:553-65.

39. Hassan SJ, Weymuller EA. Assessment of quality of life in head and neck cancer patients. Head Neck. 1993;15:485-96.

40. Hegel MI, Moore CP, Collins ED, Kearing S, Gillock KL, Riggs RL, Clay KF, Ahles TA. Distress, psychiatric syndromes and impairment on function in women with newly diagnosed breast cancer. Published on line on 13 Nov 2006. http://www3.intrscience.wiley.com 
41. Hogervorst FB, Cornelis RS, Bout M, van Vliet M, Oosterwijk JC, Olmer R, Bakker B, Klijn JG, Vasen HF, Meijers-Heijboer H. Rapid detection of BRCA1 mutations by the protein truncation test. Nat Genet. 1995;10:208-12.

42. James PA, Doherty R, Harris M, Mukesh BN, Milner A, Young MA. Optimal selection of individuals for BRCA mutation testing: a comparison of available methods. J Clin Oncol. 2006;24:707-15.

43. Kang HH, Williams R, Leary J, kConFab Investigators, Ringland C, Kirk J, Ward R. Evaluationof models to predict BRCA germline mutations. British Journal of Cancer. 2006;95:914-20.

44. Kauff ND, Perez-Segura P, Robson ME, Scheuer L, Siegel B, Schluger A, Rapaport B, Frank TS, Nafa K, Ellis NA, Parmigiani G, Offit K. Incidence of non-founder BRCA1 and BRCA2 mutations in high risk Ashkenazi breast and ovarian cancer families. J Med Genet. 2002;39:611-4.

45. Koifman S, Jorge Koifman R. Breast cancer mortality among Ashkenazi Jewish women in São Paulo and Porto Alegre, Brazil. Breast Cancer Res. 2001;3:270-5.

46. Lerman C, Hughes C, Lemon SJ, Main D, Snyder C, Durhan C, Narod S, Lynch HT. What you don't know can hurt you: adverse psychologic effects in members of BRCA1-linked and BRCA2-linked families who decline genetic testing. J Clin Oncol. 1998;16:1650-4.

47. Linch HT, Linch JF. Breast cancer genetics in an Oncology Clinic. Cancer Genet. Cytogenet. 1986;22:369-71. 
48. Mackiewicz A, Stawicka M, Bebenek M, Sorokin D, e col. A high proportion of founder BRCA1 mutations in Polish breast cancer families. Int J Cancer. 2004;110:683-6.

49. McGahan L, Kakuma R, Ho C, Basset K, Noorani HZ, Joyce J, Allanson J, Taylor S. BRCA1 and BRCA2 predictive genetic testing for breast and ovarian cancers: A systematic review of clinical evindence [Technology report no 66] . Ottawa: Canadian Coordination Office for Health Technology Assessment; 2006.

50. Ministério da Saúde, Brasil, disponível em http://www.inca.gov.br

51. NCCN Clinical Practice Guidelines in Oncology. Genetic/Familial high-risk assessment: breast and ovarian. v.1.2006. Avaiable from: http://www.nccn.org/professionals/phisician_gls/genetics_screening.pdf.

52. Neuhausen S, Gilewski T, Norton L, Tran T, McGuire P, Swensen J, Hampel H, Borgen P, Brown K, Skolnick M, Shattuck-Eidens D, Jhanwar S, Goldgar D, Offit K. Recurrent BRCA2 6174delT mutations in Ashkenazi Jewish women affected by breast cancer. Nat. Genet. 1996;13:12608.

53. Parmigiani G, berry d, Aguilar O. Determining cancer probabilities for breast cancer-susceptibility genes BRCA1 and BRCA2. Am J Hum Genet. 1998;62:145-58.

54. Pembey M, Anionwu E. Ethical aspects of genetic screening and diagnosis. In Rimoin DL, Connor M, Peyritz RE, eds. Emery and Rimoin’s Principles 
and Practice of Medical Genetics, 3rd ed. New York, Churchill Livingstone, 1996;641-653.

55. Petrucelli N, Daly MB, Culver JOB, Levy-Lahad E, Feldman GL. BRCA1 and BRCA2 heditary breast/ovarian cancer. Gene Reviews. Published on line www.genetests.org on 27/01/2006

56. Revicki DA, Cella D, Hays RD, Sloan JA, Lenderking WR, Aaronson NK. Resposiveness and minimal important differences for patient reported outcomes. Health and Quality of Life Outcomes. 2006;4:70.

57. Schwartz MD, Kaufman E, Peshkin BN, et al. Bilateral prophylatic oophorectomy and ovarian cancer screening following BRCA1/BRCA2 mutation testing. J Clin Oncol. 2003;21:4034-41.

58. Schwartz MD, Lerman C, Brogan B, Peshkin BN, Halbert CH, DeMarco T, Lawrence W, Main D, Finch C, Magnant C, Pennanen M, Tsangaris T, Willey S, Isaacs C. Impact of BRCA1/BRCA2 counseling and testing on newly diagnosed breast cancer patients. J Clin Oncol. 2004;22;1823-9.

59. Schwartz MD, Lerman C, Brogan B, Peshkin BN, Isaac C, DeMarco T, Halbert CH, Pennanen M, Finch C. Utilization of BRCA1/BRCA2 mutation testing in newly diagnosed breast cancer patients. Cancer Epidemiol Biomarkers Prev. 2005;14:1003-7.

60. Schwartz MD, Peshkin BN, Hughes C, Main D, Isaacs C, Lerman C. Impact of BRCA1/BRCA2 mutation testing on psycologic distress in a clinic-based sample. J Clin Oncology. 2002;20:514-2. 
61. Spitzer WO, Dobson AJ, Hall J et al. Measuring the quality of life of cancer patients: a concise QL-index for use by physicians. J Chron Dis. 1981; 34:585-597.

62. Struewing JP, Hartge P, Wacholder S, Baker SM, Berlin M, McAdams M, Timmerman MM, Brody LC, Tucker MA. The risk of cancer associated with specific mutations of BRCA1 and BRCA2 among Ashkenazi Jews. $N$ Engl $J$ Med. 1997;336:1401-8.

63. Tercyak KP, Peshkin BN, Brogan BM, DeMarco T, Pennanen MF, Willey SC, Magnant CM, Rogers S, Isaacs C, Schwartz M. Quality of life after contralateral prophylatic masctectomy in newly diagnosed high-risk breast cancer patients who underwent BRCA1/2 gene testing. J Clin Oncol. 2007;25. Published ahead of print on December 11, 2006.

64. US Department of Health and Human Services FDA Center for Drug Evaluation and Research. Guidance for industry: Patient-reported outcome measures: Use in medical product development to support labeling claims: Draft guidance. Health and Quality of Life Outcomes 2006;4:79.

65. Uyei A, Peterson SK, Erlichman J, Broglio K, Yekell S, Schmeler K, Lu K, Meric-Bernstam F, Amos C, Strong L, Arun B. Association between clinical characteristics and risk-reduction interventions in women who underwent BRCA1 and BRCA2 testing: a single-institution study. Cancer. 2006;107:2745-51.

66. WHOQOL GROUP. The development of the World Health Organization quality of life assessment instrument (the WHOQOL). In: Orley J, Kuyken 
W, ( editors). Quality of life assessment international perspectives.

Heigelberg: Springer Verlag: 1994:41-60.

67. Wooster R, Stratton MR. Breast cancer susceptibility: a complex disease unravels. Trends Genet. 1995;11:3-5

68. Wooster R, Gignel G, Lancaster J, Swift S, Seal S, Mangion J, Collins N, Gregory S, Gumbs C, Micklem G. Identification of the breast cancer susceptibility gene BRCA2. Nature. 1995;378:789-792. 
Anexo 1 - Termo de consentimento pós informação aplicado às pacientes do estudo

Anexo I

HOSPITAL DAS CLÍNICAS

DA

FACULDADE DE MEDICINA DA UNIVERSIDADE DE SÃO PAULO

TERMO DE CONSENTIMENTO PÓS -INFORMAÇÃO

(Instruções para preenchimento no verso)

\section{I - DADOS DE IDENTIFICAÇÃO DO SUJEITO DA PESQUISA OU RESPONSÁVEL LEGAL}

1. NOME DO PACIENTE .

DOCUMENTO DE IDENTIDADE No : SEXO: M é Fé

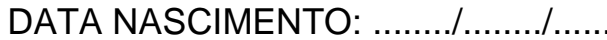

ENDEREÇO $N^{0}$ APTO:

BAIRRO:

CEP: CIDADE

TELEFONE: DDD (

..).

2.RESPONSÁVEL LEGAL

NATUREZA (grau de parentesco, tutor, curador etc.)

DOCUMENTO DE IDENTIDADE :

SEXO: M é Fé

DATA NASCIMENTO.: ....................

ENDEREÇO:

BAIRRO

CIDADE

$\mathrm{N}^{\circ}$

APTO:

CEP: TELEFONE: DDD

..).

II - DADOS SOBRE A PESQUISA CIENTÍFICA

TÍTULO DO PROTOCOLO DE PESQUISA : Impacto do encaminhamento para ambulatório de câncer hereditário na qualidade de vida de pacientes portadoras de câncer de mama.

PESQUISADOR: Miriam Hatsue Honda Federico

CARGO/FUNÇÃO: Médica

UNIDADE DO HCFMUSP: Divisão de Oncologia, Serviço de Oncologia Clínica do Instituto de Radiologia do Hospital das Clínicas da Faculdade de Medicina da Universidade de São Paulo

3. AVALIAÇÃO DO RISCO DA PESQUISA:

SEM RISCO é RISCO MÍNIMO $X \quad$ RISCO MÉDIO é

RISCO BAIXO é RISCOMAIOR é

(probabilidade de que o indivíduo sofra algum dano como consequência imediata ou tardia do estudo)

4.DURAÇÃO DA PESQUISA : dois anos 


\title{
III - REGISTRO DAS EXPLICAÇÕES DO PESQUISADOR AO PACIENTE OU SEU REPRESENTANTE LEGAL SOBRE A PESQUISA, CONSIGNANDO:
}

1. justificativa e os objetivos da pesquisa ; 2 . procedimentos que serão utilizados e propósitos, incluindo a identificação dos procedimentos que são experimentais; 3. desconfortos e riscos esperados; 4 . benefícios que poderão ser obtidos; $\mathbf{5}$. procedimentos alternativos que possam ser vantajosos para o indivíduo.

\section{CONSENTIMENTO PÓS-INFORMADO PARA PESQUISA CLÍNICA}

\author{
$\underline{\text { Informações gerais }}$
}

A senhora está com câncer na mama. Estima-se que aproximadamente 10\% das pacientes com câncer de mama sejam portadoras de alguma síndrome genética de predisposição ao câncer e que um terço tenham pelo menos um parente de primeiro grau com a doença. Dúvidas com relação a esses fator podem ser mais um fator de ansiedade durante o seu acompanhamento com conseqüente piora da qualidade de vida. Consideramos que o esclarecimento de se há um potencial hereditário das pacientes portadoras de câncer de mama pode melhorar sua qualidade de vida e inclusive possibilitar a indicação de testes genéticos em pacientes com alto risco de serem portadoras de mutações, se concordarem com o teste. Pretendemos aplicar um questionário de qualidade de vida antes da consulta no ambulatório de câncer hereditário, após a determinação do risco de ser portadora de uma mutação que predisponha ao câncer e, para aquelas pacientes que realizarem o teste genético, após o resultado desse teste.

A senhora está sendo convidada a participar desta pesquisa. Para decidir se deseja participar ou não, leia atentamente as explicações abaixo.

Este formulário de consentimento contém informações sobre a pesquisa em estudo e será discutido com o seu médico. Uma vez compreendido o estudo, e havendo interesse da senhora em participar do mesmo, será solicitada a sua assinatura no consentimento pós-informado. A senhora também receberá uma cópia para guardar em casa. Se achar necessário, consulte outros profissionais (médicos ou não) antes de assinar este documento.

A pesquisa proposta é a seguinte: "Impacto do encaminhamento para ambulatório de câncer hereditário na qualidade de vida de pacientes portadoras de câncer de mama". 


\section{Plano de estudo}

O seu tratamento para o câncer de mama não será influenciado ou modificado pela participação nesta pesquisa e seguirá a padronização de condutas existente no serviço na ocasião de sua consulta. A senhora será convidada a ser atendida no ambulatório de câncer hereditário onde, a partir de dados de sua história pessoal e familiar de câncer, será determinado o risco de ser portadora de alguma mutação que proporcione um maior risco para o desenvolvimento de câncer de mama. Caso a chance de ser portadora dessa mutação seja igual ou superior a $20 \%$, a senhora será convidada a realizar a pesquisa dessa mutação.

Para determinarmos o impacto desses fatos em sua qualidade de vida, a senhora será convidada a responder dois questionários sobre a qualidade de vida em pacientes portadoras de câncer de mama, o QLQ-C30 e o QLQ BR-23. Esses questionários são aceitos em todo mundo e foram desenvolvidos por uma organização européia que estuda câncer e traduzidos para o português por nossa equipe. Os questionários serão respondidos antes da primeira consulta no ambulatório de câncer hereditário, após a determinação da chance de ser portadora de uma mutação e, nas pacientes em que for indicado o teste genético, após o resultado do teste.

\section{Benefícios}

Muito embora seja esperado que este tipo de pesquisa beneficie as pacientes que estão participando do estudo, não se pode dizer com certeza que a senhora se beneficiará.

\section{Custo Financeiro}

O procedimento envolvido neste projeto, que é a aplicação de questionários não implicará em ônus adicional para a instituição ou para o paciente.

\section{$\underline{\text { Privacidade }}$}


Tratando-se de um estudo investigacional, sua identidade será mantida em segredo. Seu nome não será utilizado em qualquer publicação sobre o estudo. No entanto, a senhora ou o seu representante legal poderá inspecionar os seus registros médico-hospitalares.

Direito de recusar e de se retirar do estudo

A escolha de participar ou não do estudo é inteiramente de sua responsabilidade. Seu médico deve ter explicado que além do tratamento proposto nesta pesquisa, existem outras formas terapêuticas para a sua doença.

Caso a senhora se recuse a participar deste estudo, outro tratamento será oferecido, sem nenhum tipo de prejuízo ou represália. O mesmo ocorrendo caso a senhora venha a se retirar do projeto, independente do motivo.

O comitê de ética e pesquisa (CEP) deste hospital é o responsável legal para assegurar que os direitos dos pacientes sejam protegidos, tendo aprovado previamente esta pesquisa.

Em caso de dúvida, consulte o investigador principal ou a secretaria do CEP.

\section{IV - ESCLARECIMENTOS DADOS PELO PESQUISADOR SOBRE GARANTIAS DO SUJEITO DA PESQUISA:}

1. acesso, a qualquer tempo, às informações sobre procedimentos, riscos e benefícios relacionados à pesquisa, inclusive para dirimir eventuais dúvidas.

2. liberdade de retirar seu consentimento a qualquer momento e de deixar de participar do estudo, sem que isto traga prejuízo à continuidade da assistência.

3. salvaguarda da confidencialidade, sigilo e privacidade.

4. disponibilidade de assistência no HCFMUSP, por eventuais danos à saúde, decorrentes da pesquisa.

5. viabilidade de indenização por eventuais danos à saúde decorrentes da pesquisa.

\section{INFORMAÇÕES DE NOMES, ENDEREÇOS E TELEFONES DOS RESPONSÁVEIS PELO ACOMPANHAMENTO DA PESQUISA, PARA CONTATO EM CASO DE INTERCORRÊNCIAS CLÍNICAS E REAÇÕES ADVERSAS.}

Dra. Miriam Hatsue Honda Federico, tel 3069-6721 ou 3069-7225

Av. Dr. Enéas Carvalho de Aguiar, 255, $3^{\circ}$ andar, sala 7.21 
Dra. Maria Del Pilar Estevez Diz, tel 3069-6721 ou 3069-7225

Av. Dr. Enéas Carvalho de Aguiar, 255, $3^{\circ}$ andar, sala 7.21

\section{OBSERVAÇÕES COMPLEMENTARES:}

\section{VII - CONSENTIMENTO PÓS-ESCLARECIDO}

Declaro que, após convenientemente esclarecido pelo pesquisador e ter entendido o que me foi explicado, consinto em participar do presente Protocolo de Pesquisa

São Paulo,

de

de

assinatura do sujeito da pesquisa

ou responsável legal assinatura do pesquisador

(carimbo ou nome Legível) 


\section{Anexo 2 - Termo de aprovação na Comissão de Ética para Análise de Projetos de Pesquisa - CAPPesq da Diretoria Clínica do HCFMUSP}

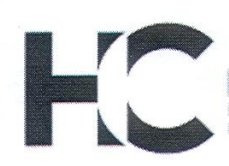

\section{APROVACÃO}

A Comissão de Ética para Análise de Projetos de Pesquisa - CAPPesa da Diretoria Clínica do Hospital das Clínicas e da Faculdade de Medicina da Universidade de São Paulo, em sessão de 25.05.05, APROVOU o Protocolo de Pesquisa $n^{\circ}$ 256/05, intitulado: "Impacto do encaminhamento para ambulatório de câncer hereditário na qualidade de vida de pacientes portadoras de câncer de mama" apresentado pelo Departamento de RADIOLOGIA, inclusive o Termo de Consentimento Livre e Esclarecido.

$$
\text { Cabe ao pesquisador elaborar e apresentar à }
$$

CAPPesq, os relatórios parciais e final sobre a pesquisa (Resolução do Conselho Nacional de Saúde n 196, de 10.10.1996, inciso IX. 2, letra "c")

Pesquisador(a) Responsável: Profa. Dra. Miriam Hatsue Honda Federico Pesquisador (a) Executante: Dra. Maria Del Pilar Estevez Diz

CAPPesq, 25 de Maio de 2005.

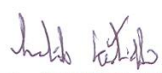

PROF. DR. EUCLIDES AYRES DE CASTILHO

Presidente da Comissão de Ética para Análise de Projetos de Pesquisa

Comissão de Ética para Análise de Projetos de Pesquisa do HCFMUSP e da FMUSP Diretoria Clínica do Hospital das Clínicas da Faculdade de Medicina da Universidade de São Paulo Rua Ovídio Pires de Campos. 225, $5^{\circ}$ andar - CEP 05403010 - São Paulo - SP Fone: 011 - 30696442 fax: 011 - 30696492 -e-mail : cappesq@hcnet.usp.br / secretariacappesq2@henet.usp.br 


\section{Anexo 3 - ficha de pré consulta.}

\section{AMBULATÓRIO DE CÂNCER HEREDITÁRIO DIVISÃO DE ONCOLOGIA - SERVIÇO DE ONCOLOGIA CLÍNICA}

Por favor, não se esqueça de trazer esta ficha preenchida na primeira consulta.

ESPAÇO RESERVADO PARA ETIQUETA

Nome

RGHC Número do SUS

Sexo: $\mathbf{M} \square \quad \mathbf{F} \square$

Data de nascimento Idade (anos)

O (a) senhor (a) tem ou teve diagnóstico de câncer? Sim $\quad \square \quad$ Não

Se sim, qual o tipo ou local e em que idade foi descoberto (anos)?

Se não, qual o motivo da procura por este serviço de aconselhamento genético?

Em que cidade ou país o (a) senhor (a), seus pais e avós
nasceram?

Na sua família, há caso (s) de câncer? Sim $\square \quad$ Não

Se respondeu sim, informe quantos:

Na sua família, há casos de câncer de mama em homem (ns)?

Sim $\square \quad$ Não

Na sua família, há casos de câncer de mama em mulheres descobertos em idade inferior a 40 anos? Sim Não

Na sua família, há casos de câncer nas duas mamas?

Sim $\square \quad$ Não

Na sua família, há casos de câncer de ovário? Sim

Não

Na sua família, há casos de câncer de intestino ou próstata?

Sim $\square \quad$ Não 
Coloque, na tabela abaixo, informações sobre todos os casos de câncer na sua família

\begin{tabular}{|l|l|l|l|l|l|}
\hline Nome & $\begin{array}{l}\text { Sexo } \\
\text { M/F }\end{array}$ & Parentesco & Localização & $\begin{array}{l}\text { Idade ao } \\
\text { diagnóstico }\end{array}$ & Vivo \\
\hline & & & & Sim $\square$ Não $\square$ \\
\hline & & & & Sim Não $\square$ \\
\hline & & & & Sim $\square$ Não $\square$ \\
\hline & & & & Sim Não $\square$ \\
\hline & & & & Sim $\square$ Não $\square$ \\
\hline & & & & Sim Não $\square$ \\
\hline & & & & & Sim $\square$ Não $\square$ \\
\hline & & & & & Sim Não $\square$ \\
\hline
\end{tabular}

Assinatura do solicitante

Avaliação médica:

matricular no ambulatório de câncer hereditário

Sim $\quad \square \quad$ Não

Nome/carimbo e assinatura do médico

\section{Data}




\title{
Anexo 4 - questionário EORTC QLQ-C30 - versão 3.0
}

\author{
EORTC QLQ-C30 (versão 3.0)
}

Nós estamos interessados em alguns dados sobre você e sua saúde. Responda, por favor, a todas as perguntas fazendo um círculo no número que melhor se aplica a você. Não há respostas certas ou erradas. A informação que você fornecer permanecerá estritamente confidencial.

Por favor, preencha suas iniciais:

Sua data de nascimento (dia, mês, ano):

Data de hoje (dia, mês, ano):

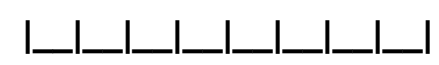

\begin{tabular}{|l|c|c|c|c|}
\hline & Não & Pouco & $\begin{array}{c}\text { Modera- } \\
\text { damente }\end{array}$ & Muito \\
\hline $\begin{array}{l}\text { 1. Você tem qualquer dificuldade quando faz } \\
\text { grandes esforços, por exemplo carregar uma bolsa } \\
\text { de compras pesada ou uma mala? }\end{array}$ & 1 & 2 & 3 & 4 \\
\hline $\begin{array}{l}\text { 2. Você tem qualquer dificuldade quando faz uma } \\
\text { grande caminhada? }\end{array}$ & 1 & 2 & 3 & 4 \\
\hline $\begin{array}{l}\text { 3. Você tem qualquer dificuldade quando faz uma } \\
\text { curta caminhada fora de casa? }\end{array}$ & 1 & 2 & 3 & 4 \\
\hline $\begin{array}{l}\text { 4. Você tem que ficar numa cama ou na cadeira } \\
\text { durante o dia? }\end{array}$ & 1 & 2 & 3 & 4 \\
\hline $\begin{array}{l}\text { 5. Você precisa de ajuda para se alimentar, se } \\
\text { vestir, se lavar ou ir ao banheiro? }\end{array}$ & 1 & 2 & 3 & 4 \\
\hline
\end{tabular}

Por favor, passe à página seguinte 


\begin{tabular}{|c|c|c|c|c|}
\hline Durante a última semana: & Não & Pouco & $\begin{array}{l}\text { Modera- } \\
\text { damente }\end{array}$ & Muito \\
\hline $\begin{array}{l}\text { 6. Tem sido difícil fazer suas atividades de } \\
\text { todos os dias? }\end{array}$ & 1 & 2 & 3 & 4 \\
\hline $\begin{array}{l}\text { 7. Tem sido difícil ter atividades de } \\
\text { divertimento ou lazer? }\end{array}$ & 1 & 2 & 3 & 4 \\
\hline \multicolumn{5}{|l|}{ 8. Você teve falta de ar? } \\
\hline 9. Você tem tido dor? & 1 & 2 & 3 & 4 \\
\hline 10. Você precisou repousar? & 1 & 2 & 3 & 4 \\
\hline 11. Você tem tido problemas para dormir? & 1 & 2 & 3 & 4 \\
\hline 12. Você tem se sentido fraco/a? & 1 & 2 & 3 & 4 \\
\hline 13. Você tem tido falta de apetite? & 1 & 2 & 3 & 4 \\
\hline 14. Você tem se sentido enjoado/a? & 1 & 2 & 3 & 4 \\
\hline 15. Você tem vomitado? & 1 & 2 & 3 & 4 \\
\hline 16. Você tem ficado obstipado/a? & 1 & 2 & 3 & 4 \\
\hline 17. Você tem tido diarréia? & 1 & 2 & 3 & 4 \\
\hline 18. Você esteve cansado/a? & 1 & 2 & 3 & 4 \\
\hline $\begin{array}{l}\text { 19. A dor interferiu em suas atividades } \\
\text { diárias? }\end{array}$ & 1 & 2 & 3 & 4 \\
\hline $\begin{array}{l}\text { 20. Você tem tido dificuldade para se } \\
\text { concentrar em coisas, como ler jornal ou ver } \\
\text { televisão? }\end{array}$ & 1 & 2 & 3 & 4 \\
\hline 21. Você se sentiu nervoso/a? & 1 & 2 & 3 & 4 \\
\hline 22. Você esteve preocupado/a? & 1 & 2 & 3 & 4 \\
\hline 23. Você se sentiu irritado/a facilmente? & 1 & 2 & 3 & 4 \\
\hline 24. Você se sentiu deprimido/a? & 1 & 2 & 3 & 4 \\
\hline $\begin{array}{l}\text { 25. Você tem tido dificuldade de se lembrar } \\
\text { das coisas? }\end{array}$ & 1 & 2 & 3 & 4 \\
\hline $\begin{array}{l}\text { 26. A sua condição física ou o tratamento } \\
\text { médico tem interferido em sua vida familiar? }\end{array}$ & 1 & 2 & 3 & 4 \\
\hline $\begin{array}{l}\text { 27. A sua condição física ou o tratamento } \\
\text { médico tem interferido em suas atividades } \\
\text { sociais? }\end{array}$ & 1 & 2 & 3 & 4 \\
\hline $\begin{array}{l}\text { 28. A sua condição física ou o tratamento } \\
\text { médico tem lhe trazido dificuldades } \\
\text { financeiras? }\end{array}$ & 1 & 2 & 3 & 4 \\
\hline
\end{tabular}


Para as seguintes perguntas, por favor, faça um círculo em volta do número entre 1 e 7 que melhor se aplica a você.

29. Como você classificaria a sua saúde em geral, durante a última semana?

$\begin{array}{ccccccc}1 & 2 & 3 & 4 & 5 & 6 & 7 \\ \text { Péssima } & & & & & & \end{array}$

30. Como você classificaria a sua qualidade de vida geral, durante a última semana?

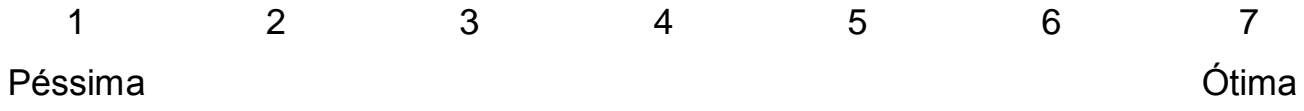




\section{Anexo 5 - questionário EORTC QLQ - BR23}

EORTC QLQ - BR23

Por vezes, os doentes nos descrevem que têm dos seguintes sintomas ou problemas. Por favor, indique, relativamente à semana passada, até que ponto sentiu esses sintomas ou problemas.

\begin{tabular}{|l|c|c|c|c|}
\hline Durante a última semana: & Não & Pouco & $\begin{array}{c}\text { Modera- } \\
\text { damente }\end{array}$ & Muito \\
\hline 1. Sentiu a boca seca? & 1 & 2 & 3 & 4 \\
\hline $\begin{array}{l}\text { 2. O que comeu e bebeu teve um sabor } \\
\text { diferente do normal? }\end{array}$ & 1 & 2 & 3 & 4 \\
\hline $\begin{array}{l}\text { 3. Sentiu os olhos doloridos, irritados ou } \\
\text { lacrimejantes? }\end{array}$ & 1 & 2 & 3 & 4 \\
\hline $\begin{array}{l}\text { 4. Teve queda de cabelo? } \\
\text { 5. Responda a esta pergunta somente se teve } \\
\text { queda de cabelo: A queda de cabelo } \\
\text { perturbou você? }\end{array}$ & 1 & 2 & 3 & 4 \\
\hline $\begin{array}{l}\text { 6. Sentiu-se doente ou indisposta? } \\
\text { 7. Sentiu arrepios de calor? }\end{array}$ & 1 & 2 & 3 & 4 \\
\hline 8. Sentiu dor de cabeça? & 1 & 2 & 3 & 4 \\
\hline $\begin{array}{l}\text { 9. Você se sentiu menos atraente (bonita) } \\
\text { devido à sua doença ou tratamento? }\end{array}$ & 1 & 2 & 3 & 4 \\
\hline $\begin{array}{l}\text { 10. Você se sentiu menos feminina (mulher) } \\
\text { como resultado da sua doença ou tratamento? }\end{array}$ & 1 & 2 & 3 & 4 \\
\hline $\begin{array}{l}\text { 11. Achou difícil observar-se nua? } \\
\text { 12. Esteve de algum modo, insatisfeita com } \\
\text { seu corpo? }\end{array}$ & 1 & 2 & 3 & 4 \\
\hline $\begin{array}{l}\text { 13. Sentiu-se preocupada com seu estado de } \\
\text { saúde no futuro? }\end{array}$ & 1 & 2 & 3 & 4 \\
\hline
\end{tabular}

Por favor, avance para a página seguinte 


\begin{tabular}{|l|c|c|c|c|}
\hline Durante as últimas quatro semanas: & Não & Pouco & $\begin{array}{c}\text { Modera- } \\
\text { damente }\end{array}$ & Muito \\
\hline $\begin{array}{l}\text { 14. Até que ponto manifestou interesse na } \\
\text { atividade sexual? }\end{array}$ & 1 & 2 & 3 & 4 \\
\hline $\begin{array}{l}\text { 15. Até que ponto foi sexualmente ativa (teve } \\
\text { relações sexuais)? (com ou sem relação } \\
\text { sexual) }\end{array}$ & 1 & 2 & 3 & 4 \\
\hline $\begin{array}{l}\text { 16. Responda apenas a esta pergunta se tiver } \\
\text { sido sexualmente ativa: Até que ponto sentiu } \\
\text { prazer? }\end{array}$ & 1 & 2 & 3 & 4 \\
\hline
\end{tabular}

\begin{tabular}{|l|c|c|c|c|}
\hline Durante a última semana: & Não & Pouco & $\begin{array}{c}\text { Modera- } \\
\text { damente }\end{array}$ & Muito \\
\hline $\begin{array}{l}\text { 17. Experimentou dores no braço ou no } \\
\text { ombro? }\end{array}$ & 1 & 2 & 3 & 4 \\
\hline 18. Sentiu seu braço ou sua mão inchados? & 1 & 2 & 3 & 4 \\
\hline $\begin{array}{l}\text { 19. Sentiu dificuldade em levantar ou abrir o } \\
\text { braço? }\end{array}$ & 1 & 2 & 3 & 4 \\
\hline $\begin{array}{l}\text { 20. Experimentou dores na área de seu seio } \\
\text { afetado/doente? }\end{array}$ & 1 & 2 & 3 & 4 \\
\hline $\begin{array}{l}\text { 21. Sentiu a área de seu seio afetado/doente } \\
\text { inchada? }\end{array}$ & 1 & 2 & 3 & 4 \\
\hline $\begin{array}{l}\text { 22. Sentiu a área de seu seio afetado/doente } \\
\text { demasiadamente sensível? }\end{array}$ & 1 & 2 & 3 & 4 \\
\hline $\begin{array}{l}\text { 23. Experimentou problemas de pele no ou } \\
\text { na área do seio afetado/doente (por exemplo, } \\
\text { comichão, pele seca ou escamosa) }\end{array}$ & 1 & 2 & 3 & 4 \\
\hline
\end{tabular}


Anexo 6 - Ficha Clínica

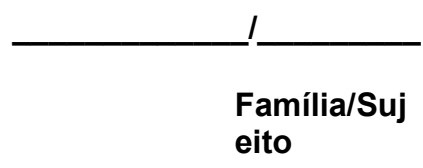

Ficha Clínica №

Data________

\section{Nome}

\section{Iniciais}

3. $\mathrm{RGHC}$ Número do SUS

4. Sexo: M $\square \quad \mathrm{F}$ $\mathrm{F}$ Idade (anos)

5. Data de nascimento

6. Diagnostico prévio de câncer? Não $\square$ Sim $\square$

6.1.Se sim, preencher, se não, pular para o ítem 6.2

6.1.1.Órgão ou região

6.1.2.Lateralidade Direito $\square \quad$ Esquerdo $\square$ Bilateral sincrônico $\square$ Bilateral metacrônico $\square$ Não se aplica $\square$

6.1.3. Histologia

$\overline{6.1 .4}$.Idade em anos ao diagnóstico (anos)

6.1.5. Estadiamento ao diagnóstico

6.2.1.Tratamento sucinto, esquema de tratamento, número de ciclos, datas de início e término

6.2.2.Hormonioterapia, medicamento(s) e dose(s), data(s) de início e data(s) de término, se inibidor de aromatase na adjuvância, explicitar o motivo do 
uso

$\overline{6.2 .3 . C i r u r g i a, ~ d a t a ~ e ~ t i p o ~ d e ~ c i r u r g i a ~}$

6.2.4. Reicidiva, local, data e tratamento

6.2. Se Não, motivo da procura

7. Fazia uso de algum tratamento profilático para câncer? Não $\square$ Sim 7.1. Se Sim, descreva o tratamento e o período de uso

8. Descreva os sinais e sintomas que podem ser atribuídos ao uso de bloqueadores hormonais, com datas e conduta proposta

9. Status de menopausa ao diagnóstico

$\overline{10 .}$ Data da menopausa

11. Houve parada da menstruação após o tratamento? Se sim, quando e até quando.

12. Houve retorno da menstruação durante o tratamento ou após sua interrupção? Quando? 
13. Origem/clínica do encaminhamento

14. Etnia: Branco $\square \quad$ Negro $\square \quad$ Pardo $\square \quad$ Amarelo $\square \quad$ Judeu Ashkenazi Outro $\square$ (especificar)

15. Hábitos:

15.1.

dieta

15.2. atividade

física

15.3. etilismo Sim $\square$ Não $\square$ parou

há

15.4. tabagismo Sim $\square$ Não $\square$ parou há

15.5 .

anticoncepcional

15.6. terapia de reposição hormonal $\operatorname{Sim} \square$ Não

16. Há caso (s) de câncer na família? Não $\square \quad$ Sim Quantos?

17. Há caso (s) de câncer de mama? Não $\square \quad \operatorname{Sim}$ Quantos?

18. Há caso (s) de câncer de mama bilateral? Não $\quad \square \quad$ Sim Quantos?

19. Há caso (s) de câncer de mama em homem (ns)? Não Sim $\square$ Quantos?

20. Há caso (s) de câncer de ovário? Não $\square \quad$ Sim Quantos? 
21. Há caso (s) de câncer de endométrio? Não $\quad \square \quad$ Sim Quantos?

22. Há caso (s) de câncer de intestino? Não Quantos?

$\operatorname{Sim}$

Coloque, na tabela abaixo, informações sobre a historia familiar de câncer ou lesão pré-maligna.

\begin{tabular}{|c|c|c|c|c|c|c|c|c|c|}
\hline $\mathrm{N}^{\mathrm{o}}$ & Iniciais & \begin{tabular}{|l} 
Sexo \\
M/F
\end{tabular} & \begin{tabular}{|l|l|} 
Topografiia \\
\end{tabular} & Parentesco* & |dade ${ }^{* *}$ & Lateralidade & $\begin{array}{l}\text { Vivol } \\
\text { morto }\end{array}$ & \begin{tabular}{|l} 
Idade \\
ao \\
ob bito
\end{tabular} & \begin{tabular}{|l|}
$\begin{array}{l}\text { Confirmação } \\
\text { por*** }\end{array}$ \\
\end{tabular} \\
\hline 1 & & & & & & Uni $\square$ bil & & & \\
\hline 2 & & & & & & Uni $\square$ bil & & & \\
\hline 3 & & & & & & Uni $\square$ bil & & & \\
\hline 4 & & & & & & Uni $\square$ bil & & & \\
\hline 5 & & & & & & Uni $\square$ bil & & & \\
\hline 6 & & & & & & Uni $\square$ bil & & & \\
\hline 7 & & & & & & $\begin{array}{l}\text { Uni } \square \text { bil } \\
\square\end{array}$ & & & \\
\hline 8 & & & & & & $\begin{array}{l}\text { Uni } \square \text { bil } \\
\square\end{array}$ & & & \\
\hline 9 & & & & & & $\begin{array}{l}\text { Uni } \square \text { bil } \\
\square\end{array}$ & & & \\
\hline $\begin{array}{l}1 \\
0\end{array}$ & & & & & & $\begin{array}{l}\text { Uni } \square \text { bil } \\
\square\end{array}$ & & & \\
\hline
\end{tabular}

${ }^{*} M$ - materno / $P$ - paterno

** Ao diagnóstico: a - anos / $\mathrm{m}$ - meses

${ }^{* * *}$ A. P. - anátomo-patológico C. O. - certidão de óbito $\mathrm{N}$ - necropsia R. M. - relatório médico $\mathrm{R}$. A. - resumo de alta R. C. - relatório de cirurgia I. V. - informação verbal O. - outros (especificar). 
OBS1.: Casos de câncer de mama bilaterais devem ser computados como dois parentes

OBS2:: São considerados parentes de $1^{\underline{0}}$ grau pai, mãe, irmãos e filhos. Para fins de aconselhamento genético, Também são considerados parentes de 1ํㅡ grau pai, mãe, irmãos e filhos dos parentes citados.

Risco de portador (a) da mutação do BRCA1/2 (\%) Outros (\%) especificar

Journal of Clinical Oncology, Vol. 20, No 6 (March 15), 2002: pp 1480-1490/ European Journal of Câncer 40 (2004) 653-665/ Breast Cancer Res 200, 2:283-290/ J Med Genet 2000;37:203-209/ Journal of Clinical Oncology, Vol 20, No 6 (March 15), 2002: pp 1480-1490

\section{Recomendações}

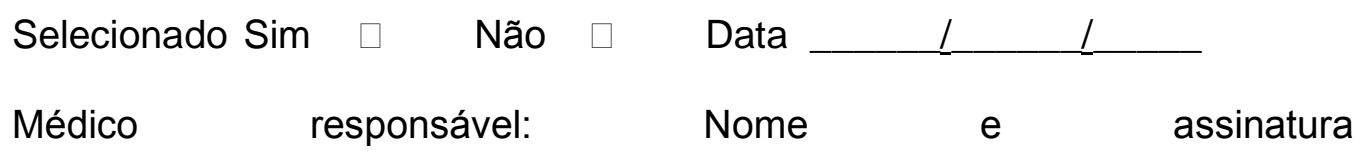




\section{Anexo 8 - Critérios para determinação dos candidatos ao teste genético para mutações deletérias do BRCA1/2. "Canadian Coordinating Office for Health} Technology Assessment" ( adaptado de McGahan, 2006)

1. Critérios para indivíduos afetados por câncer de mama ou de ovário:

Pelo menos um caso de câncer com as seguintes características:

- Ancestralidade judaica e câncer de mama antes dos 50 anos de idade ou câncer de ovário em qualquer idade (teste específico para a etnia);

- Câncer de mama, menos de 35 anos de idade;

- Câncer de mama masculino (teste para mutações do BRCA2);

- Câncer invasivo seroso de ovário em qualquer idade.

Pelo menos dois casos de câncer do mesmo lado da família com as seguintes características:

- Câncer de mama com menos de 50 anos de idade e um parente de primeiro ou segundo grau com câncer de ovário ou câncer de mama masculino;

- Câncer de mama e ovário no mesmo indivíduo ou câncer de mama bilateral com o primeiro tumor ocorrendo antes dos 50 anos de idade;

- Dois casos de câncer de mama, ambos ocorrendo antes dos 50 anos de idade em parentes de primeiro ou segundo grau;

- Dois casos de câncer de ovário, em qualquer idade, em parentes de primeiro ou segundo grau; 
- Ancestralidade judaica e câncer de mama em qualquer idade e qualquer história familiar de câncer de mama ou ovário (mutações específicas para a etnia, a menos que outro critério seja preenchido).

Pelo menos três casos de câncer na família com as seguintes características:

- Três ou mais casos de câncer de mama ou ovário em qualquer idade, com um padrão sugestivo de câncer de mama ou ovário hereditário.

2. Critérios para indivíduos não afetados por câncer de mama ou de ovário.

Indivíduos não afetados devem ser testados apenas quando indivíduos afetados não forem acessíveis (óbito), preenchidas as seguintes características:

- Parente de indivíduo com mutação deletéria conhecida do BRCA1/2 ( teste específico para a mutação familiar);

- Ancestralidade judaica e parente de primeiro ou segundo grau com:

○ Câncer de mama ou ovário antes dos 50 anos de idade; ou

○ Câncer de ovário em qualquer idade; ou

○ Câncer de mama masculino; ou

○ Câncer de mama em qualquer idade, com história familiar positiva de câncer de mama ou ovário (mutação específica para a etnia, a menos que outro critério seja preenchido).

- Em casos excepcionais o teste pode ser oferecido para parente de primeiro grau ou para indivíduo portador de câncer de mama ou ovário e heredograma fortemente sugestivo de câncer de mama e/ou ovário hereditário. 


\section{Anexo 9 - Orientações internacionais para o encaminhamento para o teste genético em indivíduos sem historia pessoal de câncer porém com história familiar positiva}

1 - European Journal of Câncer 40 (2004) 653-665

- 2 casos de câncer de mama $<40$ anos

- 3 casos de câncer de mama $<50$ anos

- 4 parentes com câncer de mama em $<60$ anos

- Mais do que 4 parentes com câncer de mama em qualquer idade

- 1 caso de câncer de ovário em qualquer idade e um caso de câncer de mama $<50$ anos

- Mais de um caso de câncer de ovário com ou sem caso de câncer de mama em qualquer idade

- Câncer de mama em homem em qualquer idade

- Câncer de mama bilateral com média de idade de diagnóstico inferior a 50 anos

$$
\text { 2-J Med Genet 2000;37:203-209 }
$$

- 2 casos de câncer de mama com média de idade entre 30-39 anos;

- 3 de câncer de mama com média de idade entre 40-60 anos;

- 1 ou mais casos de câncer de mama com idade $\leq 50$ anos mais um ou mais casos de câncer de ovário em qualquer idade ou 1 parente com ambos sem levar em consideração a idade. 
3 - Breast Cancer Res 200, 2:283-290

- Mais do que 1 caso de câncer de mama e ovário num mesmo parente

- 4 casos de câncer de mama em mulheres, sendo pelo menos 1 caso em homem

- Mais do que 6 casos de câncer de mama em mulheres

Se o sujeito em questão não se enquadrar em nenhuma categoria acima, deverá ter seu caso discutido individualmente e, quando for portador de câncer de mama ou ovário, poderá ser computado como mais um parente.

A probabilidade de ser portador de mutação do BRCA $1 / 2$ deve levar em consideração apenas o lado materno ou paterno e não, a somatória das duas famílias. 
Anexo 10 - Critérios propostos pelo "National Comprehensive Cancer Network", V.I. 2006, para câncer de mama e/ou ovário hereditários. v.1.2006 ${ }^{\text {ab }}($

- Membro de uma família com mutação conhecida do BRCA1/2.

- História pessoal de câncer de mama + uma ou mais das características abaixo:

- Idade ao diagnóstico $\leq 40 \operatorname{anos}^{\mathrm{c}}$, com ou sem história familiar.

- Idade ao diagnóstico $\leq 50 \operatorname{anos}^{\mathrm{c}}$ ou dois primários de mama ${ }^{\mathrm{d}}, \mathrm{com}>\mathrm{um}$ parente próximo com câncer de mama $\leq 50$ anos ou $\geq 1$ parente próximo com câncer de ovário.

- Diagnóstico em qualquer idade, $c o m \geq$ dois parentes próximos com câncer de ovário em qualquer idade.

- Diagnóstico em qualquer idade com $\geq$ dois parentes próximos com câncer de mama, especialmente se $\geq$ uma mulher foi diagnosticada antes dos 50 anos de idade ou teve dois primários na mama ${ }^{\mathrm{d}}$.

- Parente próximo masculino com câncer de mama.

- História pessoal de câncer de ovário.

- Se descendente de grupos étnicos associados com mutações fundadoras (por exemplo, judeu Ashkenazi, islandês, suíço, húngaro, dentre outros) ou história de câncer de mama e/ou ovário em parente próximo; não é necessária história familiar adicional.

- História pessoal de câncer de ovário + uma ou mais das características abaixo $^{\mathrm{e}}$ : 
- $\quad$ z parente próximo com câncer de ovário.

- $\geq$ um parente próximo feminino com câncer de mama em idade $\leq 50$ anos ou dois primários de mama ${ }^{\mathrm{d}}$.

- $\geq$ dois parentes próximos com câncer de mama.

- $\quad$ um parente próximo masculino com câncer de mama.

- Se descendente de judeu Ashkenazi, não é necessária história familiar adicional.

- História pessoal de câncer de mama masculino, especialmente se um ou mais das características abaixo estiver presente:

- $\quad$ um parente próximo masculino com câncer de mama.

- $\quad$ um parente próximo feminino com câncer de mama ou ovário.

- Se descendente de grupos étnicos associados com mutações fundadoras (por exemplo, judeu Ashkenazi, islandês, suíço, húngaro, dentre outros) ou história de câncer de mama e/ou ovário em parente próximo; não é necessária história familiar adicional.

\section{- História familiar exclusiva - Familiares próximos preenchem os critérios acima.}

${ }^{a} U m$ ou mais dos critérios abaixo são sugestivos da síndrome de câncer de mama/ovário hereditários e devem ser seguidos de avaliação para determinação de mutações deletérias. 
${ }^{\mathrm{b}}$ Todos os parentes do mesmo braço da família devem ser incluídos. Parentes próximos incluem parentes de primeiro, segundo e terceiro grau. Outras neoplasias malignas relatadas em algumas famílias com câncer de mama e/ou ovário hereditários incluem câncer de próstata, pâncreas e melanoma. A presença desses cânceres pode aumentar a suspeita de câncer de mama e/ou ovário hereditários.

cpode ser considerada idade entre $<40$ e $<50$ se clinicamente indicado.

dois primários de mama, inclusive doença bilateral ou casos em que há dois ou mais tumores primários ipsilaterais claramente distintos.

ehomens com história familiar limitada podem ter uma probabilidade de ser portador de mutação familiar sub estimada.

Adaptado de NCCN, 2006. 
Tabela 4 - Prevalência de mutações em BRCA1/2 correlacionadas com a história pessoal e familiar de câncer em 4.716 indivíduos não Ashkenazi

\begin{tabular}{|c|c|c|c|c|c|c|}
\hline \multirow{3}{*}{ Probando } & \multicolumn{6}{|c|}{ História Familiar } \\
\hline & $\begin{array}{c}\text { Nenhum CA de } \\
\text { mama }<50 \text { anos de } \\
\text { idade ou CA de } \\
\text { ovário em qualquer } \\
\text { idade } \\
\end{array}$ & $\begin{array}{c}\text { CA de mama }<50 \\
\text { anos de idade em } \\
\text { um parente, } \\
\text { nenhum CA de } \\
\text { ovário } \\
\end{array}$ & $\begin{array}{c}\text { CA de mama }<50 \\
\text { anos de idade em } \\
\text { mais de um } \\
\text { parente, nenhum } \\
\text { CA de ovário } \\
\end{array}$ & $\begin{array}{c}\text { CA de ovário em } \\
\text { um parente, } \\
\text { nenhum CA de } \\
\text { mama }<50 \text { anos de } \\
\text { idade }\end{array}$ & $\begin{array}{l}\text { CA de ovário em } \\
\text { mais de um } \\
\text { parente, nenhum } \\
\text { CA mama }<50 \\
\text { anos de idade }\end{array}$ & $\begin{array}{c}\text { CA de mama }<50 \\
\text { anos de idade e CA } \\
\text { de ovário em } \\
\text { qualquer idade }\end{array}$ \\
\hline & & $\%(n)$ & $\%(n)$ & $\%(n)$ & $\%(n)$ & $\%(n)$ \\
\hline $\begin{array}{l}\text { Nenhum CA de } \\
\text { mama ou ovário } \\
\text { em qualquer } \\
\text { idade }\end{array}$ & 3,9 (9/229) & $4,4(19 / 434)$ & $11(46 / 419)$ & $3,9(6 / 153)$ & $8,5(10 / 117)$ & $16,4(58 / 354)$ \\
\hline $\begin{array}{c}\text { CA de mama } \geq 50 \\
\text { anos de idade }\end{array}$ & 2,3 (4/172) & $11,2(22 / 197)$ & $10,2(12 / 118)$ & 4,3 (3/69) & $5,6(1 / 18)$ & $21,8(19 / 87)$ \\
\hline $\begin{array}{c}\text { CA de mama }<50 \\
\text { anos de idade }\end{array}$ & $9,5(55 / 579)$ & $18,4(89 / 484)$ & 36,3 (117/322) & $17,5(34 / 194)$ & $16,7(7 / 42)$ & $47,2(126 / 267)$ \\
\hline $\begin{array}{l}\text { CA de ovário em } \\
\text { qualquer idade, } \\
\text { nenhum CA de } \\
\text { mama }\end{array}$ & $6.5(5 / 77)$ & $34.1(14 / 41)$ & $42,3(11 / 26)$ & $27.7(23 / 83)$ & $42,9(12 / 28)$ & $53,5(38 / 71)$ \\
\hline $\begin{array}{l}\text { CA de mama } \geq 50 \\
\text { anos de idade e } \\
\text { CA de ovário em } \\
\text { qualquer idade }\end{array}$ & $18,5(5 / 27)$ & $11(1 / 9)$ & $36.4(4 / 11)$ & $17(1 / 6)$ & $4<, 9(1</<0)$ & $53,5(30 / 41)$ \\
\hline $\begin{array}{l}\text { CA de mama }<50 \\
\text { anos de idade e } \\
\text { CA de ovário em } \\
\text { qualquer idade }\end{array}$ & $20(5 / 25)$ & $50(4 / 5)$ & $80(4 / 5)$ & $56(5 / 9)$ & $100(2 / 2)$ & $72,2(13 / 18)$ \\
\hline
\end{tabular}


Tabela 5. Prevalência de mutações em BRCA1/2 em indivíduos não Ashkenazi correlacionadas com a idade do diagnóstico de câncer e a história familiar

\begin{tabular}{|c|c|c|c|c|c|c|}
\hline \multirow[b]{2}{*}{ Probando } & \multicolumn{6}{|c|}{ História Familiar } \\
\hline & $\begin{array}{c}\text { Nenhum CA de } \\
\text { mama }<50 \text { anos } \\
\text { de idade ou CA } \\
\text { de ovário em } \\
\text { qualquer idade } \\
\%(n)\end{array}$ & $\begin{array}{c}\text { CA de mama }<50 \\
\text { anos de idade em } \\
\text { um parente, } \\
\text { nenhum CA de } \\
\text { ovário } \\
\%(n)\end{array}$ & $\begin{array}{c}\text { CA de mama }<50 \\
\text { anos de idade em } \\
\text { mais de um } \\
\text { parente, nenhum } \\
\text { CA de ovário } \\
\%(n)\end{array}$ & $\begin{array}{c}\text { CA de ovário em } \\
\text { um parente, } \\
\text { nenhum CA de } \\
\text { mama }<50 \text { anos } \\
\text { de idade } \\
\%(n)\end{array}$ & $\begin{array}{c}\text { CA de ovário em } \\
\text { mais de um } \\
\text { parente, nenhum } \\
\text { CA mama }<50 \\
\text { anos de idade } \\
\%(n)\end{array}$ & $\begin{array}{c}\text { CA de mama }<50 \\
\text { anos de idade e CA } \\
\text { de ovário em } \\
\text { qualquer idade } \\
\%(n)\end{array}$ \\
\hline $\begin{array}{c}\text { CA de mama } \geq 50 \\
\text { anos de idade }\end{array}$ & 2,3 (4/172) & $11,2(22 / 197)$ & $10,2(12 / 118)$ & $4,3(3 / 69)$ & $5,6(1 / 18)$ & $21,8(19 / 87)$ \\
\hline $\begin{array}{l}\text { CA de mama } 40 \text { - } \\
49 \text { anos de idade }\end{array}$ & $5,6(16 / 284)$ & $10,7(31 / 289)$ & $23,8(41 / 172)$ & $13(15 / 115)$ & $12(3 / 25)$ & $39(55 / 141)$ \\
\hline $\begin{array}{c}\text { CA de mama }<40 \\
\text { anos de idade }\end{array}$ & $13,2(39 / 295)$ & $29,7(58 / 195)$ & $50,7(76 / 150)$ & $24,1(19 / 79)$ & $23,5(4 / 17)$ & $56,3(71 / 126)$ \\
\hline $\begin{array}{l}\text { CA de ovário } \geq \\
50 \text { anos de } \\
\text { idade, nenhum } \\
\text { CA de mama }\end{array}$ & $6,7(3 / 45)$ & $32(8 / 25)$ & $60(6 / 10)$ & $17(9 / 52)$ & $40(6 / 15)$ & $54,3(19 / 35)$ \\
\hline $\begin{array}{l}\text { CA de ovário }<50 \\
\text { anos de idade e } \\
\text { nenhum CA de } \\
\text { mama }\end{array}$ & $6,9(2 / 29)$ & $40(6 / 15)$ & $33,3(5 / 15)$ & $42,9(12 / 28)$ & $46,2(6 / 13)$ & $55,9(19 / 34)$ \\
\hline
\end{tabular}

Nota: a história familiar inclui pelo menos um parente de primeiro ou segundo grau e exclui o probando. CA = câncer

Adaptado de Frank et al., 2002. 
Tabela 6 - Prevalência de mutações em BRCA1/2 correlacionadas com a história pessoal e familiar de câncer em 2.233 indivíduos Ashkenazi

\begin{tabular}{|c|c|c|c|c|c|c|}
\hline \multirow[b]{2}{*}{ Probando } & \multicolumn{6}{|c|}{ História Familiar } \\
\hline & $\begin{array}{c}\text { Nenhum CA de } \\
\text { mama }<50 \text { anos de } \\
\text { idade ou CA de } \\
\text { ovário em qualquer } \\
\text { idade } \\
\end{array}$ & $\begin{array}{c}\text { CA de mama }<50 \\
\text { anos de idade em } \\
\text { um parente, } \\
\text { nenhum CA de } \\
\text { ovário } \\
\%\end{array}$ & $\begin{array}{c}\text { CA de mama }<50 \\
\text { anos de idade em } \\
\text { mais de um } \\
\text { parente, nenhum } \\
\text { CA de ovário } \\
\end{array}$ & $\begin{array}{c}\text { CA de ovário em } \\
\text { um parente, } \\
\text { nenhum CA de } \\
\text { mama }<50 \text { anos de } \\
\text { idade } \\
\end{array}$ & $\begin{array}{c}\text { CA de ovário em } \\
\text { mais de um } \\
\text { parente, nenhum } \\
\text { CA mama }<\mathbf{5 0} \\
\text { anos de idade } \\
\end{array}$ & $\begin{array}{c}\text { CA de mama }<50 \\
\text { anos de idade e CA } \\
\text { de ovário em } \\
\text { qualquer idade } \\
\%(n)\end{array}$ \\
\hline $\begin{array}{l}\text { Nenhum CA de } \\
\text { mama ou ovário } \\
\text { em qualquer }\end{array}$ & & & & & & \\
\hline idade & $5(12 / 242)$ & $12,4(38 / 307)$ & $18,1(34 / 188)$ & $18,4(29 / 158)$ & $25,7(18 / 70)$ & $30,8(65 / 211)$ \\
\hline $\begin{array}{c}\text { CA de mama } \geq 50 \\
\text { anos de idade }\end{array}$ & $4,6(7 / 153)$ & $10,5(9 / 86)$ & $17,2(5 / 29)$ & $11,5(3 / 26)$ & $50(4 / 8)$ & $33,3(8 / 24)$ \\
\hline $\begin{array}{l}\text { CA de mama }<50 \\
\text { anos de idade } \\
\text { CA de ovário em } \\
\text { qualquer idade, } \\
\text { nenhum CA de }\end{array}$ & $12,9(32 / 248)$ & $24,3(35 / 144)$ & $43,9(29 / 66)$ & $47,2(25 / 53)$ & $60(6 / 10)$ & $56,1(32 / 57)$ \\
\hline $\begin{array}{l}\text { mama } \\
\text { CA de mama } \geq 50 \\
\text { anos de idade e } \\
\text { CA de ovário em } \\
\text { qualquer idade }\end{array}$ & $25,9(15 / 58)$ & $7,7(1 / 13)$ & $83(5 / 6)$ & $41,2(7 / 17)$ & Nenhum testado & $85,7(12 / 14)$ \\
\hline $\begin{array}{l}\text { CA de mama }<50 \\
\text { anos de idade e } \\
\text { CA de ovário em } \\
\text { qualquer idade }\end{array}$ & $80(8 / 10)$ & $80(4 / 5)$ & $50(1 / 2)$ & $0(0 / 1)$ & Nenhum testado & Nenhum testado \\
\hline
\end{tabular}


Tabela 7 - Prevalência de mutações em BRCA1/2 em indivíduos Ashkenazi correlacionadas com a idade do diagnóstico de câncer e a história familiar

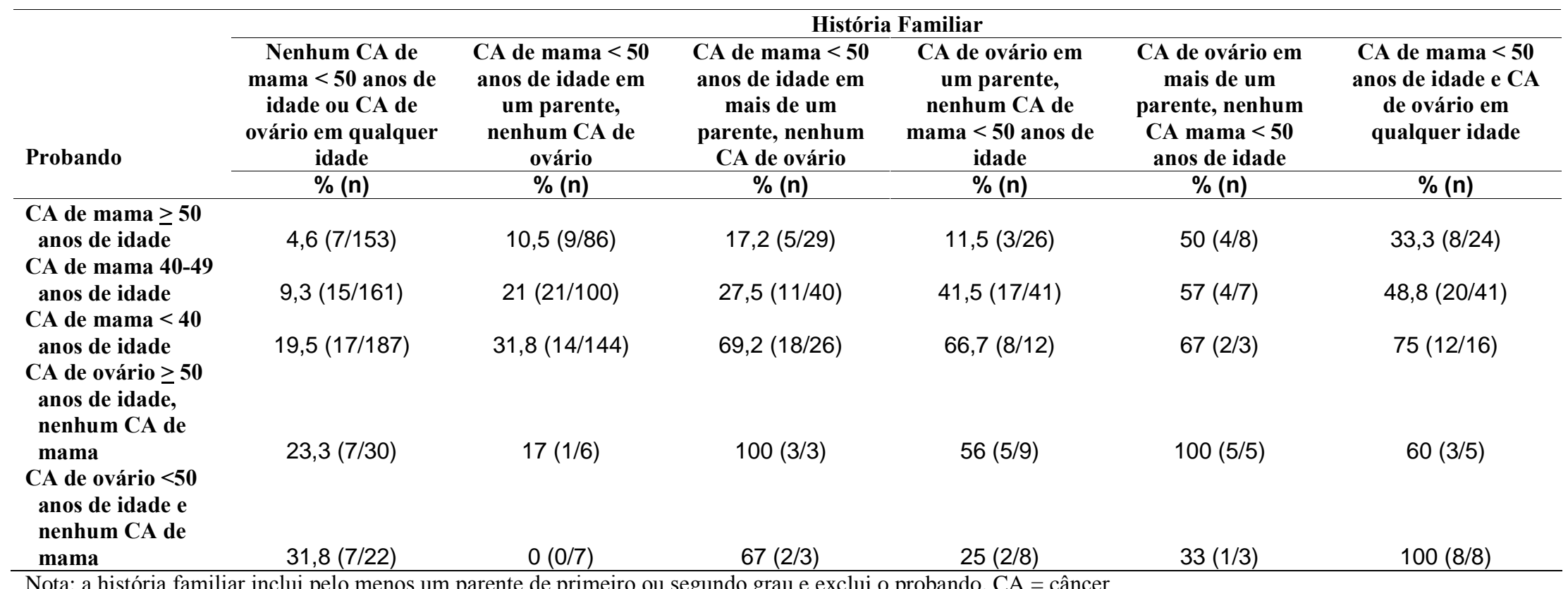

Adaptado de Frank et al., 2002. 
Tabela 8 - Comparação entre a prevalência de mutações em BRCA1/2 em indivíduos não Ashkenazi com carcinoma ductal in situ e carcinoma invasivo de mama diagnosticado antes dos 50 anos de idade

\begin{tabular}{|c|c|c|c|c|c|c|}
\hline \multirow{3}{*}{ Probando } & \multicolumn{6}{|c|}{ História Familiar } \\
\hline & $\begin{array}{c}\text { Nenhum CA de } \\
\text { mama }<50 \text { anos } \\
\text { de idade ou CA } \\
\text { de ovário em } \\
\text { qualquer idade }\end{array}$ & $\begin{array}{c}\text { CA de mama }<50 \\
\text { anos de idade em } \\
\text { um parente, } \\
\text { nenhum CA de } \\
\text { ovário }\end{array}$ & $\begin{array}{c}\text { CA de mama }<50 \\
\text { anos de idade em } \\
\text { mais de um } \\
\text { parente, nenhum } \\
\text { CA de ovário }\end{array}$ & $\begin{array}{c}\text { CA de ovário em } \\
\text { um parente, } \\
\text { nenhum CA de } \\
\text { mama }<50 \text { anos } \\
\text { de idade }\end{array}$ & $\begin{array}{c}\text { CA de ovário em } \\
\text { mais de um } \\
\text { parente, nenhum } \\
\text { CA mama }<50 \\
\text { anos de idade }\end{array}$ & $\begin{array}{c}\text { CA de mama }<50 \\
\text { anos de idade e CA } \\
\text { de ovário em } \\
\text { qualquer idade }\end{array}$ \\
\hline & $\%(n)$ & $\%(n)$ & $\%(n)$ & $\%(n)$ & $\%(n)$ & $\%(n)$ \\
\hline $\begin{array}{l}\text { CDIS }<50 \text { anos } \\
\text { de idade }\end{array}$ & $8,3(3 / 36)$ & $12(6 / 50)$ & $16,7(3 / 18)$ & $25(3 / 12)$ & $0(0 / 5)$ & $31,6(6 / 19)$ \\
\hline $\begin{array}{c}\text { CA de mama }<50 \\
\text { anos de idade }\end{array}$ & $9,5(55 / 579)$ & $18,4(89 / 484)$ & $36,3(117 / 332)$ & $17,5(117 / 322)$ & $16,7(7 / 42)$ & $47,2(126 / 267)$ \\
\hline
\end{tabular}


Tabela 9 - Comparação entre a prevalência de mutações em BRCA1/2 em indivíduos Ashkenazi com carcinoma ductal in situ e carcinoma invasivo de mama diagnosticado antes dos 50 anos de idade

\begin{tabular}{|c|c|c|c|c|c|c|}
\hline \multirow{3}{*}{ Probando } & \multicolumn{6}{|c|}{ História Familiar } \\
\hline & $\begin{array}{c}\text { Nenhum CA de } \\
\text { mama }<50 \text { anos } \\
\text { de idade ou CA } \\
\text { de ovário em } \\
\text { qualquer idade } \\
\end{array}$ & $\begin{array}{c}\text { CA de mama }<50 \\
\text { anos de idade em } \\
\text { um parente, } \\
\text { nenhum CA de } \\
\text { ovário } \\
\end{array}$ & $\begin{array}{c}\text { CA de mama }<50 \\
\text { anos de idade em } \\
\text { mais de um } \\
\text { parente, nenhum } \\
\text { CA de ovário } \\
\end{array}$ & $\begin{array}{c}\text { CA de ovário em } \\
\text { um parente, } \\
\text { nenhum CA de } \\
\text { mama }<50 \text { anos } \\
\text { de idade } \\
\end{array}$ & $\begin{array}{c}\text { CA de ovário em } \\
\text { mais de um } \\
\text { parente, nenhum } \\
\text { CA mama }<50 \\
\text { anos de idade } \\
\end{array}$ & $\begin{array}{c}\text { CA de mama }<50 \\
\text { anos de idade e CA } \\
\text { de ovário em } \\
\text { qualquer idade }\end{array}$ \\
\hline & $\%(n)$ & $\%(\mathrm{n})$ & $\%(\mathrm{n})$ & $\%(n)$ & $\%(n)$ & $\%$ (n) \\
\hline $\begin{array}{l}\text { CDIS }<50 \text { anos } \\
\text { de idade } \\
\text { CA de mama }<50\end{array}$ & $0(0 / 30)$ & $11,8(2 / 17)$ & $0(0 / 4)$ & $33(1 / 3)$ & $100(1 / 1)$ & $25(1 / 4)$ \\
\hline $\begin{array}{c}\text { CA de mama }<50 \\
\text { anos de idade }\end{array}$ & $12,9(32 / 248)$ & $24,3(35 / 144)$ & $43,9(29 / 66)$ & $47,2(25 / 53)$ & $60(6 / 10)$ & $56,1(32 / 57)$ \\
\hline
\end{tabular}


Anexo 7 - Relação das pacientes avaliáveis e o respectivo risco de ser portadora de mutação deletéria segundo os modelos de Frank, Evans e BRCAPRO. O risco está expresso em \% nos modelos de Frank e Evans e em valores absolutos no modelo BRCAPRO (grifados em amarelo os valores iguais ou superiores a 10\%).

\begin{tabular}{lcccccccc}
\hline Paciente & $\mathbf{1}^{\circ}$ quest & $\mathbf{2}^{\mathbf{0}}$ quest & Frank & BRCAPRO1 & BRCAPRO2 & BRCAPRO1/2 & Evans 1 & Evans 2 \\
\hline $\mathbf{1}$ & $\mathrm{S}$ & $\mathrm{N}$ & 13.2 & 0.253 & 0.091 & 0.343 & 4 & 4 \\
$\mathbf{2}$ & $\mathrm{S}$ & $\mathrm{S}$ & 2.3 & 0.002 & 0.005 & 0.007 & 2 & 2 \\
$\mathbf{3}$ & $\mathrm{S}$ & $\mathrm{S}$ & 11.2 & 0.12 & 0.08 & 0.2 & 9 & 10 \\
$\mathbf{5}$ & $\mathrm{S}$ & $\mathrm{S}$ & 2.3 & 0.001 & 0.003 & 0.004 & 1 & 1 \\
$\mathbf{6}$ & $\mathrm{S}$ & $\mathrm{S}$ & 2.3 & 0.001 & 0.001 & 0.001 & 6 & 6 \\
$\mathbf{7}$ & $\mathrm{S}$ & $\mathrm{N}$ & 2.3 & 0.001 & 0.001 & 0.001 & 2 & 2 \\
$\mathbf{8}$ & $\mathrm{S}$ & $\mathrm{S}$ & 13.2 & 0.042 & 0.032 & 0.074 & 4 & 4 \\
$\mathbf{9}$ & $\mathrm{S}$ & $\mathrm{N}$ & 2.3 & 0.001 & 0.003 & 0.004 & 1 & 1 \\
$\mathbf{1 2}$ & $\mathrm{S}$ & $\mathrm{S}$ & 5.6 & 0.007 & 0.008 & 0.015 & 3 & 3
\end{tabular}




$\begin{array}{lllllllll}13 & S & S & 2.3 & 0.001 & 0.001 & 0.002 & 1 & 3 \\ 15 & S & S & 2.3 & 0.001 & 0.003 & 0.005 & 4 & 4 \\ 17 & S & S & 21.8 & 0.478 & 0.168 & 0.645 & 15 & 13 \\ 19 & S & S & 2.3 & 0.008 & 0.015 & 0.023 & 1 & 1 \\ 20 & S & S & 2.3 & 0.001 & 0.001 & 0.002 & 2 & 2 \\ 21 & S & S & 2.3 & 0 & 0.001 & 0.001 & 1 & 1 \\ 22 & S & S & 2.3 & 0.001 & 0.001 & 0.001 & 1 & 1 \\ 23 & S & S & 2.3 & 0.009 & 0.011 & 0.019 & 3 & 3 \\ 25 & S & S & 13.2 & 0.019 & 0.018 & 0.037 & 4 & 4 \\ 28 & S & S & 2.3 & 0.001 & 0.002 & 0.004 & 1 & 1 \\ 29 & S & S & 5.6 & 0.012 & 0.011 & 0.023 & 3 & 3 \\ 30 & S & S & S & 13.2 & 0.021 & 0.021 & 0.043 & 4\end{array}$




\begin{tabular}{|c|c|c|c|c|c|c|c|c|}
\hline 39 & $S$ & $S$ & 10.2 & 0 & 0.001 & 0.001 & 10 & 10 \\
\hline 40 & $S$ & $S$ & 2.3 & 0.009 & 0.01 & 0.019 & 2 & 2 \\
\hline 42 & $S$ & $S$ & 2.3 & 0.007 & 0.008 & 0.015 & 2 & 3 \\
\hline 43 & $S$ & $\mathrm{~N}$ & 2.3 & 0.015 & 0.023 & 0.037 & 4 & 4 \\
\hline 44 & $S$ & $S$ & 2.3 & 0.009 & 0.011 & 0.02 & 2 & 2 \\
\hline 45 & $S$ & $S$ & 2.3 & 0.007 & 0.009 & 0.016 & 2 & 2 \\
\hline 46 & $S$ & $\mathrm{~N}$ & 2.3 & 0 & 0.001 & 0.001 & 1 & 2 \\
\hline 47 & $S$ & $S$ & 5.6 & 0.01 & 0.011 & 0.022 & 3 & 4 \\
\hline 48 & $S$ & $\mathrm{~N}$ & 2.3 & 0.004 & 0.006 & 0.01 & 2 & 2 \\
\hline 49 & $S$ & $\mathrm{~N}$ & 13.2 & 0.083 & 0.06 & 0.143 & 6 & 5 \\
\hline 53 & $S$ & $S$ & 5.6 & 0.02 & 0.02 & 0.04 & 3 & 3 \\
\hline 55 & $S$ & $S$ & 10.2 & 0.027 & 0.022 & 0.049 & 3 & 5 \\
\hline 56 & $S$ & $S$ & 2.3 & 0.008 & 0.017 & 0.025 & 2 & 2 \\
\hline 57 & $S$ & $S$ & 2.3 & 0.002 & 0.006 & 0.008 & 2 & 3 \\
\hline
\end{tabular}




\begin{tabular}{|c|c|c|c|c|c|c|c|}
\hline 59 & $S$ & $S$ & 5.6 & 0.033 & 0.041 & 0.073 & 5 \\
\hline 62 & $S$ & $S$ & 2.3 & 0.018 & 0.028 & 0.046 & 1 \\
\hline 63 & $S$ & $S$ & 2.3 & 0.027 & 0.032 & 0.059 & 1 \\
\hline 66 & $S$ & $S$ & 2.3 & 0.007 & 0.009 & 0.016 & 4 \\
\hline 67 & $S$ & $\mathrm{~N}$ & 13.2 & 0.157 & 0.099 & 0.253 & 4 \\
\hline 70 & $S$ & $\mathrm{~S}$ & 13.2 & 0.079 & 0.032 & 0.111 & 8 \\
\hline 71 & $S$ & $\mathrm{~S}$ & 2.3 & 0.002 & 0.004 & 0.006 & 3 \\
\hline 72 & $S$ & $S$ & 5.6 & 0.01 & 0.012 & 0.022 & 3 \\
\hline 73 & $S$ & $S$ & 2.3 & 0 & 0.001 & 0.001 & 1 \\
\hline 74 & $S$ & $S$ & 5.6 & 0.012 & 0.022 & 0.035 & 5 \\
\hline 75 & $S$ & $\mathrm{~N}$ & 5.6 & 0.011 & 0.012 & 0.023 & 3 \\
\hline 76 & $S$ & $S$ & 2.3 & 0 & 0.001 & 0.001 & 1 \\
\hline 79 & $S$ & $S$ & 2.3 & 0.003 & 0.005 & 0.008 & 1 \\
\hline 80 & $S$ & $S$ & 2.3 & 0.003 & 0.005 & 0.009 & 1 \\
\hline
\end{tabular}




\begin{tabular}{|c|c|c|c|c|c|c|c|c|}
\hline 82 & $S$ & $S$ & 2.3 & 0.013 & 0.004 & 0.006 & 1 & 1 \\
\hline 83 & $S$ & $S$ & 10.2 & 0.249 & 0.302 & 0.551 & 10 & 10 \\
\hline 84 & $S$ & $S$ & 11.2 & 0.01 & 0.013 & 0.023 & 4 & 4 \\
\hline 86 & $S$ & $S$ & 2.3 & 0.002 & 0.003 & 0.005 & 1 & 1 \\
\hline 87 & $S$ & $S$ & 10.7 & 0.01 & 0.014 & 0.024 & 4 & 4 \\
\hline 88 & $S$ & $S$ & 2.3 & 0.016 & 0.021 & 0.037 & 4 & 4 \\
\hline 89 & $S$ & $S$ & 2.3 & 0.038 & 0.047 & 0.085 & 4 & 4 \\
\hline 91 & $S$ & $S$ & 2.3 & 0 & 0.001 & 0.001 & 1 & 1 \\
\hline 92 & $S$ & $\mathrm{~N}$ & 2.3 & 0.069 & 0.033 & 0.102 & 10 & 7 \\
\hline 93 & $S$ & $S$ & 10.2 & 0.009 & 0.01 & 0.019 & 2 & 2 \\
\hline 100 & $S$ & $S$ & 5.6 & 0.02 & 0.02 & 0.039 & 3 & 3 \\
\hline 103 & $S$ & $S$ & 11.2 & 0.014 & 0.019 & 0.033 & 4 & 4 \\
\hline 104 & $S$ & $S$ & 11.2 & 0.416 & 0.216 & 0.631 & 14 & 12 \\
\hline 105 & $S$ & $S$ & 5.6 & 0.011 & 0.012 & 0.023 & 3 & 3 \\
\hline
\end{tabular}




\begin{tabular}{|c|c|c|c|c|c|c|c|c|}
\hline 106 & $S$ & $\mathrm{~N}$ & 2.3 & 0.001 & 0.002 & 0.003 & 1 & 1 \\
\hline 107 & $S$ & $S$ & 2.3 & 0.005 & 0.007 & 0.012 & 2 & 2 \\
\hline 112 & $S$ & $S$ & 4.3 & 0.027 & 0.017 & 0.044 & 9 & 6 \\
\hline 116 & $S$ & $\mathrm{~N}$ & 2.3 & 0.004 & 0.006 & 0.01 & 2 & 2 \\
\hline 117 & $S$ & $\mathrm{~N}$ & 2.3 & 0.016 & 0.017 & 0.033 & 3 & 3 \\
\hline 119 & $S$ & $S$ & 8.3 & 0.001 & 0.001 & 0.002 & 3 & 3 \\
\hline 120 & $S$ & $\mathrm{~S}$ & 2.3 & 0.001 & 0.002 & 0.003 & 1 & 1 \\
\hline 121 & $S$ & $S$ & 2.3 & 0.001 & 0.001 & 0.002 & 2 & 2 \\
\hline 124 & $S$ & $\mathrm{~S}$ & 2.3 & 0.004 & 0.005 & 0.009 & 2 & 2 \\
\hline 125 & $S$ & $S$ & 2.3 & 0.002 & 0.004 & 0.006 & 1 & 1 \\
\hline 126 & $S$ & $S$ & 2.3 & 0.004 & 0.006 & 0.011 & 2 & 2 \\
\hline 127 & $S$ & $S$ & 5.6 & 0.009 & 0.009 & 0.018 & 3 & 4 \\
\hline 128 & $S$ & $\mathrm{~S}$ & 5.6 & 0.012 & 0.013 & 0.025 & 3 & 3 \\
\hline 130 & $S$ & $S$ & 20 & 0.625 & 0.144 & 0.766 & 11 & 9 \\
\hline
\end{tabular}




\begin{tabular}{|c|c|c|c|c|c|c|c|c|}
\hline 131 & $S$ & $\mathrm{~N}$ & 2.3 & 0.011 & 0.01 & 0.021 & 18 & 15 \\
\hline 132 & $S$ & $S$ & 5.6 & 0.028 & 0.025 & 0.053 & 3 & 3 \\
\hline 133 & $S$ & $\mathrm{~S}$ & 2.3 & 0.002 & 0.004 & 0.006 & 1 & 2 \\
\hline 134 & $S$ & $S$ & 29.7 & 0.036 & 0.031 & 0.067 & 7 & 7 \\
\hline 135 & $S$ & $S$ & 10.2 & 0.101 & 0.105 & 0.206 & 10 & 12 \\
\hline 137 & $S$ & $S$ & 2.3 & 0.001 & 0.002 & 0.002 & 1 & 1 \\
\hline 138 & $S$ & $S$ & 2.3 & 0.003 & 0.005 & 0.008 & 2 & 2 \\
\hline 140 & $S$ & $S$ & 5.6 & 0.012 & 0.012 & 0.024 & 3 & 8 \\
\hline 141 & $S$ & $S$ & 5.6 & 0.016 & 0.015 & 0.031 & 3 & 3 \\
\hline 144 & $S$ & $\mathrm{~N}$ & 2.3 & 0.001 & 0.001 & 0.002 & 2 & 2 \\
\hline 145 & $S$ & $S$ & 2.3 & 0.008 & 0.008 & 0.016 & 2 & 2 \\
\hline 147 & $S$ & $S$ & 10.2 & 0.272 & 0.571 & 0.829 & 17 & 17 \\
\hline 148 & $S$ & $\mathrm{~N}$ & 5.6 & 0.01 & 0.01 & 0.02 & 3 & 3 \\
\hline 149 & $S$ & $\mathrm{~N}$ & 2.3 & 0 & 0.001 & 0.001 & 2 & 2 \\
\hline
\end{tabular}




\begin{tabular}{|c|c|c|c|c|c|c|c|c|}
\hline 150 & $S$ & $S$ & 4.3 & 0.089 & 0.098 & 0.187 & 3 & 5 \\
\hline 151 & $S$ & $S$ & 2.3 & 0.001 & 0.002 & 0.003 & 1 & 1 \\
\hline 152 & $S$ & $S$ & 13.2 & 0.339 & 0.163 & 0.501 & 8 & 8 \\
\hline 153 & $S$ & $S$ & 2.3 & 0.003 & 0.004 & 0.007 & 1 & 1 \\
\hline 154 & $S$ & $S$ & 2.3 & 0.002 & 0.003 & 0.004 & 1 & 2 \\
\hline 155 & $S$ & $S$ & 2.3 & 0.011 & 0.011 & 0.022 & 3 & 3 \\
\hline 156 & $S$ & $S$ & 2.3 & 0.001 & 0.002 & 0.003 & 1 & 1 \\
\hline 157 & $S$ & $\mathrm{~N}$ & 2.3 & 0.011 & 0.146 & 0.156 & 3 & 3 \\
\hline 160 & $S$ & $\mathrm{~N}$ & 2.3 & 0.001 & 0.002 & 0.003 & 1 & 1 \\
\hline 162 & $S$ & $\mathrm{~N}$ & 2.3 & 0.008 & 0.009 & 0.018 & 2 & 2 \\
\hline 164 & $S$ & $S$ & 2.3 & 0.005 & 0.009 & 0.014 & 3 & 3 \\
\hline 167 & $S$ & $\mathrm{~N}$ & 5.6 & 0.01 & 0.011 & 0.021 & 3 & 3 \\
\hline 168 & $S$ & $S$ & 4.3 & 0 & 0 & 0 & 6 & 6 \\
\hline 170 & $S$ & $S$ & 56.3 & 0.624 & 0.197 & 0.817 & 15 & 14 \\
\hline
\end{tabular}




\begin{tabular}{|c|c|c|c|c|c|c|c|c|}
\hline 171 & $S$ & $S$ & 2.3 & 0 & 0.001 & 0.002 & 1 & 2 \\
\hline 172 & $S$ & $\mathrm{~S}$ & 5.6 & 0.012 & 0.014 & 0.026 & 3 & 3 \\
\hline 174 & $S$ & $S$ & 13.2 & 0.061 & 0.047 & 0.107 & 4 & 4 \\
\hline 175 & $S$ & $\mathrm{~N}$ & 5.6 & 0.019 & 0.024 & 0.044 & 3 & 4 \\
\hline 176 & $S$ & $\mathrm{~N}$ & 5.6 & 0.018 & 0.018 & 0.036 & 3 & 3 \\
\hline 177 & $S$ & $S$ & 8.3 & 0.001 & 0.001 & 0.002 & 3 & 3 \\
\hline 178 & $\mathrm{~S}$ & $\mathrm{~S}$ & 8.3 & 0.001 & 0.001 & 0.002 & 4 & 5 \\
\hline 179 & $S$ & $S$ & 2.3 & 0.004 & 0.009 & 0.013 & 1 & 1 \\
\hline 180 & $S$ & $S$ & 4.3 & 0.202 & 0.082 & 0.283 & 10 & 7 \\
\hline 181 & $S$ & $\mathrm{~S}$ & 2.3 & 0.001 & 0.001 & 0.002 & 1 & 1 \\
\hline 185 & $S$ & $S$ & 2.3 & 0.003 & 0.005 & 0.008 & 2 & 3 \\
\hline 186 & $S$ & $\mathrm{~N}$ & 5.6 & 0.021 & 0.021 & 0.042 & 3 & 3 \\
\hline 188 & $S$ & $S$ & 11.2 & 0.013 & 0.021 & 0.034 & 4 & 4 \\
\hline 189 & $S$ & $S$ & 2.3 & 0.003 & 0.005 & 0.008 & 2 & 2 \\
\hline
\end{tabular}




$\begin{array}{lllllllll}191 & S & S & 2.3 & 0.003 & 0.004 & 0.007 & 1 & 1 \\ 192 & S & S & 2.3 & 0.006 & 0.008 & 0.014 & 2 & 2 \\ 193 & S & S & 2.3 & 0.007 & 0.009 & 0.015 & 4 & 4 \\ 195 & \text { S } & \text { N } & 2.3 & 0.027 & 0.036 & 0.062 & 1 & 1 \\ 196 & \text { S } & \text { N } & 9.5 & 0.012 & 0.013 & 0.025 & 3 & 3 \\ 197 & \text { S } & \text { S } & 4.3 & 0.009 & 0.01 & 0.018 & 2 & 2 \\ 198 & \text { S } & \text { S } & 11.2 & 0.274 & 0.311 & 0.583 & 11 & 11 \\ 199 & \text { S } & \text { S } & 2.3 & 0.001 & 0.002 & 0.003 & 1 & 2 \\ 202 & \text { S } & \text { S } & 2.3 & 0.005 & 0.006 & 0.011 & 2 & 2 \\ 203 & \text { S } & \text { S } & 6.5 & 0.035 & 0.017 & 0.052 & 8 & 5 \\ 204 & \text { S } & \text { S } & 2.3 & 0.003 & 0.004 & 0.007 & 1 & 1 \\ 205 & \text { S } & \text { S } & 2.3 & 0.001 & 0.002 & 0.003 & 1 & 1 \\ 210 & \text { S } & \text { S } & 2.3 & 0.001 & 0.004 & 0.005 & 2 & 2\end{array}$




\begin{tabular}{|c|c|c|c|c|c|c|c|c|}
\hline 213 & $S$ & $S$ & 11.2 & 0.348 & 0.255 & 0.594 & 6 & 6 \\
\hline 214 & $S$ & $S$ & 2.3 & 0.003 & 0.006 & 0.01 & 2 & 2 \\
\hline 216 & $S$ & $\mathrm{~N}$ & 5.6 & 0.019 & 0.016 & 0.035 & 3 & 3 \\
\hline 217 & $S$ & $S$ & 13.2 & 0.026 & 0.02 & 0.045 & 4 & 4 \\
\hline 218 & $S$ & $S$ & 13.2 & 0.039 & 0.027 & 0.065 & 4 & 4 \\
\hline 219 & $S$ & $S$ & 2.3 & 0.004 & 0.007 & 0.011 & 2 & 2 \\
\hline 220 & $S$ & $S$ & 13.2 & 0.023 & 0.018 & 0.041 & 4 & 5 \\
\hline 221 & $S$ & $S$ & 2.3 & 0.001 & 0.002 & 0.003 & 1 & 1 \\
\hline 224 & $S$ & $\mathrm{~N}$ & 5.6 & 0.012 & 0.013 & 0.025 & 3 & 3 \\
\hline 226 & $S$ & $S$ & 2.3 & 0.001 & 0.001 & 0.002 & 1 & 3 \\
\hline 227 & $S$ & $\mathrm{~N}$ & 2.3 & 0.001 & 0.001 & 0.001 & 1 & 1 \\
\hline 228 & $S$ & $S$ & 17.5 & 0.125 & 0.035 & 0.159 & 11 & 8 \\
\hline 229 & $S$ & $S$ & 2.3 & 0.003 & 0.004 & 0.007 & 2 & 2 \\
\hline 230 & $S$ & $S$ & 2.3 & 0.003 & 0.005 & 0.008 & 2 & 2 \\
\hline
\end{tabular}




\begin{tabular}{|c|c|c|c|c|c|c|c|c|}
\hline 231 & $S$ & $S$ & 17.5 & 0.312 & 0.156 & 0.46 & 12 & 9 \\
\hline 233 & $S$ & $S$ & 2.3 & 0.001 & 0.003 & 0.004 & 1 & 1 \\
\hline 236 & $S$ & $N$ & 2.3 & 0.039 & 0.043 & 0.081 & 1 & 1 \\
\hline 237 & $S$ & $\mathrm{~S}$ & 2.3 & 0.012 & 0.013 & 0.025 & 3 & 3 \\
\hline 238 & $S$ & $\mathrm{~N}$ & 2.3 & 0.001 & 0.002 & 0.003 & 2 & 2 \\
\hline 239 & $S$ & $\mathrm{~N}$ & 21.8 & 0.629 & 0.167 & 0.779 & 17 & 14 \\
\hline 240 & $S$ & $\mathrm{~N}$ & 2.3 & 0.003 & 0.005 & 0.008 & 2 & 2 \\
\hline 242 & $S$ & $S$ & 2.3 & 0.004 & 0.006 & 0.01 & 2 & 2 \\
\hline 243 & $\mathrm{~S}$ & $\mathrm{~N}$ & 5.6 & 0.015 & 0.016 & 0.031 & 3 & 3 \\
\hline 244 & $S$ & $\mathrm{~N}$ & 2.3 & 0.092 & 0.195 & 0.286 & 11 & 11 \\
\hline 245 & S & $\mathrm{S}$ & 13.2 & 0.046 & 0.038 & 0.084 & 4 & 4 \\
\hline 246 & $S$ & $\mathrm{~S}$ & 2.3 & 0.002 & 0.004 & 0.006 & 1 & 2 \\
\hline 248 & $S$ & $S$ & 5.6 & 0.012 & 0.461 & 0.472 & 9 & 9 \\
\hline 249 & $S$ & $S$ & 2.3 & 0.003 & 0.005 & 0.009 & 2 & 3 \\
\hline
\end{tabular}




\begin{tabular}{|c|c|c|c|c|c|c|c|c|}
\hline 250 & $S$ & $S$ & 39 & 0.308 & 0.687 & 0.998 & 16 & 16 \\
\hline 254 & $S$ & $\mathrm{~N}$ & 11.2 & 0.084 & 0.082 & 0.166 & 8 & 8 \\
\hline 255 & $S$ & $S$ & 13.2 & 0.098 & 0.066 & 0.163 & 6 & 6 \\
\hline 257 & $S$ & $\mathrm{~N}$ & 2.3 & 0.01 & 0.012 & 0.022 & 2 & 2 \\
\hline 258 & $S$ & $\mathrm{~N}$ & 13.2 & 0.074 & 0.105 & 0.179 & 7 & 6 \\
\hline 259 & $S$ & $\mathrm{~N}$ & 11.2 & 0.053 & 0.145 & 0.198 & 8 & 8 \\
\hline 260 & $S$ & $\mathrm{~N}$ & 2.3 & 0.018 & 0.048 & 0.066 & 10 & 10 \\
\hline 261 & $S$ & $\mathrm{~N}$ & 13 & 0.171 & 0.051 & 0.221 & 11 & 8 \\
\hline 262 & $S$ & $S$ & 7.9 & 0.173 & 0.138 & 0.31 & 6 & 7 \\
\hline 263 & $S$ & $S$ & 13.2 & 0.051 & 0.041 & 0.091 & 6 & 5 \\
\hline 264 & $S$ & $\mathrm{~N}$ & 10.2 & 0.027 & 0.037 & 0.064 & 11 & 10 \\
\hline 265 & $S$ & $\mathrm{~N}$ & 5.6 & 0.025 & 0.023 & 0.048 & 3 & 4 \\
\hline 266 & $S$ & $S$ & 13.2 & 0.06 & 0.046 & 0.107 & 4 & 4 \\
\hline 267 & $S$ & $S$ & 2.3 & 0.012 & 0.026 & 0.038 & 4 & 4 \\
\hline
\end{tabular}




\begin{tabular}{lllllllll}
268 & $\mathrm{~S}$ & $\mathrm{~N}$ & 5.6 & 0.13 & 0.086 & 0.213 & 3 & 3 \\
270 & $\mathrm{~S}$ & $\mathrm{~N}$ & 5.6 & 0.235 & 0.143 & 0.372 & 5 & 5 \\
$\mathbf{2 7 2}$ & $\mathrm{S}$ & $\mathrm{N}$ & 2.3 & 0 & 0.002 & 0.002 & 2 & 2 \\
\hline
\end{tabular}

O risco de ser portador para mutações dos genes BRCA1 e BRCA2 foi calculado pelos modelos de Frank, Evans e BRCAPRO. Os questionários QLQ-C30 e QLQ-BR23 foram propostos para as pacientes antes da determinação do risco (1 quest) e após a determinação do risco ( $2^{\circ}$ quest), se preenchidos registrado $S$ (sim) e se não preenchido registrado $N$ (não).Para o modelo de Frank obtivemos um risco único para mutações do BRCA1 ou BRCA2, para o modelo de Evans há a determinação de riscos independentes para o BRCA1 ou BRCA2 e para o BRCAPRO riscos independentes para cada um desses genes e um risco combinando a probabilidade de mutações em um ou outro. 
